\title{
CUHSO
}

FACULTAD DE CIENCIAS SOCIALES 



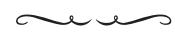

REPRESENTANTE LEGAL

Dr. Aliro Bórquez Ramírez, Rector

DIRECTOR

Dr. José Manuel Zavala Cepeda

EDITORES ADJUNTOS

Dr. Helder Binimelis Espinoza

Mg. Bertha Escobar Alaniz

\section{COMITÉ CIENTÍFICO}

Dr. Raúl Fornet Betancourt (Universidad de Aachen, Alemania)

Dra. Alcira Bonilla (Universidad de Buenos Aires, Conicet, Argentina)

Dr. Carlos María Pagano Fernández (Universidad Nacional de Salta, Universidad Católica de Salta, Argentina)

Dr. Alfredo Juan Manuel Carballeda (Universidad Nacional de La Plata, Argentina)

Dr. Carlos Reynoso (Universidad de Buenos Aires, Argentina)

Dr. Jovino Pizzi (Universidad Católica de Pelotas, Brasil)

Dr. Juan Carlos Skewes (Universidad Alberto Hurtado, Chile)

Dr. Alvaro Bello Maldonado (Universidad Católica de Temuco, Chile)

Dra. Magaly Cabrolié Vargas (Universidad Católica de Temuco, Chile)

Dr. Cristian Parker (Universidad de Santiago de Chile, Chile)

Dr. Fabien Le Bonniec (Universidad Católica de Temuco, Chile)

Dr. Pablo Salvat Bologna (Universidad Alberto Hurtado, Chile)

Dra. Francisca de la Maza (Pontificia Universidad Católica de Chile, Chile)

Dra. Noelia Carrasco Henríquez (Universidad de Concepción, Chile)

Dr. Jorge Hidalgo Lehuede (Universidad de Chile, Chile)

Dr. Rodrigo Pulgar Castro (Universidad de Concepción, Chile)

Dr. Ricardo Salas Astrain (Universidad Católica de Temuco, Chile)

Dr. David González Cruz (Universidad de Huelva, España)

Dr Tom Dillehay (Vanderbilt University, Estados Unidos)

Dr. Enric Porqueres i Gené (L'École des Hautés Études en Sciences Sociales, Francia)

Dra. Jimena Obregón Iturra (SciencesPo, Rennes, Francia)

Dr. Fernando Cortés Cáceres (Colegio de México, México)

Dr. Julio Aibar Gaete (Facultad Latinoamericana de Ciencias Sociales, México)

Dr Martín Puchet Anyul (Universidad Nacional Autónoma de México, México)

Dr. Alejandro Moreno Olmedo (Universidad de Carabobo, Universidad Católica

Andrés Bello, Venezuela)

AYUDANTE EDITORIAL

María Inés Flores 


\title{
CUHSO. CULTURA-HOMBRE-SOCIEDAD
}

ISSN O7I 6-I 557 | e-ISSN O7I9-2789| VOL. 23 | NÚM. I | 3I DE JULIO DE 2013

CUHSO es editada por la Facultad de Ciencias Sociales de la Universidad Católica de Temuco. Publica artículos inéditos en el campo de las ciencias sociales y las humanidades, en especial en las líneas disciplinares de la Facultad, en temas como relaciones interétnicas, derechos humanos, desarrollo social y cultural, disciplina e interdisciplina y marginalidad urbana.

CUHSO es una publicación semestral y está indexada en Latindex. Los números aparecen los días 3 I de julio y 3 I de diciembre de cada año. CUHSO cuenta con la asesoría y financiamiento de la Dirección General de Investigación y Posgrado en el marco de la estrategia de apoyo institucional a las publicaciones científicas de la Universidad Católica de Temuco.

\author{
EDICIONES UNIVERSIDAD CATÓLICA DE TEMUCO \\ Dirección General de Investigación y Posgrado \\ Avenida Alemania 02I I, Temuco.
}

\author{
DISEÑO Y EDICIÓN \\ www.tipografica.cl \\ CUHSO. Cultura-Hombre-Sociedad \\ Casilla i 5 D, Temuco. \\ Teléfono: $(56-45) 205233$ \\ Email: cuhso@uctemuco.cl
}

CUHSO es distribuida bajo una Licencia

Creative Commons Atribución-NoComercial-SinDerivadas 3.0 Unported. Puede consultarse una versión completa de la licencia en la siguiente dirección: http:// creativecommons.org/licenses/by-nc-nd/3.0/deed.es

La revista CUHSO nace en septiembre de 1984 al alero del Centro de Investigaciones Sociales Regionales (CISRE), de lo que en ese momento era la sede Temuco de la Pontificia Universidad Católica de Chile. Durante la década de los noventa y hasta el año 2007 es editada por el Centro de Estudios Socioculturales (CES) de la Universidad Católica de Temuco. En esta primera etapa la publicación estaba orientada al ámbito disciplinar de la antropología. En el año 2007 la revista pasa a ser una publicación semestral editada por la Facultad de Ciencias Sociales de la Universidad Católica de Temuco acogiendo trabajos de todas las disciplinas de las ciencias sociales. 


\section{CUHSO. CULTURA-HOMBRE-SOCIEDAD}

ISSN 07I6-I 557 | e-ISSN 07I9-2789 | VOL. 23 | NÚM. I | 3 I DE JULIO DE 2013

\section{Contenidos}

Editorial ..................................................................................... 7

\section{ARTÍCULOS CIENTÍFICOS}

LUCÍA TROTTA Y PAULA SOZA ROSSI

Metodología dialógica e interdisciplina en la extensión universitaria.

Reflexiones acerca de una experiencia

RICARDO ORELLANA OLIVARES Y JOSÉ MANUEL MERINO ESCOBAR

Predictores asociados a variaciones en puntajes Simce

en la región del Biobío

RAÚL GONZÁLEZ MEYER

Revisitando la historia de las teorías del desarrollo

BERNARDO GUERRERO JIMÉNEZ

Desarrollo andino: sustentable y con identidad 93

MÓNICA DE MARTINO

Género y trabajo social: algunos desafíos I09

\section{DOCUMENTOS Y TESTIMONIOS}

ALFREDO CAÑAS PINOCHET

El gillatún de Traitraico de I 89I 127 
VÍCTOR RAVIOLA MOLINA

Las ciencias sociales en la Universidad Católica de Temuco en I97 I .......... I33

Normas de presentación ............................................................. I 39 


\section{Editorial}

JOSÉ MANUEL ZAVALA CEPEDA

Director

Esta primera entrega del volumen 23 de la revista CUHSO contiene resultados de investigaciones empíricas y teóricas que muestran las preocupaciones y posibilidades de las ciencias sociales en América Latina y que van desde estudios acotados y específicos de corte más bien sociológico a revisiones y reflexiones amplias de índole teórica y epistemológica.

El lanzamiento de este número coincide con la celebración de los cuarenta años del inicio de un programa de licenciatura en ciencias sociales en la Universidad Católica de Temuco. En efecto, fue el año I 973 cuando el Programa de Bachillerato en Antropología, cuya primera promoción de estudiantes ingresó el año I97I, se transformó en Programa de Licenciatura en Antropología bajo la conducción de don Adalberto Salas. Este primer currículo de licenciatura fue cerrado el año 1978, concluyendo con ello la primera etapa de la formación en ciencias sociales en la Universidad Católica de Temuco —entonces sede de la Pontificia Universidad Católica de Chile—, etapa que se había iniciado el año I970 con el Programa de Formación de Investigadores en Ciencias Sociales liderado por el doctor Milan Stuchlik.

A cuarenta años del primer programa de licenciatura en antropología y a un año de la muerte de nuestra recordada colega Teresa Durán, una de las principales exponentes y herederas de la formación entregada por Milan Stuchlik, exdirectora y gran impulsora de esta revista, podemos satisfacernos del camino recorrido y entregar nuestro reconocimiento y agradecimientos a esa primera generación de maestros que con mucha generosidad y dedicación fueron artífices de las ciencias sociales en Temuco. Olvidando seguramente a más de algunos, cabe rendir homenaje a Milan Stuchlik, Adalberto Salas, Maurice Hebert, Thomas Melville, Majorie Bradford Melville, Olaf P. Jensen, René San Martín, Orlyn Ibarbe, Patrick Donovan y Martín Cordero, entre otros. 
Cinco son las contribuciones principales que publicamos este semestre en cuanto artículos de investigación.

La primera de ellas es obra de Lucía Trotta y Paula Soza, de la Universidad Nacional de la Plata y se plantea como objetivo reflexionar sobre la metodología dialógica y la conformación de equipos interdisciplinarios de investigaciónacción a partir de una experiencia de extensión universitaria sobre archivos policiales y memoria colectiva en relación a violaciones de derechos humanos y sistemas represivos en la provincia de Buenos Aires durante la dictadura militar. El artículo tiene un carácter evaluativo de esta experiencia de investigación aplicada y está pensado como un aporte al desarrollo de este tipo de experiencia de extensión universitaria.

El artículo siguiente tiene por autores a Ricardo Orellana y José Manuel Merino, de la Universidad de Concepción, y su objeto es analizar los resultados por comuna para la región del Biobío del Sistema de Medición de los Resultados del Aprendizaje (conocido como prueba Simce) que se aplicó a los alumnos de Cuarto básico el año 2009. El estudio se propone identificar posibles predictores que tengan relevancia estadística en los resultados aplicando un análisis de regresión jerárquica multivariado. Sin duda se trata de una contribución importante en el actual contexto de evaluación crítica del sistema educativo chileno, particularmente de educación primaria.

Raúl González, de la Universidad Academia de Humanismo Cristiano, nos propone en la tercera contribución revisitar las teorías del desarrollo desde la Segunda Guerra Mundial. Se trata de una revisión teórica en que se van señalando las inflexiones históricas en relación a cada etapa anterior, aportando con ello importante información sobre la evolución de diversas aproximaciones teóricas del desarrollo. El artículo concluye haciendo un balance del estado actual y de las perspectivas futuras de los estudios del desarrollo.

En sinergia con el artículo anterior, Bernardo Guerrero, de la Universidad Arturo Prat, discute algunas ideas y contrapuntos de las concepciones occidental y andina del desarrollo. El autor parte reconociendo que existiría una concepción andina específica del desarrollo y entrega los argumentos de tal afirmación, especificando los elementos diferenciadores y proponiendo sugerencias para potenciarla.

Finalmente, Mónica de Martino, de la Universidad de la República del Uruguay, aborda, en el último artículo de investigación de esta entrega, la evolución del concepto de masculinidad desde los planteamientos de Simone de Beauvoir y Judith Butler, complementados con la propuesta de Connell. A 
partir de estos autores, Martino señala los desafíos que se presentan al trabajo social — disciplina desde la cual ella se sitúa—, en términos de la necesidad de generar reflexión sobre las perspectivas de género a la hora de intervenir en los campos de actuación profesional.

Para cerrar este número, ponemos a disposición de los lectores dos documentos. El primero de carácter etnográfico, reproduce la relación hecha por don Alfredo Cañas del guillatún celebrado en Traitraico, Nueva Imperial, en I89I y, el segundo, más bien relativo a la historia académica de las ciencias sociales de Temuco, transcribe el discurso pronunciado por el profesor y director de Sede don Víctor Raviola en la inauguración del año académico I97 I de la entonces Sede Temuco de la Pontificia Universidad Católica, hoy Universidad Católica de Temuco.

Esperamos con estos diversos aportes continuar contribuyendo a las ciencias sociales desde el Sur del mundo, especialmente cuando estamos celebrando cuarenta años del inicio del primer programa de licenciatura en estas disciplinas. 



\title{
Metodología dialógica e interdisciplina en la extensión universitaria. Reflexiones acerca de una experiencia
}

\author{
Dialogical Methodology and Interdiscipline in University \\ Outreach. Reflections On an Experience
}

LUCÍA TROTTA Y PAULA SOZA ROSSI

Universidad Nacional de La Plata, Argentina

RECEPCIÓN: 3O/II/2OI2 · ACEPTACIÓN: 22/05/20I3

RESUMEN El trabajo es el resultado de nuestras reflexiones sobre la metodología dialógica y la conformación de equipos interdisciplinarios en procesos de investigación-acción. Las mismas surgieron a partir de una experiencia de extensión universitaria desarrollada en la Universidad Nacional de La Plata, Argentina, en conjunto con la Comisión Provincial por la Memoria (CPM) y la Asociación de Trabajadores del Estado (ATE) de la Provincia de Buenos Aires. El proyecto buscaba el acceso, apropiación y resignificación colectiva de los documentos pertenecientes al archivo de la ex Dirección de Inteligencia de la Policía de la Provincia de Buenos Aires (DIPBA) en posesión de la CPM. Es decir, un encuentro entre esos documentos que contenían parte de la historia argentina de persecución, represión y prácticas de resistencias, y sus protagonistas. El trabajo busca identificar los nudos problemáticos y las potencialidades de la experiencia, así como reconstruir la apuesta metodológica que se constituyó a partir de la disposición al diálogo y de la conformación de un nos-otros. En este proceso se analiza la presencia de una perspectiva dialógica en la conceptualización de la noción de extensión; en la opción metodológica por la investigación-acción participativa y sus tensiones presentes en el campo; en la forma de pensar y 
actuar interdisciplinariamente construyendo un otro extensionista; y en la decisión a partir de las necesidades situadas planteadas por los trabajadores y las trabajadoras de incorporar específicamente el diálogo intergeneracional e intergénero. Una posición que nos permitió un diálogo entre sujetos participantes de la experiencia de extensión y la elaboración colectiva de los denominados procesos de «re» (Vasilachis, 2007). Redefinición de la identidad, redefinición discursiva ante la mirada de los otros (la DIPBA) y una redefinición de la memoria colectiva de los trabajadores y las trabajadoras del sindicato a partir de una reconstrucción histórica colectiva. Por último, se plantean los obstáculos y elementos facilitadores que encontramos en todo el proceso, de modo de realizar un aporte que ilumine algunos aspectos para llevar adelante otras experiencias de extensión universitaria exitosas.

PALABRAS CLAVE Extensión universitaria, metodología dialógica, interdisciplina, investigación-acción participativa.

ABSTRACT This work is the result of our reflections on dialogical methodology and the formation of interdisciplinary teams in research-action processes. They arise from an experience in university outreach carried out by Universidad Nacional de La Plata, Argentina, jointly with the Provincial Commission for Memory (CPM) and the State Employees' Association (ATE), Province of Buenos Aires. The object of the project was access to, and appropriation and collective resignification of, documents from the Archive of the ex-Police Intelligence Directorate of the Province of Buenos Aires (DIPBA), held in custody by the CPM. In other words an encounter between these documents - which contain a part of Argentina's history marked by persecution and repression, and also by resistance - and their protagonists. The work seeks to identify the problem nodes and the potential of the experience, and to reconstruct the methodological challenge created by the disposition to dialogue and the formation of a relation of us-others. In this process we analyze the presence of a dialogical perspective in the conceptualization of the notion of outreach; in the methodology chosen for the participative research-action and its tensions in the field; in the application of interdisciplinary thought and action to construct an other outreacher; and in the decision based on the needs tabled by workers to specifically incorporate inter-generation and inter-gender dialogue. This position allowed us a dialogue between the subjects who participated in the outreach experience and the collective creation of the so-called «re»-processes (Vasilachis, 2007): redefinition of identity, redefinition of discourse under the eyes of 
the others (DIPBA), and redefinition of the collective memory of the union workers from a collective reconstruction of history. Finally, we present the obstacles and facilitating elements which we found throughout the process, enabling our contribution to illuminate certain aspects. These will help in carrying out further successful university outreach experiences.

KEYWORDS University outreach, dialogical methodology, interdiscipline, participative research-action.

\section{Introducción}

Este trabajo es el resultado de una serie de reflexiones sobre la metodología dialógica y la conformación de equipos interdisciplinarios en procesos de investigación-acción. Las mismas surgieron a partir de una experiencia de extensión universitaria ${ }^{1}$ desarrollada en la Universidad Nacional de La Plata, Argentina, en conjunto con la Comisión Provincial por la Memoria (CPM) y la Asociación de Trabajadores del Estado (ATE) de la Provincia de Buenos Aires. El proyecto buscaba el acceso, apropiación y resignificación colectiva de los documentos pertenecientes al archivo de la ex DIPBA, ${ }^{2}$ es decir, un encuentro de los y las protagonistas con esos documentos que contenían parte de la historia argentina de persecución y represión política, pero también sus prácticas de resistencias. En este sentido, durante el proyecto se generó un espacio de debate y aprendizaje mutuo sobre el rol de las diferentes disciplinas y los sujetos destinatarios de la experiencia en la co-construcción de conocimiento social sobre nuestra historia reciente. Esto fue posible en la medida en que fueron considerados los ritmos propios de una metodología crítica, donde, al decir de Vasilachis (2007), la posición del sujeto cognoscente es revisada para

I. El proyecto de mención se tituló «Los sindicatos bajo la mirada de la Dirección de Inteligencia de la Policía de la provincia de Buenos Aires (DIPBA): hacia una construcción colectiva de la historia de la represión a las organizaciones gremiales» y se desarrolló durante los años 2006 y 2007.

2. Dirección de Inteligencia de la Policía de la Provincia de Buenos Aires. El Archivo se encuentra en guarda de la CPM desde el año 200 I y contiene informes de inteligencia y otros documentos producidos y recopilados por la DIPBA desde I 957 en su función de detectar y perseguir en forma sistemática a organizaciones políticas, sociales, religiosas, estudiantiles y gremiales. 
poder acercarnos de manera innovadora al sujeto conocido. De allí que una metodología dialógica resultó ser la adecuada para nuestro objetivo de accióntransformación, de los otros/as como de nosotros/as mismos/as (Fals Borda, I979). Las reflexiones y escritura a posteriori nos permiten entonces dar cuenta de manera más clara lo que constituyó nuestro eje articulador: vincular en la investigación-acción participativa el proyecto de extensión universitaria, del cual formamos parte.

\section{Diálogos en acción}

El diálogo se fue constituyendo en el eje vector del proyecto. En primer lugar, desde el aporte que hicieran los/as compañeros/as que provenían del área de educación, en la manera de conceptualizar a la extensión universitaria como comunicación-acción. En segundo lugar, en la forma de co-construir la interdisciplina para la conformación del equipo de trabajo. Aquí, la disposición a escuchar al otro, en tanto portador de un saber específico, fue posible a partir de un punto unificador representado por la decisión ideológica y cognitiva de intentar una investigación-acción transformadora.

Por otra parte, el diálogo también estuvo presente en la vinculación con los/ as trabajadores/as del sindicato, en todo el proceso que requirió armar el proyecto, elegir la metodología y técnicas de trabajo y planificar las actividades de manera conjunta. Ello permitió que éstas pudieran ir ajustándose en el transcurso del proyecto en función de las necesidades situadas de los/as trabajadores/ as. El ajuste se realizó resignificando aquellas técnicas de carácter clásico inscritas en el paradigma tradicional positivista (exposición histórica), como a las llamadas técnicas participativas (observación participante, dispositivo taller), cuidando que la puesta en práctica de éstas no reprodujera una relación de poder hacia el polo del sujeto cognoscente (Vasilachis, 2007; Fals Borda, I979).

Por último, a partir del diálogo construido principalmente con las referentes del Área de Derechos Humanos del sindicato que promovieron el proyecto, hubo dos necesidades que ellas mismas nos exteriorizaron a las que prestamos especial atención: la de dar sonoridad a la voz de las mujeres de y los/as jóvenes de la organización. Es por ello que parte esencial de nuestro trabajo fue promover el diálogo intergeneracional e intergénero.

Decidimos por todo esto organizar la estructuración del presente trabajo en función de la multiplicidad de diálogos que tuvieron lugar en el desarrollo de la experiencia de extensión universitaria. 


\section{Primer diálogo: extensión como comunicación y reconocimiento del otro}

Comprender un proyecto de extensión universitaria en tanto instancia dialógica de comunicación-acción implicó una predisposición crítica hacia la noción de extensión y la exigencia de la definición de un objeto, ${ }^{3}$ para llegar a convertirse también en un resultado de la experiencia.

Quizás porque en la elección de ese objeto ya se nos aparecían personas con las cuales nos habíamos vinculado previamente, en tanto representantes del sindicato durante nuestro trabajo en el archivo de la ex DIPBA, las habíamos visto emocionarse, enojarse, asombrarse con los documentos pertenecientes a la inteligencia policial realizada sobre el sindicato y sus trabajadores a lo largo de décadas, por lo que traducirlos/as en meros objetos destinatarios de nuestra tarea nos generaba desde un principio irritación y controversia.

De este modo, nos propusimos inscribir el proyecto en una perspectiva que entiende a la extensión como comunicación, y donde el diálogo es el principal medio para que se dé una experiencia significativa para todos los actores intervinientes. Sin desconocer, por otro lado, la propia historicidad contenida en la noción de extensión universitaria. La misma se constituye luego del movimiento de Reforma Universitaria de r9 8 como uno de los pilares, junto con la docencia y la investigación, de la universidad latinoamericana y es un término cuya definición y significación fue y es un espacio de disputas. Originado en Córdoba, Argentina, el movimiento reformista cristalizó sus principios en formas de organizar e imaginar la universidad latinoamericana. Entre los principios de autogobierno, representación de estudiantes y graduados en los órganos de gobierno, modernización de la enseñanza, libertad de cátedra y compromiso con la cuestión social, el último será central en todos los movimientos estudiantiles posteriores, pero también derivará en corrientes intelectuales y movimientos políticos en varios países de Latinoamérica (Krotsch, 200I: I30).

La extensión universitaria —actividad «extramuros»— será el área específica para desarrollar este vínculo con lo social, donde convivirán una vertiente culturalista, en términos de difundir, extender la cultura de la élite universitaria a los sectores más desfavorecidos; y, por otro, una vertiente que entiende la extensión como un trabajo social, de generación de vínculos solidarios y cola-

3. En los formularios de presentación a concurso de proyectos de extensión universitaria se exige la definición de un objeto de extensión, en tanto destinatario de la acción. 
borativos con el pueblo a partir del encuentro en situaciones concretas para la solución de problemas específicos (Bralich, I994: 40).

La vertiente que primó hasta mediados del siglo XX fue la de una universidad que, consciente de su condición de institución superior del saber y privilegiada, proyectaba sus saberes legítimos al resto de la sociedad, entendiendo a los destinatarios como simples depositarios, y definiendo unilateralmente el contenido y el alcance de esa proyección (Tünnermann Bernheim, 200I: 5). Así los primeros reformistas proclamaban una universidad pública de libre acceso para las mayorías, pero también promovían una concepción de la extensión, de ese lazo de la institución universitaria con esas mayorías, a partir del dictado de conferencias y charlas a los/as trabajadores/as para que pudieran escuchar la palabra de la universidad (Bralich, I994).

En las décadas del cincuenta y sesenta las universidades latinoamericanas fueron institucionalizando sus programas de extensión y al mismo tiempo se fue produciendo un proceso de apertura en la propia concepción. Tünnermann Bernheim (200I) identifica dos aportes esenciales en la transformación de la conceptualización: la Segunda Conferencia Latinoamericana de Extensión Universitaria y Difusión Cultural realizada en México en I972, y los aportes de Paulo Freire en su análisis crítico de la educación y la pedagogía dominante, funcional al sistema de opresión capitalista. En el primer caso, luego de la conferencia citada, se identificaron distintas respuestas en el vínculo universidadsociedad, entre ellas el cuestionamiento del statu quo y el aporte de desencadenar procesos de cambio en alianza con los sectores oprimidos y otras fuerzas de cambio. ${ }^{4}$ Por otro lado, Paulo Freire aportó un análisis crítico del término extensión y propuso una forma de relación entre distintos espacios de saber a partir de la noción de comunicación (Freire, 200I).

En su reconocido libro Pedagogía del oprimido (1970), Freire critica la educación bancaria, es decir, aquella educación en la que el educador deposita

4. En la actualidad si bien persiste el término extensión, las universidades argentinas tienden a definirla como una actividad que pretende que los conocimientos adquiridos en las distintas etapas de la formación académica se vinculen con la sociedad. La idea es que por medio de la extensión, la universidad transmita a otros actores sociales parte de sus conocimientos y que, a la vez, estos saberes se vean enriquecidos y ampliados por el aporte que dichos actores puedan realizar sobre el tema en cuestión, basados en un paradigma de democratización de los saberes y de interacción creativa entre ambos espacios. Para más información, véase <http://www.unlp.edu.ar/extension>. 
en los educandos un conocimiento totalmente desvinculado de la realidad y, a través de esta pasividad impuesta, se logra mantener el statu quo, ya que los oprimidos tenderán a adaptarse al mundo en lugar de transformarlo. Freire propone en cambio una educación problematizadora, que se centre «en que los hombres sometidos a la dominación, luchen por su emancipación» (Freire, I 985 : 99). La educación como práctica de la libertad supone una metodología basada «en la palabra generadora, cuyo sentido fundamental es que surge de una tarea de discusión y reflexión colectiva, de la cual nace una relación dialógica (basada en el diálogo igualitario y mutuamente enriquecedor) entre educador y educando» (Puiggrós, I987: 54). Es necesario, en este caso, que el educador asuma una postura radical democrático-revolucionaria y para ello que entienda a la educación como un acto de conocimiento, partiendo de la comprensión de los educandos para alcanzar una comprensión más exacta de la realidad (Freire, 1985). Esto no implica para Freire un mero proceso de concientización de los sectores populares, sino también proveerlos de instrumentos útiles, como el dominio de elementos de la cultura dominante y el desarrollo de una conciencia crítica, en la lucha contra la opresión (Bralich, I994: 72).

De allí que para Freire el concepto de extensión, que supone una relación entre un sujeto que extiende y un objeto que recibe bajo una lógica mecanicista, desde la sede del saber hasta la sede de la ignorancia, no se corresponda con la idea de una educación liberadora, ya que «transformando al hombre en casi una cosa, lo niegan como un ser de transformación del mundo. Además de negar [...] la formación y la constitución de conocimientos auténticos. Además de negar la acción y la reflexión, verdaderas, a aquellos que son objetos de tales acciones» (Freire, 200I: 2I). Asimismo, postula una concepción dialógicacomunicativa del conocimiento que, en tanto acción de los sujetos, implica en el mismo proceso de conocimiento una acción transformadora de la realidad (Freire, 200I: 28). Aprender supone además un proceso de concientización, es decir, de apropiación crítica de nuestro lugar en el mundo para transformarlo (Freire, 200I: 40).

El acto cognoscitivo incluye sujetos cognoscentes, un objeto a conocer, pero fundamentalmente la comunicación entre éstos. Por lo que no es posible entender el pensamiento sin su doble función: cognitiva y comunicativa. En palabras del autor: «La educación es comunicación, es diálogo, en la medida en que no es la transferencia del saber, sino un encuentro de sujetos interlocutores, que buscan la significación de los significados» (Freire, 200I: 77). En esta dimen- 
sión revolucionaria que contiene la concepción dialógica, Fals Borda (I979: 294), en coincidencia con Freire, señala que la apropiación de conocimiento implica la resignificación de lo actual en un proceso histórico. Ambos autores formaron parte del campo de confluencia entre distintas corrientes de pensamiento y disciplinas que entre las décadas del sesenta y el setenta abogaban en toda América Latina por producir conocimientos científicos que permitieran a sectores subalternos de la sociedad comprender críticamente la realidad para transformarla a partir de un diálogo entre saber académico y saber popular (Ortiz y Borjas, 2008: 6I7). Entre las distintas corrientes que convergieron en este campo, aparece una coincidencia en términos epistemológicos: por un lado, postulan que no existe el conocimiento neutral y que es necesario el desarrollo de conocimiento crítico, el cual necesita del acercamiento al conocimiento empírico, práctico, de las bases sociales (en nuestro caso, de los/las trabajadores/as portando conocimiento a partir de su experiencia como tales). Y, por otro lado, enfatizan una dimensión vinculada a la acción que, en la teoría falsbordiana, se constituirá en la investigación-acción participativa (IAP) (Ortiz y Borjas, 2008).

Este nuevo bagaje dentro de las ciencias sociales surge en un contexto epistemológico donde los marcos de referencia o paradigmas tradicionales dejaban ciertos procesos sociales vinculados con una construcción consciente de la historia en la penumbra del conocimiento (Fals Borda, I979: 259). Además, el paradigma naturalista, exaltando la figura de un observador neutral, invisibiliza que el propio observador forma parte del universo a observar e incide en el mismo. Esta condición oscurecida por el canon positivista tenía como consecuencia incluso que técnicas de campo como la "observación participante» y la «observación por experimentación» tendían a conservar las diferencias entre el observador y lo observado. La técnica de la «inserción en el proceso social», en cambio, fue uno de los primeros avances que reconoce el papel protagónico de las masas populares, con la consiguiente disminución del papel del intelectual-observador como monopolizador o contralor de la información científica (Fals Borda, 1979: 262).

Éstos y otros aportes intentarán conformar un paradigma alterno de una ciencia social crítica, donde «la investigación social y la acción política, con ella, pueden sintetizarse e influirse mutuamente para aumentar tanto el nivel de eficacia de la acción como el entendimiento de la realidad» (Fals Borda, I979: 73). 


\section{Segundo diálogo: la investigación acción participativa, un encuentro dialógico}

Una segunda instancia donde el diálogo estuvo presente fue en la elección metodológica. Retomando la idea de la elección ideológica contenida en el «para quién» de Fals Borda, proponemos en pos de una mayor riqueza analítica de la experiencia subdividir este "para quién» en tres instancias que dan cuenta del recorrido metodológico realizado: el «entre quiénes», el «con quiénes» y el «porqué» de nuestra investigación-acción.

La primera instancia, el «entre quiénes», incluye tanto al equipo de investigación-acción como a lo que en jerga tradicional se denominan los/as destinatarios/as de nuestro proyecto de extensión universitaria.

En la constitución del equipo partimos por reconocer la necesidad del aporte del saber de los otros/as, en tanto representantes de las distintas perspectivas disciplinares, como condición en la conformación del punto de mira y de acción para el encuentro con los/las trabajadores/as del sindicato. El mismo se compuso a partir de la participación de graduados y estudiantes provenientes de la sociología, la comunicación social, la historia, la informática y la archivística. Allí, sin duda, que la mayoría perteneciéramos al campo de las ciencias sociales era una condición necesaria pero no suficiente para lograr un encuentro entre todos/as. La co-construcción de lo interdisciplinar se vio reforzada por una disposición a escucharnos y por un punto unificador: la decisión ideológica y cognitiva de intentar hacer una investigación-acción transformadora.

Hubo otra condición que sumó en este sentido: una trayectoria común, un encuentro previo al proyecto y un reconocernos de manera transversal en la condición de trabajadores y/o extrabajadores de la Comisión Provincial por la Memoria, que no sólo aportó en la configuración de nuestra identidad grupal sino también en torno a una formación común: la archivística, que como conocimiento técnico nos permitió identificar y localizar los documentos del archivo en su contexto de producción.

Este reconocimiento marcado por el deseo mancomunado de socializar el acceso de los protagonistas a los documentos de la represión política, facilitó la constitución del marco común, la perspectiva cognitiva, que delimitó el proyecto y que se relaciona con la segunda instancia, la que implica definir el «con quiénes». Coincidimos en adoptar una metodología (también pedagogía) donde los encuentros dialógicos propiciados desde la técnica-taller intentaran resignificar las maneras tradicionales de la relación con los otros/as, donde 
sin substraernos a la responsabilidad de ser personas portadoras de un saber universitario cuidáramos el proceso a través del cual entre todos/as llegáramos a alcanzar un buen sentido gramsciano sobre el tema del proyecto (Fals Borda, I979). La elección entonces de las técnicas de trabajo estuvo desde los inicios orientada a incorporar las distintas necesidades situadas de los/as trabajadores/as, así como sus saberes y sentires en tanto clave para la construcción colectiva de conocimiento.

En tercer lugar y en estrecha relación con las anteriores instancias, definimos el "porqué», cuyo núcleo era socializar los documentos, hacer que los/as trabajadores/as se reencontraran con su agencia histórica como trabajadores/ as en lucha en Argentina, antes, durante y después de la última dictadura militar.

Decidimos adoptar la metodología de la investigación-acción participativa dado que para nosotros/as era la perspectiva que nos permitía respetar la especificidad de un proyecto de extensión, como también acercarnos a aportar de forma, aún acotada, a la construcción de saberes hacia una ciencia alternativa al canon tradicional. Una ciencia crítica de la realidad como de sí misma en cuanto a las maneras en que se construye conocimiento.

Interferencias en el diálogo: tensiones estratégicas de la IAP

Posicionarse desde esta perspectiva supuso hacer frente a varias de las tensiones estratégicas que señala Fals Borda como propias de la IAP y que vivenciamos a lo largo de nuestro proyecto. El desafío epistemológico y la imposición de la acción transformadora serán el marco en el que se dirimirán dichas tensiones sintetizadas por el autor colombiano como tensión teoría-práctica, tensión sujeto-objeto y tensión entre participación y cosmovisión del mundo; y que desarrollaremos a continuación, para más adelante presentar distintos momentos del proyecto en los que tuvimos que enfrentarnos con las mismas.

La tensión entre teoría y práctica. Fals Borda, preocupado por la escisión entre el conocer y el actuar, característico del paradigma dominante de construcción de conocimiento, expresa: "Tratar de vincular el conocimiento y la acción - la teoría y la práctica一, como en el castigo de Sísifo, es un esfuerzo permanente e inacabado de comprensión, revisión y superación sobre una cuesta sin fin, difícil y llena de tropiezos» (Fals Borda, I979: 256). En contra de los paradigmas deductivos, la IAP propone un paradigma holista participa- 
tivo que, siguiendo un pausado ritmo de reflexión y acción, permita ir haciendo ajustes en el camino y cuya validación estará dada por elementos propios del campo, entre ellos, la percepción de los grupos involucrados. La validación en la IAP - a diferencia de las metodologías tradicionales que circunscriben la misma a la obtención de resultados- se realiza por medio de la acción concreta, esto es, que desde el inicio la causa última tiene una dimensión teóricopráctica, donde lo aleatorio de la acción social queda sujeto al marco de la praxis (Fals Borda, I979: 26I). Retomando conceptos aristotélicos, el autor propone una praxis con frónesis o propósito.

La tensión sujeto-objeto. Trascendiendo la dicotomía planteada por el paradigma tradicional, la IAP rescata los vínculos interpersonales mediados por sentimientos, normas, actitudes, opiniones y experiencias diversas, y un camino que implica apreciar la contribución del otro para llegar a una relación sujeto-sujeto de carácter horizontal y simétrica. Este diálogo entre distintos tipos de conocimiento será la base de una participación auténtica, que al mismo tiempo supone una devolución sistemática con el propósito de intercambiar el conocimiento. En este punto el rol del lenguaje es central para garantizar esa comunicación efectiva (Fals Borda, 2008).

El paradigma de la ciencia social crítica estipula entonces que la diferencia entre sujeto y objeto puede reducirse en la práctica de la investigación y para ello es necesario entablar un diálogo con el otro a través de un lenguaje claro, lo que implica formas de publicación y producción intelectual más abiertas (Fals Borda, I979: 287).

La tensión de la filosofía de la participación y la cosmovisión del mundo (Weltanschaung). El marco de la IAP conlleva como supuesto adoptar una actitud empática hacia los demás, denominada «compromiso» o "vivencia», que significa experiencias de vida y participación auténticas. En este camino, deja de ser una metodología de investigación para convertirse en una mirada del mundo sostenida por practicantes sentipensantes dispuestos a luchar por la transformación social.

Junto a Donna Haraway, pensamos que una de las condiciones de posibilidad de una inteligibilidad social que incluya a los otros, y sus pareceres y sentires, implica necesariamente un compromiso emocional del investigador. No excluir las emociones en la construcción de saberes permite traducir conocimientos entre comunidades muy diferentes y diferenciadas en términos de poder (Femenías y Soza Rossi, 20 I I: I 5 ). 


\section{Las tensiones de la IAP en el campo de acción}

La construcción del marco de referencia de nuestra investigación-acción fue una construcción gradual, desordenada, con conceptos que se fueron explicitando y conjugando en el propio proceso mediante el intercambio y aporte disciplinar y experiencial entre los/as integrantes del equipo y con los/as trabajadores/as. Marco de referencia que este mismo escrito nos ayudó a explicitar y que inscribe la técnica-taller que eligiéramos para llevar adelante los encuentros dialógicos en este campo de sentidos.

Identificamos en este proceso la presencia de las tensiones señaladas por Fals Borda, tensiones que fuimos resolviendo en el transcurso de la investigación-acción.

Uno de los propósitos de los talleres era que nuestro conocimiento sobre los procesos históricos, sobre la última dictadura argentina y los documentos de la DIPBA, colaboraran en las reflexiones sobre las prácticas sindicales actuales de los/as trabajadores/as de la ATE.

Lo que buscábamos era propiciar el diálogo entre los sindicatos, su historia y la universidad; para eso necesitábamos las voces de los protagonistas de esos cientos de legajos confeccionados por la DIPBA. El aporte que estas organizaciones tuvieran para hacer, desde sus vivencias específicas y el propio análisis de su historia, resultaba por demás interesante en tanto introducían una mirada todavía ausente en los papeles hallados: el de las propias organizaciones víctimas del espionaje y la persecución (Giménez y otros, 20I2).

Y así, a partir del diálogo comunicativo se producía un nuevo conocimiento resignificando esa historia y, al mismo tiempo, un conocimiento de nuestra propia práctica en el campo de la extensión universitaria.

Ahora bien, llevar a cabo este propósito necesitó de reajustes sobre la marcha. Una anécdota de la experiencia puede dar bien cuenta de la presencia latente de la primera tensión descrita por Fals Borda: como balance del primer taller, en nuestro encuentro posterior con las representantes sindicales, interlocutoras claves desde el inicio del proyecto, se explicitó una demanda puntual: «¿Porqué no nos dan una clase sobre la historia?». En esa demanda se ponía sobre la mesa el hecho de que al querer apegarnos a la generación de un diálogo horizontal no habíamos reparado suficientemente que en la interacción cog- 
nitiva con los/as trabajadores/as, como sujetos conocidos, tenían una representación sobre nosotros/as en tanto universitarios y determinadas expectativas. Esto implicaba una autoridad de saber sobre el período histórico seleccionado para el análisis documental y sobre las características particulares del entramado social en las distintas etapas de nuestra historia reciente. En consecuencia, y gracias al proceso de validación con los otros, preparamos para el segundo taller una exposición que diera cuenta de una contextualización sociohistórica sobre las relaciones de fuerza entre los trabajadores y los sectores dominantes. Caímos en la cuenta que la horizontalidad no la garantizábamos al eludir la responsabilidad que conlleva portar un saber emanado de la universidad como fuente legítima de conocimiento científico.

En nuestro temor inicial queda reflejado el peligro de la asimetría que arrastra determinada técnica enmarcada en un paradigma específico, en este caso el paradigma tradicional de transferencia unilateral de saberes. Como define Fals Borda en relación a la potencialidades y limitaciones de ciertas técnicas de las ciencias sociales:

Hay que poner en su contexto conformista y reconocer sus limitaciones a aquellas técnicas empíricas derivadas del paradigma normal que cosifican la relación social, creando un perfecto divorcio entre sujeto y objeto de investigación, es decir, manteniendo la asimetría entre entrevistador y entrevistado (I979: 264).

Por otro lado, el mismo Fals Borda advierte que ninguna técnica garantiza el logro de los objetivos planificados, como tampoco define al proyecto en sí.

En este sentido, una técnica de exposición más tradicional realizada en un marco específico de comunicación dialógica e identificación de fines comunes, se convirtió en una experiencia compartida, una herramienta analítica en función de las bases y no del investigador, permitiéndonos trascender la dicotomía sujeto-objeto descrita más arriba. Fue fructífero a este fin utilizar un lenguaje claro y preciso que permitió una comunicación efectiva, tanto para la elaboración del material complementario sobre la historia y el archivo de la ex DIPBA, que se distribuyó en cada taller, así como en el diseño y redacción de la publicación colectiva que relata la experiencia. Consideramos que en los talleres realizados se lograron comunicar y articular los distintos saberes, sentimientos y experiencias de los trabajadores/as e integrantes del equipo de extensión, transversalizados por las categorías de género y generación, otro de 
los propósitos del proyecto. Esto permitió la apertura del alcance técnico del trabajo, en nuestro caso dar lugar a la multiplicidad de voces.

La técnica taller fue la que habilitó esa participación auténtica. El taller es una estrategia que se inserta en un espacio de comunicación complejo, de creación de significados y/o negociación de conceptos y que, en la puesta en juego de diversos universos culturales, se construye el sentido y la significación del contenido (Lucarelli, 2000). Para que éste sea viable es necesario alcanzar un resultado en un interjuego entre el tiempo y la organización grupal, donde el aprendizaje termine siendo el resultado de la interrelación entre la producción individual y la producción colectiva. Siguiendo a Lucarelli (2000), podemos decir que todo taller atraviesa distintas fases: una introductoria, donde se anticipa la organización del encuentro y la tarea; una fase del desarrollo propiamente dicho, que conjuga la realización de las tareas por medio de distintas técnicas y modalidades (por ejemplo, el debate en grupos más pequeños, la puesta en común, etcétera); y una fase final llamada de afianzamiento, donde se reelabora la experiencia apelando al marco teórico y reflexionando sobre las particularidades que ésta tuvo. Tanto el proceso de escritura de la publicación final que relata la experiencia, como este mismo trabajo, forman parte de esa etapa.

Por último, el compromiso emocional, condición de posibilidad para involucrarse con los otros, estuvo presente en las reuniones y encuentros con los/ as representantes del sindicato y de las otras instituciones copartícipes, en la producción de materiales y la realización de los talleres, es decir, en todas las instancias del proyecto.

Uno de nuestros propósitos originales era articular puentes entre las distintas instituciones y fomentar la restitución de los lazos sociales entre diferentes sectores, afectados por las políticas neoliberales inauguradas con la última dictadura militar. En este sentido, podemos decir que la empatía y los vínculos generados a lo largo de toda la experiencia, entre nosotros/os y con los otros/ as, marcaron nuestra trayectoria académica y personal.

\section{Tercer diálogo: un encuentro entre nos-otros}

Hemos reflexionado de qué modo en la temática de la interdisciplinariedad, más allá de las expresiones políticamente correctas, en la práctica no pocas veces el vínculo entre disciplinas reproduce una relación una-otra, donde la primera, autolocalizada en la posición de una, interactúa con la otra como un 
texto anfitrión de las diferencias que no conmueven un pensar «autosuficiente y completo». Al decir de Deleuze, si no se revisa el modelo disciplinar soberano, se reproduce la creencia de las disciplinas como reinos poseedores de un aparente poder absoluto.

Para el caso de nuestro proyecto de extensión, la revisión de nuestras formaciones tradicionales — que circunscriben los objetos de estudio y generan limitaciones empobrecedoras - tuvo como condición de posibilidad de diálogo interdisciplinar adoptar los aportes de las epistemologías y metodologías «alternativas» volcadas a la investigación-acción. Así, también repensar las prácticas de construcción de saber-acción implicó incorporar reflexiones de la epistemología del sujeto conocido a la epistemología del sujeto cognoscente.

Adscribiendo al pensamiento de Foucault en cuanto a las disciplinas - como discursos o conjuntos de saberes organizados de acuerdo con modelos científicos de un campo epistémico- el asumir la responsabilidad de la conocida articulación poder-saber nos desafió a replantearnos cuestiones implícitas en las distintas formaciones académicas y prácticas naturalizadas. Por eso para superar las limitaciones de lo que podría llamarse un collage de miradas disciplinares, es requisito la consciente elaboración de un marco general y común donde cada uno/a de los representantes en mirada introspectiva revise conceptos y metodologías propias de su campo. Siguiendo a Ignacio Lewkowicz, construir un nuevo saber común involucra pensar en suplementos que trasciendan el complemento, dado que los primeros generan algo nuevo al destotalizar un saber autosuficiente que concibe al complemento como necesidad transitoria.

En este punto es importante reconocer los aportes del debate multicultural para pensar el diálogo interdisciplinar. Haciendo un paralelo con éste, podemos plantear dos maneras de pensar a las disciplinas y sus relaciones.

Adherir a una concepción del multiculturalismo mosaico, al decir de Benhabib (2006), arrastra consigo la purificación de las diferencias que, circunscritas a las relaciones entre culturas, escamotea la visibilidad de las relaciones intraculturales. Llevado al análisis disciplinar, esta concepción obstaculiza reconocer las diferencias internas al proyectar la diversidad y la divergencia de líneas de pensamiento en las otras disciplinas. En realidad, se niegan los puntos de demasiada proximidad a fin de garantizar una pertenencia «sin conflictos» en el interior de la disciplina propia, donde quedan invisibilizadas las divergencias ideológico-epistemológicas intradisciplinares.

Transferir a las culturas disciplinares la imagen auditiva del multiculturalismo, nos incentiva a tolerar cierto nivel de incertidumbre en relación a las defini- 
ciones de la otra disciplina. El dejar en suspenso las definiciones sobre la otra da lugar a escuchar lo que las demás disciplinas tienen para decir sobre sí mismas.

Para el proyecto de extensión, la construcción del diálogo tuvo como base la confianza generada a partir de la valoración común sintetizada: la disposición a escucharnos. Siguiendo a Fals Borda, entre todos/as — previa revisión de nuestras prácticas disciplinares- pudimos a través del encuentro dialógico co-construir un punto culminante de unificación entorno a la investigaciónacción participativa y al interés común de construir una ciencia social critica.

\section{El otro conocido}

Nos parece pertinente traer a colación la reflexión epistemológica de Irene Vasilachis, reconocida estudiosa de la metodología cualitativa cuya preocupación radica en dar cuenta de la situación de personas en pobreza extrema. Para la autora es imperioso propiciar como actividad persistente una reflexión epistemológica, actividad que ya está presente en la práctica de los investigadores, en la ciencia que "se está haciendo».

Esta reflexión la llevó a revisar los paradigmas que constituyen lo que denomina la epistemología del sujeto cognoscente. Sin desconocer sus méritos en la producción de conocimiento, advierte cómo ésta, al mantener un sentido unidireccional en un vínculo que parte del sujeto cognoscente, no sólo propicia una separación con el sujeto conocido sino que también lo preserva de ser transformado, de ser conmovido (Vasilachis, 2007: 6).

Denominará epistemología del sujeto conocido a aquella que tiene como presupuesto una igualdad esencial de los seres humanos, impidiendo ver en el otro un objeto a ser conocido. Este presupuesto le otorga un papel central al sujeto conocido en la definición de sus aspiraciones, deseos, motivaciones y fines por lo cual la validez de la producción de conocimiento será proporcional a la menor tergiversación de los mismos. La condición para que el sujeto provea conocimiento sobre sí mismo es que se produzca un interacción comunicativa, una interacción cognitiva. En palabras de la autora, «de lo que se trata es de considerar el resultado del proceso de conocimiento como construcción cooperativa en la que los sujetos esencialmente iguales realizan aportes diferentes» (Vasilachis, 2007: II). En esta interacción hay una mediación representativa en ambos sentidos de los sujetos que establecen el diálogo. Por un lado, el científico apelará a aquellas teorías generales que intentaron describir, explicar e interpretar la acción de los sujetos a lo que refiere su investigación, mientras 
el sujeto conocido, desde sus representaciones, no sólo situará al investigador y su actividad, sino que se posicionará frente a él. Esta metodología destaca como central la disposición del investigador no sólo para encontrar al sujeto conocido, sino también para darle un lugar que supere la expresión y lo reconozca como libre. Esto implica cuidar que los resultados de su investigación no reproduzcan, por falta de conciencia sobre las implicancias del conocimiento, relaciones de desigualdad (Vasilachis, 2007: I4).

Desde esta epistemología pueden producirse lo que se denomina procesos de «re», que van desde la resistencia hasta la redefinición de la propia identidad frente a las representaciones creadas en torno a ellos (Vasilachis, 2007: 2I). Procesos de redefinición discursiva que nosotros encontramos en la expresión de uno de los grupos que bajo la técnica taller expresó en una síntesis creativa la resistencia ante la mirada de la Dirección de Inteligencia de la Policía de la Provincia de Buenos Aires: «nos magullaron pero no nos quebraron». Frase elegida por el equipo de extensión para titular la publicación colectiva.

\section{El otro extensionista}

Para tomar recaudos e intentar sortear tanto la objetivización del otro disciplinar como del otro a conocer, debemos repensar algunas de las dificultades específicas de la construcción de la interdisciplina en los proyectos de investigación-acción enmarcados en la extensión universitaria. Así, la metodóloga de origen uruguayo Susana Rudolf (20I0) nos recuerda que para prevenir lo que describe como una tentación original omnipotente de las disciplinas, debemos favorecer un diálogo horizontal y permanente con la gente que no es de «nuestro club» dado que todos los clubes «ciegan» para cosas que sólo ven los de afuera.

En el caso de nuestro proyecto, incentivamos un diálogo interdisciplinar con miras a repensar las prácticas de construcción de saber-acción, saber-poder entre los distintos voceros disciplinares que integraban nuestro equipo — los/as representantes de historia, sociología, comunicación social, archivística, informática y artes visuales- y así replantearnos cuestiones implícitas en las distintas formaciones académicas y prácticas naturalizadas. Como en otros vínculos y relaciones sociales, en los vínculos interdisciplinares éramos conscientes que estaba implícito el tema del poder (Rudolf, 20I0: 85).

Para los proyectos de extensión, construir interdisciplina excede la justificación clásica de hacerlo porque se está frente a una realidad compleja. Y nos 
acerca a una perspectiva más terrenal — no por eso sencilla- donde debemos aceptar que además de existir diversos criterios y formas de comprensión de los fenómenos sociales, también estamos frente a sujetos «de transferencia», quienes atribuirán a cada profesional matices diversos, así como distintas expectativas. Para Rudolf estamos frente a una oportunidad privilegiada de intentar romper con la «endociencia», a fin de incluir los saberes de los/as ciudadanos/as, sin que esto implique diluir una productiva distinción entre disciplinas científicas y saber popular.

\section{Una mirada situada, preguntas localizadas}

Como toda visión de mundo, las distintas disciplinas —en tanto discursos de saber que reclaman legitimidad para sus proposiciones cognitivas- necesariamente adoptan una posición de transmisión de sus conocimientos y pareceres, al menos en principio con las otras disciplinas del campo común en ciencias sociales. La tendencia contemporánea exige cada vez más generar una difusión de las reflexiones analíticas que sin duda deben conmover las creencias previas sobre una posición neutral de los/as investigadores/as frente a la producción de sus distintos saberes teórico-prácticos.

Nos interesa compartir las reflexiones que autoras, desde la perspectiva de género, aportan para localizar a los/as investigadores sociales. En este sentido es que el concepto de locus excéntrico ilumina la necesaria revisión de miradas canónicas que defienden una posición del sujeto cognoscente falaz, un sujeto de conocimiento como observador neutral.

El locus excéntrico exige como condición de posibilidad desplazarnos de las coordenadas de construcción clásica de conocimiento científico a fin de constituir una práctica cognoscitiva que, en tanto locus excéntrico, tome en cuenta la variabilidad y el cambio en las acciones humanas, como volver consciente la excentricidad, abandonando así la pretensión de «ningún lugar objetivo» hacia lo que Dona Haraway denominó un saber situado. A través de este concepto la autora insiste en señalar que hay en toda mirada una naturaleza corporizada y en consecuencia un cuerpo marcado que la sostiene.

No estamos frente a una solución reduccionista ya que para la bióloga-filósofa un saber «situado» no se opone a un saber «objetivo». Localizarnos exige una práctica de desplazamientos desde los saberes hegemónicos (y o canóni$\cos$ ) hacia el rechazo a la escisión sujeto-objeto. Sólo así lograremos situarnos donde justamente la parcialidad (de la mirada) será condición para que las 
proposiciones de saber racional puedan plantearse, entenderse y solucionarse (Femenías y Soza Rossi, 20 I I: I 5).

En la misma sintonía, desde la epistemología del punto de vista de Dorothy Smith (Yañez, 20I I), los documentos de carácter histórico en nuestros talleres -en tanto textos que median relaciones de dominación-, además de ser una fuente de información sobre las organizaciones sociales, son también maneras de explorar y de ingresar en las prácticas cotidianas. Así, a través del relato de la experiencia emergen las relaciones sociales y/o la organización social en las que los/as narradores/as están inmersos/as.

Los interrogantes, cuestionamientos y reflexiones que guiaron la elaboración de los talleres retomaban la tensión entre la condición de trabajadores y los sectores dominantes. Y en ese sentido nos preguntábamos:

¿Quiénes eran los fichados? ¿Cuál era el criterio para ser fichado? Evidentemente que «te fichen» marcaba y marca una desigualdad de posiciones, que denota en parte una derrota. Pero también dice mucho sobre que por algo te miran. Porque potencialmente «el fichado» es parte de una disputa de poder. Y si bien el documento como las fichas concentran relaciones de poder desiguales por lo que «te hacen legajo», son cristalizaciones de esa relación de fuerzas; al mismo tiempo se nos presentan como un medio para deconstruir esa desigualdad. Había entonces que desnaturalizar los documentos que teníamos frente a nosotros, descongelarlos, para ver detrás de éstos a los actores que disputaban su parte de la verdad (Giménez y otros, 201 2: 66-67).

\section{Los espacios puentes: diálogo intergeneracional e intergénero}

Los espacios puentes son una alegoría que da cuenta de nuestra concepción de la relación entre el equipo de extensión universitaria y los/as integrantes del sindicato. Su denominación refiere a un camino que comunica espacios que están interrelacionados pero no necesariamente conectados. En este caso, intentamos generar un encuentro a partir de una doble vía de circulación de saberes, sentires y pensares mediante el ejercicio de la voz y el mutuo reconocimiento en tanto interlocutores de un posible diálogo.

La epistemología del punto de vista favoreció nuestra reflexión sobre el trabajo de extensión. Teniendo en cuenta la metáfora de Dorothy Smith (I996) sobre su experiencia como pasajera del tren, podemos decir que la metodolo- 
gía taller circunscribe la tendencia a la objetivación del otro, en tanto el marco cognitivo adoptado y el marco temporal que habilita un proyecto de extensión permiten imaginar múltiples oportunidades para bajar del tren y encontrarse con el otro. Si bien en el transcurso del proyecto fueron realizados dos talleres, llegar a esa instancia supuso una serie de reuniones previas con las referentes del sindicato donde la disposición a encontrarnos implicó de ambas partes un respeto mutuo por los tiempos lógicos de cada institución. Y, en este trayecto, al decir de Vasilachis, habilitamos la propia conmoción y la transformación del equipo de extensión en tanto sujeto cognoscente.

Éramos conscientes que reconocer al otro en sus múltiples diferencias suponía incorporar en la interacción comunicativa criterios de demarcación identitaria que influyen en la constitución de las distintas voces, como las categorías de género y generación.

Desnaturalizar los resabios biologicistas en la construcción social del conocimiento sobre el ser humano implica repensar al sexo y a la edad no como algo dado, sino como una construcción sociosimbólica que da significado a las distintas maneras de «estar en el mundo». En este sentido, las categorías de género y generación revolucionan el pensamiento científico (evitando el androcentrismo y el adultocentrismo), dando cuenta de distintas posiciones de habla que era lícito incluir en tanto enriquecían la referencia experiencial de los textos documentales elegidos para la dinámica de los talleres.

En paralelo a la necesidad de revisar las consecuencias del paradigma biológico en las ciencias sociales, la elección de diferenciar las experiencias de los trabajadores por género ${ }^{5}$ y generación ${ }^{6}$ respondió también a una demanda

5. El género da cuenta de la construcción social de la identidad sexual, en tanto dicha construcción asigna a las personas roles distintos, derechos, oportunidades, responsabilidades y expectativas de proyecto vital de acuerdo al sexo. Esto a partir del aspecto simbólico que se deriva de las implicancias asignadas desde lo social a un cuerpo marcado como femenino o masculino. Mientras el sexo sólo refiere a las diferencias biológicas entre varones y mujeres, sin explicar la existencia de estereotipos y normativas que se vuelven prescriptivas y limitantes para alcanzar la equidad entre los géneros.

6. La generación como categoría que supera la demarcación de la edad como dato biológico y refiere a cuestiones sociales o colectivas define un colectivo imaginario de personas que compartirán limitaciones y potencialidades epocales. A la demarcación histórica se añaden variaciones en las maneras de transitar el ciclo vital en tanto potencialidades y limitaciones que se inscriben en relación al adultocentrismo y al grupo de pares. Así dan un significado original a sus experiencias compartidas. No sólo 
concreta del sindicato. Las referentes consultadas mostraron interés en visibilizar la situación específica de las militantes sindicales y, al mismo tiempo, su intención de incorporar a los jóvenes en la tradición histórica de las modalidades de lucha sindical. En este sentido, citamos a dos referentes de la organización que destacaron especialmente la importancia del diálogo intergeneracional:

El vínculo entre las generaciones será indispensable para construir la memoria del sindicato y del pueblo entero.

Con ese objetivo en el horizonte es necesario construir una mirada histórica propia y combinarla con la fuerza rebelde de los jóvenes. Es la mejor manera de articular las experiencias del pasado con las del futuro (Giménez y otros, 2012).

En el caso de la categoría de género, distintas participantes expresaban una experiencia común: la carga emocional, el costo psíquico, que implicaba la práctica de militancia sindical, al tiempo que garantizar la organización del hogar, con el costo de ser "culpables» de cualquier desorden en el ámbito doméstico. A esta tensión subjetiva, Smith (2012) la llama conciencia bifurcada porque las mujeres deben realizar actividades en escenarios con lógicas distintas y hasta contrapuestas, que limitan su participación política anclándolas en la localidad doméstica.

Otra de las dificultades enunciada por las militantes remite a las relaciones de subalternidad al interior de la organización sindical. Un ejemplo paradigmático fue el esfuerzo de un grupo de mujeres militantes que, teniendo las condiciones de representación y habiendo perseverado en la afiliación sindical, evaluaban la resistencia a afiliarse por parte de sus compañeros varones, como producto de su condición de mujeres «ilegítimas representantes» en un ámbito laboral mayoritariamente masculino como la Fábrica Militar de Pólvoras y Explosivos de la Ciudad de Azul, Provincia de Buenos Aires, Argentina.

En estos ejemplos queda expresado cómo la dicotomía productivo-reproductivo incidió históricamente en el ideal de trabajador como varón proveedor y cómo eso, más allá de las transformaciones históricas, incidía en la subvaloración del aporte de las mujeres a la constitución de las acciones sindicales, sea desde las limitaciones de tiempo disponible frente a una democratización

compartirán experiencias, sino también formas de pensamiento y un tipo particular de acción histórica relevante. 
escasa de las tareas de reproducción doméstica y de la fuerza de trabajo o desde la invisibilización que implica comprender la fuerza de acción sindical sólo atendiendo a los dirigentes formales, en su mayoría aún varones.

En relación a los/las jóvenes, la mirada adultocéntrica que se centra en el preconcepto de la juventud como motor de cambio social, les asigna la responsabilidad de la transformación de lo «no hecho»y, al mismo tiempo, una visión que transmite que quien tiene el saber legítimo es sólo quien vivió los acontecimientos. Esta perspectiva cercenaba las otras maneras de pensar los acontecimientos pasados y las acciones sindicales presentes y futuras.

\section{Consideraciones finales}

De los conceptos no podemos recoger y sacar más que lo que hemos puesto en ellos [...] y, con ellos, no podemos hacer otra cosa que echar puentes sobre el río caudaloso de la realidad, por diminutos que sean los ojos de esos puentes.

H. Rickert, Citado en Fals Borda (I979: 269)

Las reflexiones de Rudolf (2010) sobre la trayectoria de un Programa de Extensión en Uruguay nos ayudaron a reflexionar en retrospectiva sobre los obstáculos y elementos facilitadores presentes en nuestra experiencia de investigación-acción. Creemos que estas líneas pueden aportar al desarrollo futuro de otras experiencias de extensión que tomen como marco de acción a la IAP.

Entre los obstáculos nos encontramos, en primer lugar, con un acceso restringido a materiales de teorías críticas alternativas y metodologías dialógicas. Ya sea por su escasa presencia en los currículos de formación en las distintas disciplinas de las ciencias sociales, como por una circulación fluida en el eje académico norte-sur, en detrimento del eje sur-sur; por ejemplo, nos encontramos con la paradoja de conocer la bibliografía falsbordiana desde editoriales españolas.

Otra de las dificultades a las que nos enfrentamos fue la escasa sistematización y publicación de las complejidades de construir interdisciplina en proyectos de extensión. Así, tuvimos que ir construyendo nuestras propias reflexiones sin ninguna referencia a estrategias de superación del quehacer extensionista. A esto se sumaban las tensiones propias de la convivencia en el equipo de extensión de disciplinas con estatus de legitimidad académica diferenciales: el aprender a expresar nuestras divergencias sin temor a disensos irreconciliables que pusieran en peligro el proyecto. 
Por otro lado, identificamos algunos elementos que facilitaron nuestra tarea y el sostenimiento en el largo plazo del compromiso extensionista. Uno de ellos fue la común trayectoria laboral en tanto trabajadores de la CPM. Otro, nuestra formación predominante dentro del campo de las ciencias sociales y la capacitación común en archivística, lo cual nos permitió valorar el acervo documental en su contexto de producción. A lo cual se suma un acuerdo ideológico-cognitivo con cimientos en la afectividad al interior del equipo y con los/as compañeros/as del sindicato.

Este último punto fue central para retomar luego de un impasse el compromiso de concretar la publicación que permitiera, por un lado, la sistematización necesaria para futuras replicas de la experiencia y, por otro, una devolución a los/as trabajadores/as.

Situadas en la escritura de este trabajo, transcurrido un intervalo de tiempo significativo desde la experiencia de los talleres y la elaboración colectiva de la publicación final, consideramos que, aún con limitaciones, logramos construir un marco cognitivo común que, desde el diálogo interdisciplinar, favoreció el encuentro con los/as trabajadores/as del sindicato. Un encuentro donde los distintos sujetos participantes estuvieron dispuestos a escucharse y conmoverse. Aún resuena en nuestra memoria la frase que utilizaran para referirse a nosotros/as: «acá vienen los/as compañeros/as de extensión».

\section{Referencias}

Benhabib, Seyla (2006). Las reivindicaciones de la cultura: Igualdad y diversidad en la era global. Buenos Aires: Katz.

Bralich, Jorge (I994). Educación popular. Historia y conceptualización. Montevideo: EPPAL.

FALS BORDA, Orlando (I979). «Cómo investigar la realidad para transformarla». En El problema de cómo investigar la realidad para transformarla. Bogotá: Tercer Mundo.

-. (2008). «La investigación acción en convergencias disciplinarias». Disponible en <http://historiactualdos.blogspot.com.ar/2008/I I/la-investigacinaccin-en-convergencias.html>.

Femenías, María Luisa y Paula Soza Rossi (20I I). "Para una mirada de género situada al sur». En María Luisa Femenías y Paula Soza Rossi (comp.), Saberes situados/Teorías trashumantes. Editorial de la Facultad de Humanidades y Ciencias de la Educación. Idihcs-Cinig. 
Freire, Paulo (1985). Pedagogía del oprimido. Buenos Aires: Siglo XXI.

-. (200I). Extensión o comunicación. México: Siglo XXI.

Giménez, Sebastián, Lucía Trotta, Paula Soza Rossi, Carolina Salvador, Santiago Cueto Rua y Viviana Doba (2012). Nos magullaron pero no nos quebraron: Los sindicatos bajo la mirada de la DIPBA. Experiencia de extensión universitaria con ATE Provincia. La Plata: Universidad Nacional de La Plata, Facultad de Humanidades y Ciencias de la Educación.

Krotsch, P. (200I). Educación y reformas comparadas. Buenos Aires: Universidad Nacional de Quilmes, Colección Cuadernos.

LuCARelli, Elisa (2000). Estrategias didácticas de enseñanza y evaluación. Programa de Formación Docente Continua. Programa de Publicaciones. Serie Conferencias y Clases Plenarias. Secretaría General Académica. Rectorado, Universidad Nacional del Nordeste.

Ortiz, Marielsa y Beatriz BorJas (2008). «La investigación-acción participativa: aporte de Fals Borda a la educación popular». Espacio Abierto, I 7 (4): 6I 5-627. Disponible en <http://redalyc.uaemex.mx/src/inicio/ArtPdfRed. jsp?iCve $=\mathrm{I} 22 \mathrm{I} 7404>$.

Puiggrós, Adriana (I987). «Alfabetizar es participar». En Discusiones sobre educación y política. Buenos Aires: Galerna.

Rudolf, Susana (2010). «La interdisciplina en los procesos de extensión». En La extensión en obra. Uruguay: Editorial Extensión Universidad de la República

Smith, Dorothy (I996). "Problematizar el mundo cotidiano: un método feminista». En Ágata Gligo (ed.), El mundo silenciado de las mujeres (pp. I35-I79). Santiago: CIDE.

-. (20I2). «El punto de vista (Standpoint) de las mujeres: conocimiento encarnado versus relaciones de dominación». Revista del CEHIM, 8 (8).

Tunnermann Bernheim, Carolina (200I). "El nuevo concepto de extensión universitaria». En Memorias V Congreso Iberoamericano de Extensión, «Sociedad, Educación Superior y Extensión: Balance y perspectivas». México: ANUIES. Colección Documentos. Disponible en $<$ http://www.udea.edu. co/portal/page/portal/BibliotecaPortal/InformacionInstitucional/Autoevaluacion/SistemaUniversitarioExtension/NuevoConceptoExtensionUniversitaria-CarlosTunnermann.pdf>.

VASILACHIS, Irene (2007). «El aporte de la epistemología del sujeto conocido al estudio cualitativo de las situaciones de pobreza, de la identidad y de las representaciones sociales». En Forum: Qualitative Social Research, 8 (3). 
YaÑEZ, Sabrina (20II). «Develando la propuesta de Dorothy Smith: aportes epistemológicos y metodológicos para el abordaje de lo social». En Revista Diálogos (Universidad Nacional de San Luis), 2 (I): I I I-I 26.

\section{Sobre las autoras}

Lucía Trotta es licenciada en Sociología por la Universidad Nacional de La Plata (UNLP), Argentina. Maestranda en Ciencias Sociales con Orientación en Educación, Flacso, Argentina. Docente e investigadora del Departamento de Ciencias de la Educación y del Departamento de Sociología de la UNLP. Su correo electrónico es <luciatrotta_e@yahoo.com.ar>.

Paula Soza Rossi es licenciada en Sociología por la Universidad Nacional de La Plata (UNLP), Argentina. Maestranda en Género, Sociedad y Políticas, Prigepp, Flacso, Argentina. Docente e investigadora del Centro Interdisciplinario de Investigaciones en Género y del Departamento de Sociología de la UNLP. Su correo electrónico es < paulasoza11@yahoo.com.ar>. 



\title{
Predictores asociados a variaciones en puntajes Simce en la región del Biobío
}

\author{
Predictors Associated with Variations in Simce Scores in the \\ Biobio Region
}

\begin{abstract}
RICARDO ORELLANA OLIVARES Y JOSÉ MANUEL MERINO ESCOBAR Facultad de Ciencias Sociales, Universidad de Concepción, Chile
\end{abstract}

RECEPCIÓN: 3O/II/2OI2 - ACEPTACIÓN: II/O6/20I3

RESUMEN El creciente interés por contar con investigaciones que expliquen diferencias en resultados académicos en el Sistema de Medición de los Resultados del Aprendizaje (Simce) que vayan más allá de la mera construcción de un "ranking educativo», es el fundamento del propósito principal de este estudio que busca identificar posibles predictores de tipo social, cultural o económico, que incidan de manera estadísticamente significativa en variaciones en los resultados de la prueba mencionada aplicada el año 2009 a Cuarto básico. La población comprendida corresponde a la totalidad de la región del Biobío, Chile. Como esta población resulta demasiado extensa para el análisis de nivel individual, se trabajó con las medias comunales del Simce en las 54 comunas que comprenden la mencionada región. El método de recolección de datos consistió en una búsqueda exhaustiva de la mayor cantidad de predictores disponibles en bases de datos confiables como el Censo, Casen, Sinim y Simce. Los datos obtenidos fueron ordenados, analizados y correlacionados a través del programa de análisis estadístico SAS. El análisis estadístico de regresión lineal múltiple permitió establecer un modelo óptimo trivariado para la variable dependiente, conformado por las variables independientes: evaluación docente, crecimiento anual comunal de la población y porcentaje de acceso a computador. Finalmente, este modelo 
explicó un $57 \%$ de la variación total de los resultados Simce 2009 con un error alfa de I por 10.000 .

PALABRAS CLAVE Análisis estadístico de regresión lineal múltiple, región del Biobío, prueba Simce, modelo óptimo trivariado.

ABSTRACT The increased interest of having investigations that explain academic differences on the academic results in the system of measuring the quality of education (Simce) beyond of a simple makeup of «educative ranking», emerges as a purpose of this study to identify possible predictors of social, cultural and economic type, that impact in a statistically significative way on variations of results of the Simce evaluation applied in 2009 to the 4 grade of elementary level. The population studied was the total of the Biobío region, Chile. As this population is too large to be analyzed, it was decided to work with the average Simce score at the 54 communes-level which belong to the Biobio region. The data collection method consisted on an exhausted research of the majority of the variables available in the aggregated data such as Censo, Casen, Sinim and Simce. The obtained results were organized, analyzed and correlated, across the program of statistical analysis labeled SAS. Multiple linear regression analysis it was possible to establish an optimal model composed by three independent variables: teachers evaluation, annual increased of the population and percentage of access to computer. Finally, this model, explained $57 \%$ out of total variations of the 2009 Simce results, with an alpha error of I per I0.000.

KEYWORDS Hierarchical multivariate regression analysis, Biobío region, Simce evaluation, optimal model of three independent variables.

\section{Introduccion}

Sin duda alguna, es posible afirmar que la calidad de educación que recibe un niño o adolescente condicionará gran parte de sus expectativas de vida futura y un eventual ascenso social.

Innumerables investigaciones constatan la estrecha relación de una buena educación con la formación de ciudadanos autónomos, informados, eficientes, responsables y tolerantes; con conocimientos, valores y habilidades para adaptar o crear innovaciones tecnológicas, y con la habilidad de razonar y la capacidad de aprender por su propia cuenta (Schiefelbein, I997). 
En América Latina y el Caribe se ha manifestado públicamente que se debe mejorar la calidad y equidad de la educación. Generar objetivos como ampliar el acceso a la educación, modernizar los procesos pedagógicos, enfatizar la evaluación sistemática de los procesos educativos y generar un consenso social en cuanto a reconocer la educación como prioridad nacional, resulta una tarea que en muchos países de este continente no ha sido aún llevada a cabo (Swope y Schiefelbein, 1999).

En nuestro país, con la reforma educacional de la década de los noventa, Chile reconoce que la educación es uno de los aspectos clave para el desarrollo, y, más central aún, para el desarrollo con equidad.

Ante la mayor preocupación por la educación surge entonces una cuestión relevante del proceso educativo, la evaluación. En la actualidad, la preponderancia de la evaluación en el sistema educativo es un tema totalmente aceptado y no se discute su importancia ni tampoco la exigencia de que a través de ésta se cumpla un papel de retroalimentación para mejorar el aprendizaje y para tomar decisiones que mejoren el funcionamiento del sistema. La evaluación quizás no determina la calidad de la educación, pero sin duda alguna puede ayudar a su mejoría (Velázquez, I996).

En este contexto, surge el Sistema de Medición de los Resultados del Aprendizaje. El Simce es un programa que se pone en marcha en el año I988 y que se propone evaluar el rendimiento escolar y la calidad de la educación impartida en los establecimientos educacionales del país. Actualmente, permite tener una radiografía de los logros en conocimientos básicos que alcanzan los alumnos en las escuelas y tener una idea más completa sobre la distribución del conocimiento al interior del sistema educativo (Gonçalves, I995, cit. en Gómez y Edwards, I995).

Si bien existen no pocos cuestionamientos sobre el valor de los resultados de la prueba Simce, a pesar de sus falencias y/o errores constituye una prueba fiable cuyos informes son esperados y pueden ser utilizados con bastante eficiencia. El Simce ha necesitado de varios años para poder ser considerado como un sistema serio, fiable y eficaz (Olivares, I996).

Dentro de este contexto son muchos los que estiman como crucial el aporte de la investigación en educación a la resolución de los problemas y desafíos que enfrentan los sistemas educativos. Consecuentemente, muchos países han desarrollado programas de investigación y evaluación educativa para apoyar la formulación de políticas y la implementación de reformas (Cariola y otros, I997). 
Ante la necesidad de estudios que contribuyan a explicar las razones de las variaciones producidas en la prueba Simce, necesidad reconocida tanto a nivel de investigadores como también a nivel gubernamental (Olivares, I996; Cariola y otros, I997; Tiana, I997), surge el presente estudio que centra su atención en identificar predictores que pueden explicar, en la región del Biobío, variaciones en los puntajes de la prueba.

\section{Hacia el problema de investigación}

Una de las características particulares de este estudio es que a diferencia de otras investigaciones sobre el tema, que entregan pautas y resultados a nivel nacional, éste sólo se circunscribe a la región del Biobío con sus singulares características.

Cabe señalar que existe una cantidad considerable de autores que han investigado de distintas maneras temáticas relacionadas a la prueba Simce, por lo que necesariamente este estudio debía presentar algunas particularidades diferenciadoras (Gómez y Edwards, I995; Mizala y Romaguera, 200 I; Nocetti, 2004; Simonsen, 2007; Ramírez, 2007).

En primer lugar, gran cantidad de estudios realizados se concentran en encontrar predictores más bien de tipo psicológico, tales como la motivación de los padres o el ambiente que se vive en determinadas salas de clase. De ninguna forma se pretende restar validez a estos estudios, sino más bien complementar estos efectos descritos con otro tipo de posibles variables o determinantes, ya sean de tipo social, cultural o económico.

Resulta interesante entonces, por ejemplo, comprobar empíricamente la afirmación contraria - muchas veces escuchada y a veces con muy poca base empírica-, de que a mayores porcentajes de población en condición de pobreza, los resultados académicos disminuirían considerablemente.

En segundo lugar, esta investigación en particular considera sólo los puntajes Simce agregados de los establecimientos municipalizados, aislando estos resultados de los promedios totales comunales que incluyen a los dos tipos de establecimientos particulares restantes. Esta decisión se basa en que sólo el I7\% de las 54 comunas de la región cuentan con los tres tipos de establecimientos (municipales, particulares subvencionados, particulares pagados) que componen el denominado «promedio total» en el nivel de Cuarto básico. Por lo tanto, y en razón a que un $20 \%$ de las comunas de la región dispone solamente de establecimientos de tipo municipal, nos parece prudente comparar 
exclusivamente el promedio comunal de establecimientos municipales, en desmedro del puntaje Simce total a nivel comunal.

La metodología planteada en el párrafo anterior encuentra sustento en investigaciones previas como la de Olivares (I996), quien critica la publicación de resultados en forma general, no tomando en cuenta las diferencias de establecimientos que tienen las comunas y utilizando rankings de resultados que distan mucho de la realidad.

Otra de las razones que llevaron a esta focalización sólo en los resultados de establecimientos de tipo municipal es que son éstos los únicos posibles de intervenir de manera real, con políticas sociales eficientes en caso de diagnosticar, ya sea en este estudio u otros, problemas que puedan ser mejorados o solucionados.

En base a estos problemas que puedan ser detectados, toma especial preponderancia el rol de la sociología, en específico de la sociología de la educación, en el diagnóstico y posterior generación de políticas sociales adecuadas para nuestra región o país, aportes que claramente pueden ser complementados con los provenientes desde disciplinas como la psicología o el trabajo social. Aunque podría parecer obvio e innegable el papel protagónico del sociólogo al vincular su conocimiento y actividad sociológica a las políticas sociales, autores como Freeman y Rossi (1984, cit. en Fernández, I987), critican que en la formación de sociólogos se produce una orientación más académica que profesional. Al respecto, Fernández (1987) argumenta que debe estimularse el desarrollo de políticas y de investigaciones aplicadas en las universidades. A su juicio, las universidades cuentan con las personas más idóneas y que pueden dar más garantía de objetividad en sus enfoques y análisis que otros organismos más directamente comprometidos en el diseño e implementación de políticas sociales. A su vez, destaca de sobremanera el papel de las universidades regionales en la creación de políticas sociales más adecuadas y pertinentes a las particulares realidades regionales.

\section{Metodología}

El estudio es de carácter observacional, se basa en datos secundarios y es de naturaleza relacional-explicativa, ya que pretende establecer posibles predictores significativos que pueden influir en los promedios obtenidos por los alumnos en la prueba Simce en la región del Biobío.

Este estudio de carácter regional incluyó el total de comunas que componen 
la región del Biobío. La región cuenta con 54 comunas y 1.095 establecimientos educacionales a nivel de Cuarto básico. De un total de 25.998 alumnos que rindieron la prueba Simce en 2009, se seleccionaron I4.I I 6 alumnos distribuidos en 789 establecimientos de tipo municipal.

Las razones que fundamentan esta selección indican, en primer lugar, que corresponden a alumnos que integran la población socialmente más vulnerable de la región. En segundo lugar, dado que son sólo los establecimientos municipales los que están presentes en cada una de las 54 comunas de la región, ya que muchas no cuentan con establecimientos de tipo subvencionado ni menos particulares pagados, esta forma de comparación entre comunas resulta mucho más equitativa.

La variable dependiente del estudio corresponde al «puntaje promedio comunal de las pruebas de Lenguaje, Matemáticas y Comprensión del Medio de los establecimientos municipales del Simce de Cuartos años básicos del año 2009». Para la selección de predictores o variables independientes se realizó una exhaustiva búsqueda de investigaciones relacionadas con rendimiento académico y también de manera específica con la prueba Simce. Dicha búsqueda arrojó una serie de variables asociadas a disimiles resultados académicos, las cuales han sido utilizadas frecuentemente en investigaciones tanto de carácter nacional como internacional, por lo que existiría relativo consenso científico sobre su utilización (Ortiz, I987; Schiefelbein y Simmons, I98 I, cit. en Téllez, I989; Muelle, I984, cit. en Téllez, I989; Vélez, Schiefelbein y Valenzuela, I994; Ivanovic, Castro e Ivanovic, I995; Gómez y Edwards, I995; Jadue, I996; Repetto, I997; Hanushek y Taylor, I990, cit. en Mizala y Romaguera, 200I; Deller y Rudnicki, I993, cit. en Mizala y Romaguera, 200I; Mizala y Romaguera, I998, cit. en Mizala y Romaguera, 200 I; Aravena, Del Pino y San Martín, 2003; Arancibia y otros, I995, cit. en Recart, Mathiesen y Herrera, 2005; Ramírez, 2007).

Las fuentes de información utilizadas para construir la base de datos secundarios fueron: I) la base de datos con los resultados oficiales de la prueba Simce del año 2009 de la región del Biobío, proporcionada por Ministerio de Educación de Chile; 2) la base de datos estadística con los resultados oficiales de la Encuesta de Caracterización Socioeconómica Nacional (Casen) proporcionada por Ministerio de Planificación de Chile; ${ }^{1}$ la base de datos del Sistema Nacional de Información Municipal (Sinim), proporcionada por Subsecretaría

I. En la actualidad Ministerio de Desarrollo Social. 
de Desarrollo Regional y Administrativo del Ministerio del Interior de Chile; y 3) la base de datos Evaluación Docente Región del Biobío 2009 del Ministerio de Educación de Chile.

De acuerdo a los objetivos del estudio, se utilizó un análisis de regresión lineal múltiple, es decir, se analizó cómo un conjunto de variables predictoras de distinta naturaleza (sociales, culturales, económicas, etcétera) afectan a la variable dependiente «puntaje promedio comunal de las pruebas Simce de Lenguaje, Matemáticas y Comprensión del Medio efectuadas en 2009 por los Cuartos años básicos de los establecimientos municipales», en la región del Biobío.

Respecto a la utilización de esta técnica estadística en particular, se considera acertada la decisión de utilizar el procedimiento estadístico de regresión lineal. Como es sabido, los fenómenos sociales rara vez son unicausales, por lo que las posibilidades que entrega la técnica de regresión, obviamente cumpliendo con los requisitos que implica su correcta utilización, permite no sólo contribuir a explicar diferentes fenómenos sociales de manera multicausal, sino también controlar otros factores que pudieran sesgar los resultados obtenidos.

El análisis de los datos fue efectuado mediante el programa estadístico The SAS System.

\section{Resultados}

En primer lugar y antes de comenzar con el análisis de tipo univariado se calcula un modelo nulo que corresponde a una regresión de la variable dependiente sin ningún predictor o variable independiente. La variación total de la variable dependiente, esto es, la suma total de los cuadrados de la regresión corresponde a 6954,98I 48 .

El intercepto en esta ecuación en variables dependientes continuas, que en este caso corresponde a 237,01852, siempre equivale a la media aritmética de la variable dependiente; en otras palabras, el promedio Simce de todos los establecimientos educacionales municipales de las 54 comunas de la región del Biobío. Es preciso señalar que la variable de tipo dependiente presenta una distribución normal que fue corroborada por una prueba de KolmogorovSmirnov donde no se apreciaron diferencias significativas entre las frecuencias observadas y la teóricas, por lo tanto pertenecen a una distribución normal (Sig. O,II2). Sin embargo, se procedió igualmente a convertir en logaritmo natural no arrojando diferencias sustanciales entre estos nuevos modelos y los que utilizaron la variable no transformada. 


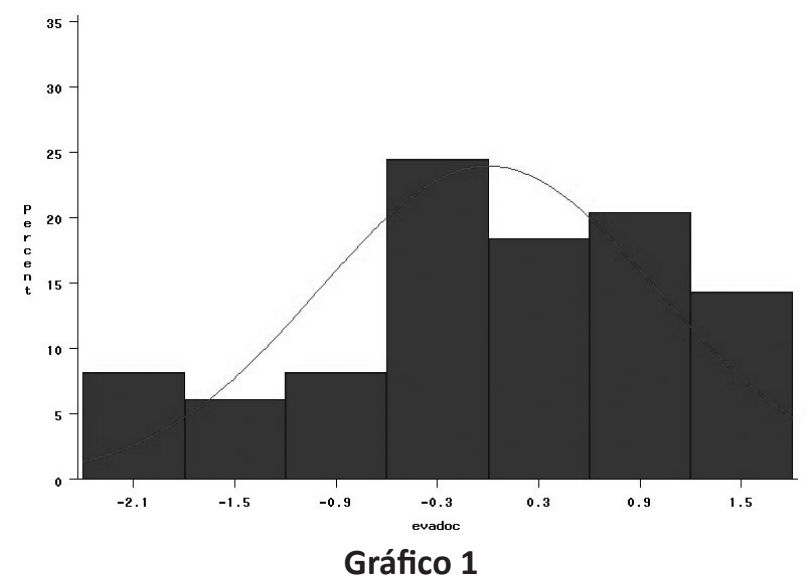

El proceso de modelización comienza con el cálculo y selección de predictores significativos. En este estudio y como es común en estadística, un error alfa inferior al $5 \%$ fue utilizado en la prueba de significación como criterio determinante en la selección de los predictores significativos para la variable dependiente.

El proceso de obtención de predictores significativos consistió en examinar mediante el modelo lineal de regresión ordinaria las correlaciones mediante modelos de una o más variables independientes utilizadas como posibles factores determinantes del «puntaje promedio comunal de las pruebas de Lenguaje, Matemáticas y Comprensión del Medio de los establecimientos municipales del Simce de Cuartos años básicos de 2009».

Se seleccionó de esta forma un conjunto de predictores significativos de orden cero con la variable dependiente. De las 4I variables de tipo independiente que fueron analizadas como posibles predictores (tres variables categóricas fueron convertidas en variables dummies para su análisis mediante regresión), ${ }^{2}$ siete resultaron estadísticamente significativas para la variable dependiente, siendo la variable «evaluación docente» (evadoc) el predictor con mayor grado de explicación del modelo (34\%) y con un nivel de error de I por I 0.000 .

Luego, y en consecuencia con los objetivos planteados en este estudio, estos siete predictores significativos fueron utilizados como base y analizados en mayor profundidad mediante la asociación de modelos polivariados de predic-

2. Provincia (Ñuble, Biobío, Arauco y Concepción); Pladeco (Sí y No); y Territorio de Planificación (Laja Diguillín, Punilla, Valle Itata, Amdel, Biobío Centro, Biobío Cordillera, Arauco, Reconversión y Pencopolitano). 
Tabla 1. Predictores significativos para la variable dependiente

\begin{tabular}{|lccc|}
\hline Modelos & SS Modelo & Adj $\mathbf{R}^{2}$ & $\mathrm{Pr}<$ \\
Ruralidad & 691.69 & .0821 & .0202 \\
Déficit acceso energía & 684.17 & .0810 & .0209 \\
\hline Acceso a computador & 1713.30 & .2353 & .0001 \\
Crecimiento anual comunal & 863.45 & .1001 & .0158 \\
Analfabetismo & 490.63 & .0527 & .0522 \\
Acceso a Internet & 540.00 & .0685 & .0340 \\
\hline Evaluación docente & 2507.45 & .3483 & .0001 \\
\hline
\end{tabular}

tores significativos hasta obtener un modelo óptimo. El modelo óptimo debe ser entendido como el conjunto de variables más eficientes para la explicación de los efectos sobre la variable dependiente.

Un riguroso proceso de modelización estadística permitió la construcción del mencionado modelo ( $\left.\mathrm{R}^{2} \mathrm{Adj}=0,57 \mathrm{a}=0,000 \mathrm{I}\right)$ y que permite explicar parte considerable de las variaciones de la variable dependiente provocadas por los tres predictores constituyentes del modelo estadístico.

En virtud de los coeficientes tipificados beta, la variable «evaluación docente» (evadoc), resultó ser el predictor más relevante para el modelo óptimo encontrado. Sobre la dirección de los efectos que produce la variable independiente evadoc, es posible apreciar que existe una relación directamente proporcional altamente significativa entre el puntaje promedio comunal de las pruebas de Lenguaje, Matemáticas y Comprensión del Medio de los establecimientos municipales del Simce de Cuartos años básicos de 2009 y la nota promedio comunal que obtuvieron los profesores evaluados mediante la evaluación docente. En palabras simples y según la estimación de los parámetros, se espera que por cada punto que aumente el promedio obtenido por el profesorado en la evaluación docente, el puntaje promedio comunal de las pruebas de Lenguaje, Matemáticas y Comprensión del Medio aumente en aproximadamente 20 puntos.

Esta relación encontrada coincidiría con la hipótesis ya clásica de que la calidad de los profesores está íntimamente relacionada con el nivel de aprendizaje de sus alumnos. Por lo tanto, buenos profesores, ya sea con gran cantidad de conocimientos y/o efectivas estrategias de enseñanza, verán esto traducido en mejores resultados obtenidos por sus alumnos. 


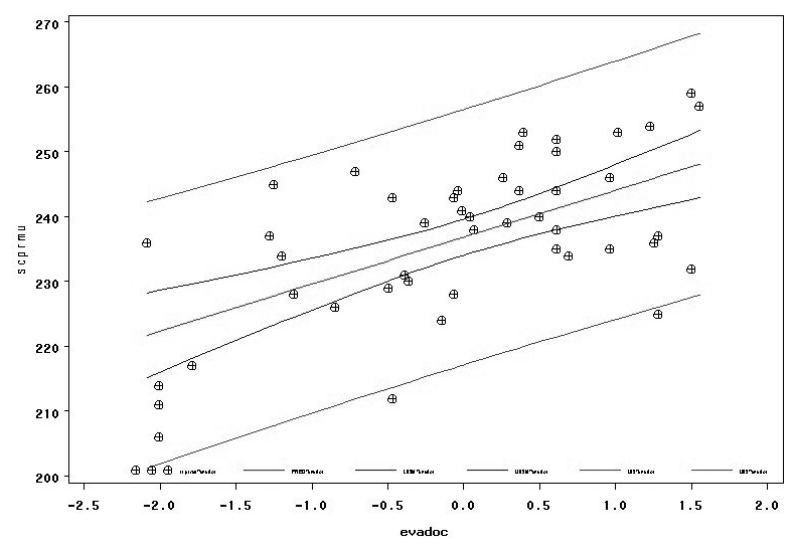

Gráfico 2

Carlos Beca (2003), director del Centro de Perfeccionamiento, Experimentación e Investigaciones Pedagógicas, confirma lo señalado argumentando que un profesor que luego de la evaluación se ubique en la categoría de deficiente, es aquél cuyo desempeño docente presenta un conjunto de debilidades serias para el aprendizaje de sus alumnos. Un profesor mal evaluado, argumenta, debería recibir oportuna y especial atención.

Schulmeyer (2004) argumenta que hoy se aprecia un cierto consenso en la idea de que el fracaso o el éxito de todo sistema educativo depende en gran medida de la calidad del desempeño de sus docentes. Independiente de las mejoras en los planes de estudio, textos, tecnología e infraestructura, ante la ausencia de docentes eficientes, no podrá tener lugar un perfeccionamiento real de la educación.

En los gráficos estandarizados que se presentan, es posible apreciar la distribución de los datos para la variable evaluación docente. Es posible apreciar la curva ascendente y que casi la totalidad de los datos del mejor modelo de tipo univariado se ubican entre los intervalos de confiabilidad al $95 \%$, tanto para el dato individual como para la media del modelo. Se aprecia además una curtosis negativa y sesgo ligeramente negativo. Luego de realizar la prueba de Kolmogorov-Smirnov es posible comprobar que las frecuencias observadas y la teóricas no difieran de forma estadísticamente significativa, por lo tanto pertenecen a una distribución normal (Sig. ०,200).

Si bien algunos autores sugieren para la construcción de modelos multivariados la incorporación de variables bajo una lógica causal temporal, como 


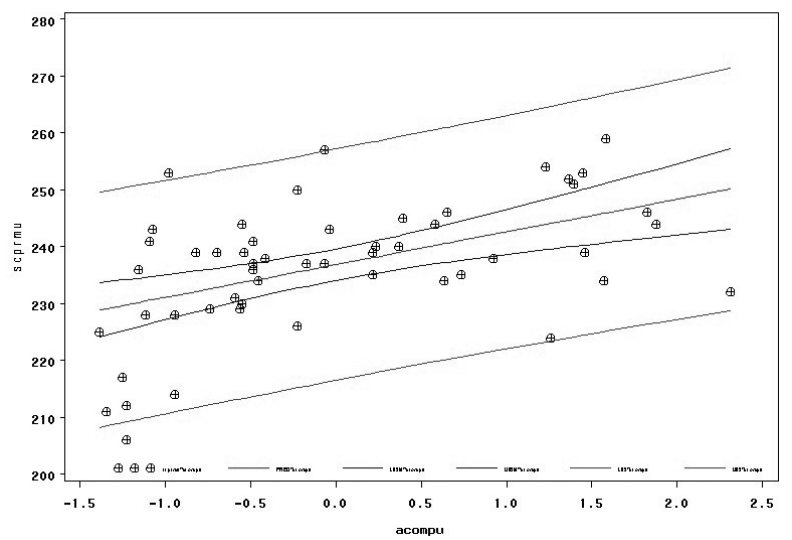

Gráfico 3

éste es un estudio de tipo exploratorio que incorpora distintos tipos de variables y de diferentes bases de datos, lo que dificultaría este orden temporal, sumado también a que la explicación del modelo que incorpora la variable evaluación docente es mucho más elevada que las demás encontradas, se optó por la construcción de un modelo multivariado basándose en la lógica de máximos niveles de explicación y confiabilidad para este análisis estadístico.

Continuando con la modelización estadística, al introducir una segunda variable independiente como predictora de la variable dependiente, la variable acceso a computadores (acompu $)^{3}$ contribuye a aumentar la explicación del modelo a un $5 \mathrm{I} \%$ con aceptables niveles de error $(0,02)$. La dirección de los efectos, como era de esperarse, es directamente proporcional al aumento de puntajes en la prueba Simce. La lectura de los parámetros indica que por cada $2 \%$ que aumente el porcentaje de acceso a computadores, el puntaje promedio comunal de las pruebas de Lenguaje, Matemáticas y Comprensión del Mediose espera aumente en un punto, manteniendo constantes las demás variables. $\mathrm{Al}$ comprobar este segundo modelo mediante una prueba $\mathrm{F}$ de efectos adicionales resulta absolutamente aceptable bajo criterios de error estadísticos.

Al respecto, la oportunidad que ofrecen los computadores, utilizándolos de manera efectiva, para el mejoramiento de la calidad y de las técnicas de enseñanza no es algo desconocido. Para Rojas (2007), el uso del computador

3. Acceso ya sea a través del hogar o en lugares habilitados como escuelas, liceos o cibercafés. 
incide de una u otra forma en el mejoramiento de la calidad de la educación, afirmación que es confirmada por Saavedra y De la Fuente (2006), al señalar que el computador se ha transformado en una herramienta indispensable en la educación, especialmente en el aprendizaje de materias abstractas como las matemáticas y los idiomas. Las autoras destacan las nuevas posibilidades de enseñanza a través de métodos audiovisuales que hacen casi olvidar a la clásica enseñanza en el pizarrón.

Investigaciones desarrolladas en Colombia (Rojas, Forero y Flórez, 2007) demuestran que los computadores contribuyen al desarrollo mental del estudiante e incrementan el logro académico. Niños que utilizaron computadores en su proceso de aprendizaje, mejoraron su actitud hacia la escuela y su rendimiento académico.

Investigaciones desarrolladas en Chile (Saavedra y De la Fuente, 2006) muestran cómo las herramientas tecnológicas basadas en el computador generan verdaderos puentes cognitivos y desarrollan en los niños el interés por conocer.

Sin embargo, es necesario recalcar que uno de los mayores e indiscutidos avances en educación, como es el uso de los computadores, puede traer consigo un aumento de las brechas sociales. Este problema es también reconocido en estudios existentes (Sheingold y otros, I988, cit. en Sanfeliz y Behar, I990; Olivares y otros, I996), los que argumentan que cuando sus beneficios son patrimonio casi exclusivo de aquellos que por su posición socioeconómica tengan acceso al computador, su uso puede contribuir a ahondar aún más las diferencias existentes (cognoscitivas y no cognoscitivas), entre estudiantes de los diferentes estratos sociales si no se garantiza un acceso igual para todos.

Finalmente, la variable crecimiento anual de las ciudades (creanu), al ser introducida como tercera variable independiente, contribuyó a aumentar la explicación para las variaciones en la variable dependiente a un $57 \%$ con un nivel de error de, ,००० I. La prueba $\mathrm{F}$ de efectos adicionales nuevamente validó la incorporación de esta última variable, no así al probar introducir un cuarto predictor.

Sobre la dirección de los efectos que produce la variable independiente creanu, es posible apreciar que existe una relación inversa altamente significativa entre el puntaje promedio comunal de las pruebas de Lenguaje, Matemáticas y Comprensión del Medio de los establecimientos municipales del Simce de Cuartos años básicos de 2009 y el porcentaje de variación de la población comunal. Las comunas que experimentaron un mayor aumento poblacional 


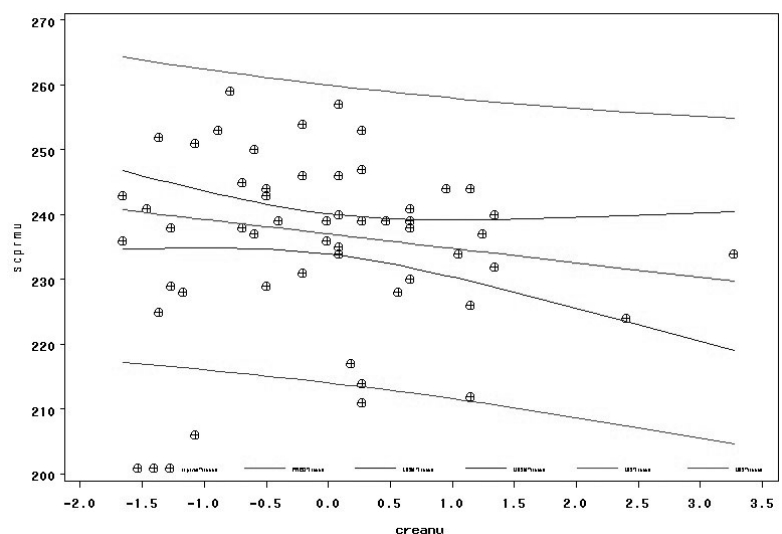

Gráfico 4

experimentaron una baja en sus promedios Simce. De hecho, por cada I \% que aumente la población referente al año anterior en las comunas de la región del Biobío, se espera que disminuya en cuatro puntos el puntaje promedio comunal de las pruebas de Lenguaje, Matemáticas y Comprensión del Medio. Para esta relación inversamente proporcional, no fue posible encontrar estudios similares.

$\mathrm{Al}$ analizar los residuos desprendidos del modelo óptimo mediante la diferencia entre el valor de la variable dependiente y el valor predicho aplicando una prueba de Cook's, no se aprecian residuos que afecten de manera significativa los valores encontrados. Para detectar la presencia de autocorrelación en el modelo de regresión, se aplicó la prueba de Durbin Watson que representa la prueba más frecuentemente utilizada. El valor D encontrado $(2,22)$ nos asegura que la autocorrelación muestral sea nula, por lo que no se presentarán problemas en las perturbaciones. Finalmente, y al analizar los diagnósticos de colinealidad, no se aprecian inconvenientes que hagan pensar relaciones lineales entre ambas variables independientes.

\section{Conclusiones}

En primer lugar, y concordando con lo planteado por Olivares (I996), el Simce a pesar de las falencias o errores que pueda tener, constituye un test confiable cuyos informes son esperados y pueden ser utilizados con bastante eficiencia. Luego ya de sus casi veinte años de aplicación, puede considerarse un sistema de medición serio, seguro y eficaz. 
Sin embargo, es posible apreciar que comunas como Concepción o Chiguayante, que aparecen en los primeros lugares en torno a los resultados totales de la aplicación del Simce 2009, al considerar sólo los establecimientos de tipo municipales su ubicación decrece ostensiblemente. Este resultado indicaría que, en muchos casos, existirían municipios con bajísimos y preocupantes niveles de resultados Simce, pero que estos se encontrarían «disfrazados» en el promedio total por la existencia de establecimientos particulares subvencionados y pagados, frecuentemente asociados a mejores resultados académicos.

Afirmaciones que sostenían que mayores porcentajes de población en condición de pobreza en la región del Biobío afectarían negativamente en los puntajes promedio en la prueba Simce 2009, no resultaron ser estadísticamente significativas. Así también, mayores promedios de ingreso comunal no resultaron ser un predictor estadísticamente significativo para la variable dependiente «puntaje promedio comunal» de las pruebas de Lenguaje, Matemáticas y Comprensión de Medio de los establecimientos municipales del Simce de Cuartos años básicos de 2009.

El modelo óptimo establecido para la variable dependiente logró explicar en su conjunto de variables el $57 \%$ de las variaciones a los puntajes de la evaluación Simce, con un nivel de error inferior al I por I0.000.

Es importante señalar que resulta evidente e indiscutible la existencia de un gran efecto provocado por las variables de tipo contextual que componen el modelo óptimo trivariado sobre las variaciones en los resultados de la prueba Simce 2009.

Es necesario recalcar que estos resultados son sólo aplicables al área de estudio de esta investigación, que correspondió a la totalidad de las comunas de la región del Biobío. Así también, los puntajes Simce analizados correspondieron al nivel de Cuarto básico, por lo que un análisis a las pruebas de Octavo básico o Segundo medio, que también componen el Simce, pudiese confirmar las variables acá seleccionadas como predictores o arrojar otras variables significativas, tomando en cuenta que la edad de los alumnos es totalmente diferente y el contexto psicosocial también podría no ser similar.

Por lo tanto, este estudio aporta con información relevante que debería ser considerada y complementada en el ámbito educativo regional, con el fin de orientar las decisiones que favorezcan el incremento de los niveles de aprendizaje de los escolares de nuestra región del Biobío.

A partir de los resultados obtenidos pareciera necesario orientar las políti- 
cas educativas regionales hacia un aumento en las disponibilidad de acceso a computadores por parte del total de la población, pero de mayor manera por parte de la población más socialmente vulnerable con el fin de equiparar, en parte, esta posibilidad de acceso tecnológico con la población de mayor poder adquisitivo.

El crecimiento de las ciudades de la región en el período descrito, a la luz de los resultados de este estudio, trajo consigo una disminución en los puntajes de la prueba Simce 2009. Si bien no fue posible encontrar en la literatura razones de esta correlación, a juicio de los investigadores una posible razón sería que los establecimientos educacionales de las comunas con mayor crecimiento respecto al año anterior no fueron capaces de absorber la mayor cantidad de demanda educativa producto del crecimiento de la población. La infraestructura educacional en estos territorios no habría sido suficiente y ello se pudo traducir en una baja en la calidad de la educación entregada y, por tanto, en una baja en los puntajes de la prueba Simce. En contrapartida, las comunas que presentaron bajo, nulo o negativo crecimiento de su población, pudieron mantener o mejorar sus niveles de enseñanza en desmedro de las que crecieron de manera explosiva. Esta correlación encontrada podría llevar a pensar en un excesivo tamaño de los cursos como causante de los bajos resultados. Al respecto, si bien investigadores como Lorena Bravo (2007) afirman que cursos abundantes traen consigo menores niveles de aprendizaje, la gran mayoría de los estudios consultados afirman que el tamaño de los cursos no guarda relación con mayores o menores niveles de aprendizaje por parte de los alumnos (Heyneman y Loxley, I983; Ortiz, I987; Schiefelbein, I981, cit. en Téllez, I989; Wolff, Schiefelbein y Valenzuela, I993; Vélez, Schiefelbein y Valenzuela, I994; Mizala y Romaguera, 200I; Hanuskek, I995, cit. en Mizala y Romaguera, 200I).

Así también parece necesario un aumento en la cobertura de aplicación de la evaluación docente, como también una mayor difusión sobre ella para reducir las suspicacias, reticencias o desconocimiento que genera este elemento de medición. Por lo tanto, a diferencia de lo percibido por gran cantidad de profesores que se muestran negativos hacia la evaluación, considerándola sancionatoria y no expresiva de buen desempeño (Cabrera y Vegas, 200I), según las evidencias aportadas por este estudio esta evaluación docente mediría efectivamente la calidad de los profesores y su efecto en la enseñanza, objetivo buscado por el Gobierno; y más que establecer una competencia entre profesionales, buscaría hacer a éstos más competentes en su ejercicio educador. 
Finalmente, el porcentaje restante de variación que no es explicado en este estudio $(43 \%)$ representa un desafío para estudios futuros que puedan incorporar una cantidad aún mayor de variables de tipo contextual, así como también incluir variables relativas al alumno en sí y no tan sólo a su entorno, a través de un estudio de análisis multiniveles.

\section{Referencias}

Aravena, R., G. Del Pino, E. San Martín (2003). «Conclusiones del Simce». Statistica et Societatis, 2: I-I4.

BECA, Carlos (2003). «¿Para qué un sistema nacional de evaluación?» Revista de Educación (Ministerio de Educación de Chile), 305: 32-34.

Bravo, Lorena (2007). «El bajo rendimiento escolar y los problemas de conducta». EducarChile. Disponible en <http://www.educarchile.cl/Portal. Base/Web/VerContenido.aspx? GUID=bc7bco24-fc65-483c-aboI-If 4 adfafd 7 8f\&ID=I37578\&FMT=44>.

Cabrera, V. y L. Vegas (200I). «Evaluación docente: Un estudio indagatorio a partir de la actitud de los profesores de la comuna de Concepción». Visiones, I: I I-2O.

Cariola, P. y otros (I997). "La vinculación entre la investigación y la toma de decisiones en educación: un nuevo enfoque». Red Latinoamericana de Información y Documentación en Educación. Disponible en $<$ http://www. reduc.cl>.

FERnÁndeZ, Francisco (1987). «La sociología y su aplicación a las políticas sociales». Estudios Sociales, 5 I: 9-2 I.

Gómez, M. y V. Edwards (I995). Equidad y educación básica en Chile. Análisis comparativo de la equidad de la educación por regiones y comunas según los datos del SIMCE 1992. Santiago: PIIE.

Heyneman, S. y W. Loxley ( 1983 ). «The Effect of Primary-school Quality on Academic Achievement Across Twenty-nine High-and Low-income Countries». The American of Sociology, 88 (6): I I62-I I94.

Ivanovic, D., C. Castro y D. Ivanovic (I995). «No existe una teoría sobre el rendimiento escolar». Revista de Educación (Ministerio de Educación de Chile). Disponible en <http://www.reduc.cl>.

Jadue, Gladys (I996). "Características de los hogares de bajo nivel socioeconómico y educacional. Sus efectos en el rendimiento escolar». Estudios Pedagógicos, 22: 6I-68. 
Mizala, A. y P. Romaguera (200I). «Factores socioeconómicos explicativos de los resultados escolares en la educación secundaria en Chile». El Trimestre Económico, 68 (272): 5I 5-545.

Nocetti, Alejandra (2004). Efectos contextuales operando sobre puntajes del Simce en la región del Biobío. Tesis de magíster en Administración Educacional. Facultad de Educación, Universidad de Concepción.

Olivares, Josefina (I996). «Sistema de medición de la calidad de la educación de Chile: Simce, algunos problemas de la medición». Revista Iberoamericana de Educación, I0: I77-196.

Olivares, M. y otros (I996). «El computador: una herramienta eficaz en los procesos educativos». Revista de Pedagogía, 387: 236-238.

OrTIZ, Carlos (1987). «Los factores del rendimiento escolar y la realidad nacional». Estudios Sociales, 5 I: 65-75.

Ramírez, María (2007). «Diferencias dentro de las salas de clases. Distribución del rendimiento en matemáticas». Puntos de Referencia, 284: I-4.

Recart, M., M. Mathiesen y M. Herrera (2005). «Relaciones entre algunas características de la familia del preescolar y su desempeño escolar posterior». Enfoques Educacionales, 7 (I): IO5-I23.

Repetto, Paula (I997). "Las variables familiares y su relación con el rendimiento académico». De Familias y Terapias, 8: 54-59.

Rojas, C., H. Forero y O. Florez (2007). «Los computadores en el sector educativo: una experiencia en Colombia». Educación y virtualidad, Universidad de Antioquía. Disponible en <http://www.campusvirtualgitt.net/ experiencia $7 \cdot \mathrm{htm}>$.

Rojas, Carlos (2007). «Uso de computadores y logo en una escuela de zona rural». Instituto SER. Bogotá. Disponible en <http://fisica.usach.cl/ cecilia/ educacion2/lectura2.pdf $>$.

SaAvedra, J. y J. DE la Fuente (2006). «El computador en la educación, un comodín para el aprendizaje». Padres OK. Disponible en <http://www.entelchile.net/familia/Educacion/computador_educacion/computador_educacion.html>.

Sanfeliz, A. y M. Behar (I990). «Uso de computadoras en el nivel básico». Tecnología y Comunicación Educativas, I 5: 25-35.

Schiefelbein, Ernesto (I997). «Educación en las Américas: Calidad, equidad y ciudadanía». OEA. Disponible en <http://www.reduc.cl>.

Schulmeyer, Alejandra (2004). «Estado actual de la evaluación docente en trece países de América Latina». Programa de Promoción de la Reforma 
Educativa en América Latina y El Caribe (Preal). Disponible en <http:// www.preal.org/Archivos/Bajar.asp?Carpeta=Preal\% 20 Publicaciones $\%{ }_{5} \mathrm{CL}$ ibros\&Archivo=02-MP.pdf $>$.

Simonsen, E. (2007). «Simce. Sistematización de la prensa referida a educación». Observatorio de Políticas Educativas. Disponible en <http:// www.opech.cl/prensa/tematicas_2007/pruebas_estandarizadas/07-05-SIMCE \% 20-informe \% 2ode \% zoprensa \% 20OPECH-\% $20 \%$ 20mayo \% 20 2007.pdf>.

Swope, J. y P. Schiefelbein (I999). «Políticas educativas en las Américas: Propuestas, consensos y silencios». CIDE. Disponible en <http://www.reduc.cl/reduc/swope2.pdf>.

Téllez, Francisco (1989). Revisión de los estados del arte de la investigación latinoamericana bajo la perspectiva de la relación entre educación y pobreza. Santiago: CIDE.

Tiana, Alejandro (I997). "Tratamiento y usos de la información en evaluación. Organización de estados iberoamericanos para la educación, la ciencia y la cultura». Disponible en <http://www.oei.es/calidad2/tiana.htm>.

Velázquez, Víctor (I996). "La evaluación como recurso para elevar la calidad de la educación en México». Revista Iberoamericana de Educación, IO: I97-2II.

Velez, E., E. Schiefelbein y J. Valenzuela (I994). «Factores que afectan el rendimiento académico en la educación primaria. Revisión de la literatura de América Latina y El Caribe». Revista Latinoamericana de Innovaciones Educativas, I7: I-I6.

Wolff, L., E. Schiefelbein y J. Valenzuela (I993). «Improving the Quality of Primary Education in Latin America and the Caribbean: Towards the 2Ist. Century». Regional Studies Program Report, The World Bank, 28. Disponible en <http://www.worldbank.com>.

\section{Sobre los autores}

Ricardo Orellana Olivares es sociólogo y académico de la Facultad de Ciencias Sociales de la Universidad de Concepción. Su correo electrónico es $<$ rorellana@udec.cl>.

José Manuel Merino Escobar es doctor en sociología y académico de la Facultad de Ciencias Sociales de la Universidad de Concepción. Su correo electrónico es <jmerino@udec.cl>. 


\title{
Revisitando la historia de las teorías del desarrollo
}

\author{
Revisiting the History of Development Theories
}

RAÚL GONZÁLEZ MEYER

Universidad Academia de Humanismo Cristiano, Chile

RECEPCIÓN: I I/O9/20I2 • ACEPTACIÓN: 4/O6/20I3

RESUMEN El artículo reconstruye el debate en economía del desarrollo desde la Segunda Guerra Mundial hasta hoy. Para ello, lo conecta con el valor del progreso y de la producción de riqueza que ganaron lugar en siglos anteriores. Se revisan los factores que permitieron la emergencia de un discurso desarrollista y, luego, las teorías que surgieron más tarde: el paradigma de la modernización, socialismo industrialista, la Comisión Económica para América Latina (Cepal), dualismo, teoría de la dependencia, aproximaciones sociales, visiones ambientalistas, desarrollo a escala humana, sustitución de importaciones, neoliberalismo, neoestructuralismo, desarrollo étnico, capital humano, desarrollo humano, antidesarrollo y otros. Estas teorías o aproximaciones son vistas desde las inflexiones que marcan respecto a etapas anteriores, así como respecto de las circunstancias históricas que parcialmente explican su emergencia. El artículo concluye proponiendo una posición sobre el estado y el futuro del campo de los estudios de desarrollo en relación con los retos de la sociedad actual. La tesis del artículo es que la referencia teórica y política del desarrollo ha sido y es un concepto controvertido, en disputa e incrustado en la historia.

PALABRAS Clave Progreso, desarrollo, modernización, industrialización, Estado, cultura, estrategias, ecología, liberalismo, socialismo. 
ABSTRACT The article reconstructs the debate on economic development since the Second World War until today. For that, connects to the value of progress and wealth production that won place in previous centuries. It reviews the factors that made the development discourse emerge, and then, the various theories that surfaced later: modernization paradigm, industrialist socialism, the Economic Commission for Latin America (Cepal), dualism, dependency theory, social approaches, environmentalist's visions, human scale development, import substitution, neo-liberalism, neo-structuralism, ethnic development, human capital, human development, anti-development, and others. These theories or approaches are seen in terms of the inflections that marks respect of earlier times, as of historical circumstances that partly explain its occurrence. The article concludes by proposing a position on the state and future of the field of development studies in relation to the challenges of today's society. The thesis of the article is that theoretical and policy reference of the development has been and is a contested concept, embedded in history.

KEYWORDS Progress, development, modernization, industrialization, State, culture, strategies, ecology, liberalism, socialism.

\section{Introducción}

Este artículo reconstruye la trayectoria de las teorías del desarrollo económico, campo especialmente constituido luego de la Segunda Gran Guerra. Sin embargo, muchos de sus contenidos estaban presentes desde períodos anteriores y habían sido parte de la constitución del análisis económico, en lo referido al aumento de la riqueza material, de su distribución y del funcionamiento del sistema económico.

Aun considerando dichos antecedentes históricos, podemos reconocer que cerca de la mitad del siglo XX se despliega un «movimiento desarrollista» específico, teórico y práctico. Dicho movimiento tiene como foco a un grupo de países definidos como «atrasados «, «subdesarrollados» o «no desarrollados» de América Latina, Asia, África Subsahariana y África Árabe. Sin embargo, no se circunscribe a ellos como suele predominantemente afirmarse, sino que abarca también a países más "avanzados», de la Europa del Sur, la Europa del Este y aun, las realidades de los países llamados centrales, en los cuales también se pueden identificar "políticas de desarrollo». Por ejemplo, en Europa 
Occidental, la política de modernización rural, particularmente en Francia, que busca eliminar un sector de agricultura pequeña considerada tradicional, para acercarse a los estándares de productividad norteamericana de la época (Peemans, 2002). Esta universalidad espacial de la cobertura de la teoría y acción desarrollista se acentúa en el tiempo con la aparición de consideraciones que se van a presentar como pertinentes tanto en el Norte como en el Sur. Entre ellas, las relativas a la realidad ecológica, a partir de los años setenta, o los impactos del neoliberalismo y globalización en los años ochenta y noventa.

\section{Progreso, desarrollismo y Estado}

La emergencia del desarrollismo del siglo XX se inscribe dentro de la historia más larga del avance de la idea de progreso en y desde Occidente, entendida como una condición de la humanidad, expresión del despliegue de la razón, y subjetivamente valorada como positiva (Le Goff, 2005). Desde ese lente se pudieron establecer con convicción, desde los países centrales y algunas élites periféricas, dicotomías del tipo civilización-barbarie, razón-irracionalidad, ilustración-ignorancia o ciencia-superstición. ${ }^{1}$ El progreso se concreta e identifica en la ciencia, la tecnología y la producción de riqueza, expresiones empíricas de la capacidad humana de comprensión del mundo físico, y luego social, y de manipularlo u organizarlo para su beneficio (Preston, I999). Aquel trayecto no estuvo falto de escepticismos, problematizaciones o contestaciones en el propio centro donde ocurrió el progreso: los análisis sobre la explotación y alienación del trabajo o su sometimiento al capital (socialismo utópico, Hegel, Marx), los límites al crecimiento y mejoramiento de las condiciones de vida por la contradicción entre crecimiento demográfico y tierras fértiles escasas (Malthus y economistas del siglo XIX), la necesidad de vías propias de industrialización — protegida y con apoyo estatal— en relación al patrón liberal inglés como en la escuela histórica alemana (F. Lizt). A ello se agregan cuestionamientos al progreso occidental provenientes desde realidades más periféricas, por ejemplo, desde la búsqueda de armonizar desarrollos técnicos y grados de modernización con el resguardo de las organizaciones y culturas campesinas,

I. Las empresas colonialistas están sostenidas subjetiva y éticamente en esa idea de civilización superior como expresión de progreso acumulado y en despliegue. Superioridad que estaría en las dimensiones tecnológicas y axiológicas y en que el «contacto» permite transmitir algo bueno para el colonizado. 
en lo que podríamos denominar el intento de una vía comunitario-campesina de modernización, expresados en el «populismo ruso» de la segunda mitad del siglo XIX, también, posteriormente, en el gandhismo y, en algún grado menor, en el maoísmo; asimismo, en las ideas de pensar el desarrollo desde una singularidad espacio temporal en las ideas de Haya de La Torre sobre Indoamérica.

La noción de desarrollo como fundamento y referencia central para la acción política nacional e internacional, luego de la Segunda Guerra Mundial, puede ser imaginada como una «refracción» de aquella ideología y cultura del progreso. Por un lado, es prolongación o reencarnación de éstas. Por otro, representa una variación en términos de una explícita acción para construirlo, a través de dispositivos institucionales, políticos y teóricos, y la elaboración de estrategias. Allí emerge el campo de las "ciencias sociales del desarrollo» (economía, sociología, antropología, ciencia política) que se ordena bajo las preguntas relacionadas de por qué algunos países son desarrollados, qué recorrido han hecho, y qué debe hacerse para que aquellos que no lo son avancen a ese estadio. Ello comprenderá también a países de modernización intermedia y, aun, comprenderá la profundización del avance de los países considerados adelantados, a fin de consolidar una sociedad de alto consumo de masas. Se define, así, un campo de teoría y acción con paradigmas dominantes de valor temporal, y que será también uno de importantes disputas a distintos niveles, incluyendo la puesta en cuestión de la propia noción de desarrollo y de su pertinencia universal.

Varios fenómenos antes y durante la mitad del siglo XX contribuyen a aquella «refracción» antes señalada. En lo histórico, la descolonización de buena parte de Asia y de África del Norte y Subsahariana, donde sus nuevas clases dirigentes y luchadores anticoloniales sustentaron su legitimidad tanto en el principio de la autonomía nacional como en el avance hacia el desarrollo, diagnosticado como negado por la condición colonial. En América Latina, las tendencias hacia proyectos de industrialización nacional producto de los límites del modelo primario exportador, del reforzamiento de la industrialización espontánea resultante de eventos externos — guerras y Gran Depresión- y del surgimiento de nuevos grupos — clases medias, industriales y grupos populares- que pusieron en crisis un tipo de dominación oligárquica heredada del siglo XIX. En Europa, las tareas de reconstrucción de la posguerra, incluyendo el Plan Marshall, que alimentan acciones programadas y estratégicas; pero también los planteamientos de la necesidad de políticas de desarrollo en Europa del Sur, caracterizada con insuficiente modernidad propicia peligro- 
samente el surgimiento de líderes nacionalistas carismáticos; y la emergencia de un bloque nuevo de países socialistas en Europa del Este que se proponen salir de su atraso relativo y desarrollar sus fuerzas productivas a través del «atajo histórico» con que es connotada esa orientación, en comparación a la vía capitalista. Por último, el avance de una lectura de pobreza material como caracterizadora de buena parte del mundo, en contradicción con la visión de una modernidad avanzada en lo científico-tecnológico y que hacía emerger, en élites internacionales, de manera complementaria y contradictoria, por un lado, impulsos éticos a actuar y, por otro, miedo a las inestabilidades políticas futuras por expectativas masivas de bienestar que no fueran satisfechas.

En lo teórico, en conexión con aquellos procesos históricos, varios fenómenos empujan el lugar protagónico del desarrollo como referencia normativa para la acción. El keynesianismo había dado fundamentos sólidos a la acción estatal dentro del capitalismo para enfrentar la amenaza permanente de insuficiente demanda agregada como fuente de ciclos depresivos. Ello se prolongaría luego entre economistas poskeynesianos que en perspectivas de mediano plazo concluían la inexistencia de mecanismos espontáneos del mercado para asegurar trayectorias de crecimiento económico con equilibrio en el tiempo entre el ahorro y la inversión y entre el aumento de la fuerza de trabajo y el aumento de los empleos² (Harrod, I948). Más decisivamente aun, es un período en que gana prestigio la planificación, la que es connotada de un recurso clave para una acción política racional, con una ganancia en tiempo y eficacia para construir el desarrollo y en que la URSS aparece como encarnación y ejemplo exitoso de ello. Aun países no socialistas se sentirán atraídos por la planificación soviética, como la India post-Gandhi, y la mayoría de los países occidentales crearán ministerios de planificación la que, dentro del contexto y lenguaje de la

2. Los poskeynesianos partieron del postulado keynesiano de que en un momento dado la economía podría tener un equilibrio con empleo alto si la magnitud de la inversión era suficiente para ocupar la masa de ahorro generado. Pero se centraron en que dado que esa inversión, como proceso permanente en el tiempo para asegurar aquel equilibrio, significaba un aumento también permanente de la capacidad productiva, necesitaba, a la vez, un crecimiento permanente de la demanda agregada de bienes y servicios que hiciese el proceso sustentable en el tiempo y que, a la vez, dicho ritmo fuera tal, que asegurase la ocupación del natural crecimiento de la fuerza de trabajo, no generando, en el mediano plazo, ya sea un déficit de trabajadores o ya sea un desempleo estructural. 
Guerra Fría, se caracterizará como indicativa y democrática en oposición a la imperativa y autoritaria de los países socialistas. Esto se acompaña del aumento de técnicas que le van dando sustancia, como la matriz insumo-producto, la que relacionaba las producciones de cada sector de la economía con la necesidad de insumos provenientes de los otros sectores y de sí mismo, los que definían los «coeficientes técnicos de producción». Junto con ser un cuadro que representaba en términos estáticos las relaciones intersectoriales de la economía se ofrecía como un gran instrumento de planificación de las necesidades de producción (y de importación) a partir de establecer algunas grandes metas centrales de crecimiento de determinados sectores económicos. Dos autores precursores de esta técnica fueron W. Leontief y Von Neumann en la década de los treinta y cuarenta.

\section{Lectura desde la dicotomía tradición/modernidad: evolucionismo y dualismo}

Una aproximación inicial envolvente de la perspectiva desarrollista la constituye el paradigma de la modernización (García, I986). Éste ordenó el tiempo histórico desde las categorías de sociedad tradicional y sociedad moderna, en donde el subdesarrollo aparece como la expresión económica de aquel primer "estadio», definido como la antítesis de una sociedad moderna cuyas referencias avanzadas eran Estados Unidos y parte de Europa. Lo tradicional quedaba asociado a un estadio retardado sin historia, marcado - al contrario de la situación moderna - por la no acumulación de medios productivos, bajo producto, bajo consumo, baja productividad, falta de motivaciones hacia el progreso y el confort material, y falta de agentes e instituciones generadores de actividad económica en función de una ganancia. Dicho enfoque dotó de una lectura universal del momento histórico — transición de lo tradicional a lo moderno- y al proyecto de modernizarse como el desafío histórico de los países.

Esta condición moderna contenía dimensiones políticas, como la secularización y la existencia de sistemas de partidos y representación; culturales, como la valorización del confort material y el cálculo racional; y económicas, asociadas al crecimiento, a los procesos de ahorro-inversión, que lo hacen posible, y a un proceso incesante de división, especialización y productividad del trabajo y la expansión de los mercados, para lo que la industrialización aparecía como una condición y vía necesaria. Estas tres dimensiones se entendían reforzándose mutuamente, actuando cada una como condición favorable para las otras, 
aunque era finalmente en lo económico donde debía fundamentalmente verificarse el grado de modernización avanzado. Lo cultural, sin embargo, era clave para dotar de las fuerzas motivacionales centrales de la modernización y lo político para presionar y «administrar» el cambio societal sujeto a posibles resistencias y desequilibrios (Almond, I960).

En ese marco se puede inscribir la popular obra de W.W. Rostow y su sistematización en cinco etapas del proceso histórico de modernización económica recorrido por Occidente, llamado a hacer de espejo para mirar el recorrido llevado a cabo y por acometer en cada sociedad nacional. Todo comienza en una sociedad tradicional en los términos antes descritos. Desde esa situación, pasando por sucesivas etapas, se podía llegar a la moderna sociedad de la abundancia con alto consumo de bienes privados y públicos (Rostow, I963). Los cambios primero son lentos y suponen el nacimiento de agentes y fuerzas minoritarias que van difundiendo las prácticas, valores e instituciones modernos hasta hacerlos prevalecer. Ésta es una acumulación en el tiempo pero que tiene saltos y que en su faceta más económica se expresa en el aumento del ahorro y la inversión. La etapa clave es la tercera, la del «despegue» — históricamente asociable a la revolución industrial - en que se impone la inflexión hacia la sociedad económica moderna, aunque pueden existir reversiones o estancamientos. Dentro de la amplia acumulación de factores que van produciendo esa dirección y momento, algunos juegan un rol particularmente importante: la existencia de una masa mínima crítica de «hombres de empresa» capaces de usar productivamente el capital económico acumulado; la existencia de una institucionalidad que permita que el excedente potencial de la economía sea mayoritariamente transferido y usado por dichos agentes inversores; la existencia de sectores productivos líderes, como lo fue la industria textil en Inglaterra o el ferrocarril en otros países, que abren enormes oportunidades de inversión y arrastran a través de enlaces a una buena parte del resto de la economía.

Algo importante en la lectura de Rostow es que la llegada al bienestar masivo y de alto consumo, etapa de la abundancia de bienes y servicios, requiere de una fase previa que prosigue a la del despegue y que es un período de acumulación de fuerzas productivas. Aun así, su visión termina siendo una representación histórica poco conflictual de los procesos de modernización que hace un tanto invisibles los dolores de la acumulación originaria, la expropiación de los campesinos y la explotación de los obreros, como lo había descrito Marx, el siglo anterior.

En ese mismo marco de análisis, aunque con una focalización más precisa 
en la realidad de los países pobres, podemos ubicar el enfoque dualista. Para éste, en su versión más clásica, aquellos están constituidos por dos economías separadas, una tradicional agrícola-rural y otra moderna (capitalista) industrial-urbana (Lewis, I 964). ${ }^{3}$ La primera, caracterizada en los términos convencionales - baja productividad, bajo producto, bajo consumo, sin inversiónes además descrita con una enorme masa de población que tenía productividad cero o muy baja, menor a lo que consumía para sobrevivir. Este «excedente estructural de mano de obra» en el sector rural, si dejaba de estar en el campo no producía disminución de la producción agrícola. Desde esa premisa, el dualismo planteaba que el desafío central para el desarrollo era el traslado de esa masa excedentaria hacia el sector capitalista moderno - convirtiéndola en proletariado industrial - definido con productividad alta y en donde existía una masa de utilidades constantemente reinvertidas. Ello suponía algún salario diferencial positivo en la industria que atrajese migrantes, pero que en la medida que fuese una oferta importante permitiría mantener el nivel de salarios urbanos dentro de márgenes acotados que no pusieran en cuestión la acumulación moderna, hasta que fuese absorbida toda la masa excedentaria, momento que definía una sociedad y economía unificadas (Lewis, 1964).

Sin embargo, dentro de este marco, autores dualistas plantearon que este proceso podía ofrecer problemas, los que resultaron ser de gran actualidad y significado para muchos países «en transición» (Ranis, 1993). Uno era que si la mayoría de los migrantes algún grado de aporte hacían a la actividad agrícola, aunque fuese con productividad baja — como parecía ser la realidad de las economías agrarias-, dicha migración disminuía la producción de alimentos encareciendo sus precios y dificultando la reproducción básica de los trabajadores urbanos y/o bajando la tasa de ganancia en el sector moderno por la necesidad de aumentar los salarios. Ello llevaba a enfatizar algo que se hizo clave en los debates sobre desarrollo: la necesidad de la modernización agrícola como condición para la industrial y para el éxito de la modernización en general. El otro era la posibilidad que la migración campo-ciudad fuera a un ritmo por sobre la oferta de empleo generada por el sector moderno, lo que

3. Sin embargo, en su versión original la noción de dualismo fue usada en un estudio sobre Indonesia en que el economista holandés Boecke distinguía dos economías paralelas dentro del sector agrícola: la economía campesina de autosubsistencia (tradicional) y una economía comercial de exportación (moderna) (Kanbur y McIntosch, I993). 
llevaría a un desempleo urbano, a la manera de un "excedente estructural de mano de obra», pero ahora en la ciudad. Para enfrentar esto era necesario asegurar una composición del crecimiento que le diera importancia a los sectores productivos creadores de empleo y a un ritmo de modernización tecnológica que no provocara un desmedido ahorro de mano de obra. ${ }^{4}$ Algunos autores cono G. Ranis y J. Fei plantearán que estos dos problema habían sido muy bien resueltos por la estrategia de modernización seguida por Japón durante el siglo XX levantando, de paso, a este proceso como una referencia de modernización exitosa distinta a la occidental (Ranis, I993).

\section{Círculos viciosos y otros diagnósticos orientadores de la acción desarrollista del Estado}

Estos primeros tiempos de análisis enmarcado en el imperativo del desarrollo hicieron emerger diagnósticos y proposiciones más puntuales y específicos que, aunque no alcanzaron el carácter de «teorías del desarrollo», configuraron un núcleo de representaciones acerca de los países subdesarrollados. Asimismo, tuvieron el importante significado de fundar y orientar lo que debía ser la «necesaria» o "correcta» acción desarrollista del Estado.

Un tipo de representaciones es la de los «círculos viciosos», la que puede tomar varias formas cercanas entre sí. Por ejemplo, países pobres con pocos ingresos generan poco ahorro, lo que determina una inversión baja, esto define un crecimiento muy pequeño del producto y del ingreso, con lo que el ahorro y la inversión continuarán siendo bajos, reproduciéndose el ciclo señalado. Ello puede alcanzar formulaciones radicales como las de Leibenstein acerca de países pobres con trabajadores mal alimentados, productividad baja y pobreza que se reproduce (Leibenstein, I957). En definitiva, se es pobre porque se es pobre (Nurkse, I973). También se populariza en la época la visión de las economías subdesarrolladas como extravertidas y fragmentadas, es decir, con un sector moderno orientado hacia el exterior y carente de articulaciones internas — tipo enclave- lo que impedía la difusión del progreso técnico en su interior.

4. La cuestión del ritmo de creación de empleo urbano reaparecería con fuerza en la discusión a mediados de los años setenta en torno a la noción de sector informal urbano que constituiría en su momento la base de un diagnostico de los problemas de la industrialización del «tercer mundo» en cuanto incapaz de generar suficientes puestos de trabajo. 
Eso era contrapuesto a las economías avanzadas que eran caracterizadas como intravertidas y con fuertes articulaciones internas, conformando un espacio económico nacional denso (Perroux, 1958).

Algo importante es que esos diagnósticos fundaban la necesidad de políticas que ya sea rompiesen círculos viciosos o generasen articulaciones internas. Los agentes privados y los incentivos de mercado si bien no eran rechazados por buena parte de los teóricos desarrollistas, particularmente los «no socialistas», eran calificados de incipientes o insuficientes para aquella tarea en los países subdesarrollados. Esto abrió el espacio a discutir cuál era el tipo de acción estatal pertinente. En algunas formulaciones este aparece como el agente que debe dar «el gran empujón» para que se desencadene un proceso de modernización y de economía nacional autopropulsada (Rosenstein-Rodan, I962). Ello equivalía a señalar que era necesario alcanzar "un esfuerzo mínimo crítico» - es decir un umbral de acción estatal que había que sobrepasar- bajo el cual el despegue hacia el desarrollo no se produciría, análogo al necesario para asegurar el vuelo de un avión.

Ello se combinó con la controversia entre una acción estatal global y comprensiva o una focal y estratégica. La primera, enunciada como del «desarrollo equilibrado", planteaba la necesidad de una intervención estatal simultánea en la demanda y la oferta de diversos sectores económicos para que se retroalimentaran y produjeran una sinergia ascendente, impidiendo, además que algún sector económico se transformara en cuello de botella del sistema (Rosentein-Rodan, I962). La segunda, partiendo que los recursos estatales eran limitados para intervenir tan masivamente, planteaba la necesidad de una intervención estatal seleccionada que produjese el máximo de impactos creadores de tejido económico (enlaces) y de economías externas que generaban múltiples rentabilidades públicas y privadas ausentes, antes de cada intervención (Hirschman, I96I).

En cierta medida, los análisis generados, más tarde, desde la noción de polo de crecimiento de F. Perroux, pueden también ubicarse en la última perspectiva señalada. Este enfoque planteaba que el desarrollo no era nunca equilibrado sino que se generaba en algunos sectores productivos y en algunos puntos en el espacio para desde allí difundirse. Lo clave era la existencia de una «industria matriz» que cumplía el rol de arrastrar a través de eslabonamientos, a una parte significativa de la economía (Kuklinski, I985). Esto llevará en los años sesenta a propuestas de creación de polos de desarrollo - transformado en un enfoque paradigmático de desarrollo regional- en zonas subnacionales consi- 
deradas atrasadas y con potencialidad de consolidar ciudades intermedias (De Mattos, 1984).

También el diagnóstico de que en los países pobres existía una gran cantidad de pequeñas empresas levantó en algunos economistas, como G. Myrdal respecto de la estrategia de desarrollo de la India, la idea que la estrategia de desarrollo debía no destruir sino tomar como base ese patrimonio (Myrdal, I957). Esto, porque una modernización económica basada en la sola gran empresa, como referencia dominante, amenazaría con generar islotes de modernidad y una sociedad fragmentada. Ello se inscribía además en la problemática de lograr armonizar crecimiento económico con creación de empleo. En elaboraciones posteriores ello será conectado con ideas de una tecnología apropiada o intermedia que pudiera conciliar crecimiento con empleo. Esto se enfrentó a un cierto predominio de la idea que siempre era mejor la máxima expansión, con la tecnología más de punta y el máximo de economías de escala en la producción (Dickson, I980).

\section{Socialismo y planificación: variante radical del desarrollismo}

El socialismo, luego de la Segunda Gran Guerra, aparece como una propuesta que se expande como alternativa al desarrollo económico capitalista para los países subdesarrollados. Esto en el contexto geopolítico de la Guerra Fría donde se inscribía la disputa por la superioridad de un sistema socioeconómico sobre otro. La vía socialista se ofreció como «atajo histórico» para producir un desarrollo de las fuerzas productivas allí en las vastas zonas del planeta donde el capitalismo, dada su fase más concentrada e imperialista, no era capaz o, en el mejor de los casos, lo haría mucho más lentamente. En ese sentido, el socialismo, en su lectura marxista, encarnado prácticamente en la URSS, y ahora en el Este europeo, estaba llamado a cumplir lo que en una visión clásica debía haber sido tarea del capitalismo. Ello sin embargo presenta cierta ambigüedad, pues los partidos comunistas de América Latina, portadores de la matriz marxista, sostuvieron por varios decenios la idea de un rol histórico a ser jugado por un capitalismo nacional ( «antiimperialista», «antioligárquico»y "antimonopólico»). En este caso, la crítica a la posibilidad de modernización por vía capitalista es puesta en el centro por la Escuela de la Dependencia, entendida por ello como una aproximación neomarxista, al cuestionar el rol históricamente progresista del capitalismo para los países dependientes. 
El objetivo central para ese propósito desarrollista era también la industrialización acelerada, impulsando las bases energéticas, la explotación de los recursos naturales de base, así como las infraestructuras en vialidad y transporte. Acento característico de la propuesta socialista fue la primacía de la industria de medios de producción, en particular aquellos referidos a los considerados sectores industriales de punta (Rutkowski, I965). La orientación industrialista planteó, a su vez, la cuestión de la extracción de capital (excedente) desde la agricultura hacia la industria y el aumento de la productividad agrícola para sostenerla, lo que, en el fondo, era una decisión sobre las condiciones de vida en el sector rural para sostener el desarrollo industrial.

Para el ejercicio de su estrategia y como principio característico, el enfoque socialista definió la necesidad de construir un «área social, estatal o nacional», la que establecía relaciones de supremacía respecto de otras formas minoritarias de propiedad y gestión: la capitalista y la pequeña producción mercantil (pequeña producción sin asalariados con destino a la venta: unidades campesinas o urbanas, como producción de cereales o servicios residenciales). La colectivización de la gran propiedad privada existente —industrial, financiera, comercial y agraria- y luego su constante ampliación se entendía como la condición básica para una modernización económica acelerada. Ella era concebida, además, como la base material para el despliegue del otro componente central del enfoque, cual era la existencia de una planificación integral de la economía, entendida, en su sentido más profundo, como expresión de que la razón humana podía construir un sistema socioeconómico apropiado a sus fines, aunque sujeta al respeto de lo que los planificadores socialistas llamaban las «leyes económicas» (Lange, 1965b). A través de esa modalidad, los teóricos y planificadores de las experiencias socialistas planteaban que se aseguraría el total uso productivo del excedente económico, impedido en el capitalismo. Ello pues el mercado dilapida producción al producir ajustes de oferta y demanda de manera ex post (sistema anárquico), a veces a través de fuertes crisis de sobreproducción y porque parte de dicho excedente es consumido suntuariamente o dilapidado por las clases propietarias y no usado para ampliar la base productiva de la economía.

En un plano concreto, la gestión planificada de la economía suponía definir y armonizar ciertos agregados, como el crecimiento armónico de las distintas ramas de la producción para que no hubiese cuellos de botella; las exportaciones con las importaciones; la expansión de los medios de pago (dinero) con la parte del producto que se distribuía bajo la forma de mercancías; y, sobre 
todo, establecer cuántos medios productivos se consagraban a producir bienes de consumo y cuántos para ampliar los propios medios de producción, determinando la tasa de crecimiento de la economía. Ello atravesado, además, por el debate acerca de la efectiva apropiación social de esos medios o de la tecnoburocratización del poder. ${ }^{5}$ Este tipo de definiciones se fueron dando en medio de permanentes tensiones que expresaban el hecho que los contenidos precisos del enfoque socialista no estaban definidos previamente a su puesta en marcha (Lange, I965a).

Así surgieron polémicas sobre los grados de centralización y descentralización de la planificación; sobre el uso de los medios administrativos o de mercado para orientar la producción; sobre el uso de los estímulos materiales o morales para reconocer los esfuerzos; sobre los grados de colectivización agrícola y las relaciones entre agricultura e industria necesarias para el desarrollo de esta última; sobre la composición entre crecimiento de bienes de producción y de consumo (Lange, I965b). Éstas no fueran discusiones sólo técnicas, sino con componentes ideológicos y grupos de interés internos, particularmente dentro de los partidos comunistas gobernantes, y que marcaron supremacías relativas o más duraderas de unas corrientes sobre otras. Estas tensiones hicieron parte del debate y marcaron diferencias de proyectos socialistas en la URSS, Europa del Este, Asia, África, el Mundo Árabe y América Latina.

La caracterización presente del socialismo es compleja. La crisis política terminal del socialismo soviético y del Este europeo disminuyó las experiencias socialistas actualmente existentes y el propio carácter socialista de éstas resulta discutible dadas la importancia mucho mayor de la propiedad privada, del capital extranjero, de los mecanismos de mercado, en China, Vietnam y Cuba, lo que ha tendido a aumentar las diferenciaciones socioeconómicas que se producen en su interior (Centre Tricontinental, 200I). Esas orientaciones pueden tener explicaciones al interior de esos países que intentan justificarlas en términos del marco teórico-conceptual «marxista». Por ejemplo, en China señalándose que aún el capitalismo y la propiedad privada pueden jugar roles progresistas o, en Cuba, que un error posible puede haber sido un intento de desarrollo socialista ( «condiciones subjetivas») cuando las «condiciones objetivas» estaban demasiado inmaduras.

5. Esto se refiere al ideario socialista de una efectiva apropiación de los medios de producción por los trabajadores y las tensiones con el peso decisivo que fue tomando la tecno-burocracia desde el aparato estatal (Kardelj, I976). 


\section{El estructuralismo latinoamericano: capitalismo periférico, dependencia y revolución}

Desde fines de los años cuarenta la preocupación por el desarrollo vio surgir una corriente estructuralista latinoamericana nucleada en torno a la Comisión Económica para América Latina (Cepal) que teórica y programáticamente acompañó los procesos de industrialización que habían comenzado en varios países del continente, desde fines del siglo XIX, y con la primera guerra y de la depresión de los años treinta. Una originalidad de dicha institución fue introducir la noción de sistema económico mundial y de división internacional del trabajo como base de la conformación de un capitalismo periférico y de un capitalismo central. El primero caracterizado por países limitados a ser productores y exportadores de productos primarios y compradores de manufacturas desde los países centrales.

Para la Cepal esto impedía proyectar una modernización de largo alcance dada la realidad de baja elasticidad de la demanda de productos primarios lo que, a su vez, comparada con la alta elasticidad de la demanda de los productos industriales, conducía al deterioro de los términos de intercambio para los países periféricos. Esto último también influido por el peso que en el mercado mundial tenían las empresas de los países centrales, dado el mayor poder de los capitalistas y asalariados en estos países, lo que hacía que el aumento de su productividad se tradujese en mayores ganancias y salarios en el Centro y no en precios más bajos para la periferia (Rodríguez, I980). Esto constituyó una fuerte crítica a la afirmación liberal clásica (A. Smith y D. Ricardo) sobre las ventajas que siempre aportaría la especialización productiva entre países, de acuerdo a las «ventajas comparativas». Constituía, además, sacar el problema de la explicación del subdesarrollo de los solos términos de una sociedad tradicional aún insuficientemente modernizada y llamar la atención sobre una estructura económica mundial como factor central de bloqueo.

Ello condujo a la propuesta de pasar a una industrialización programada con protagonismo del Estado y de un empresariado nacional que debía consolidarse en el propio proceso. Aquella «industria naciente», ${ }^{6}$ como condición

6. Noción que había sido usada un siglo antes por la «escuela histórica alemana» para justificar un proteccionismo alemán y oponiéndose a concederle a la economía liberal inglesa el valor de una verdad universal en sus doctrinas del libre comercio (Blaug, 200I). 
de emergencia y sustentación debía, al menos durante una primera etapa, ser protegida, principalmente a través de aranceles, de las importaciones de países industriales. Se la entendía comenzando por manufacturas simples de consumo final, sustitutivas de importaciones, y desde allí avanzando hacia etapas más complejas en la medida que la propia expansión iba haciendo rentables la producción interna de bienes intermedios o de capital. El centro de gravedad en cuanto a demanda era el mercado interno de los países y de allí la calificación de «desarrollo hacia dentro». Se planteaba que, estratégicamente, el proceso de industrialización debía financiarse con ahorro nacional, pero en una primera etapa por el bajo ahorro propio de los países pobres, obligaba a acudir a capital externo que la Cepal vio especialmente relacionado con fondos de cooperación internacional, aunque también comprendiera capitales privados de naturaleza productiva (inversión directa) o financiera (préstamos comerciales) (Prebisch, I95I). De manera optimista el proceso se imaginaba con círculos virtuosos entre crecimiento industrial, mayores ingresos, mayor ahorro interno y mayor capacidad interna de financiamiento de la inversión, y entre crecimiento industrial, mayor empleo, mayores ingresos, mayor demanda e incentivo a mayor expansión industrial.

Sin embargo, la dinámica de la industrialización latinoamericana fue planteando problemas y nuevas propuestas que se hicieron parte del ideario cepaliano. El proceso reclamaba importaciones de tecnología, insumos y materias primas que no eran posible financiar con estructuras monoexportadoras, en algunos casos de propiedad extranjera; la ampliación de los mercados internos fue limitada por razones demográficas y por la mala distribución del ingreso; la agricultura por un lado expulsaba y por otro mostraba incapacidad para abastecer a una población crecientemente urbana; el ahorro interno era bajo y aparecía limitado, al menos en parte, por las pautas de consumo de las clases ricas bajo el «efecto demostración» de los países avanzados; ${ }^{7}$ la creación de empleo moderno industrial y urbano no era suficiente y muchos migrantes rurales se transformaban en desempleados o subempleados urbanos. En ese contexto problemático varias políticas fueron agregándose o cobrando mayor fuerza dentro del ideario industrialista cepaliano: la reforma agraria, la integración económica y la formación de un mercado latinoamericano, las políti-

7. De acuerdo a Celso Furtado, en América latina, particularmente por la conducta de sus clases ricas, se produjo antes una modernización en el consumo que en las estructuras productivas (Furtado, I970). 
cas de redistribución del ingreso, las capacidades programadoras del Estado y las políticas de desarrollo regional (Prebisch, 1963).

Pero algunos análisis estructuralistas latinoamericanos se fueron radicalizando más en su crítica al capitalismo y dirigieron su atención hacia las estructuras de poder externas e internas que mantenían las situaciones que bloqueaban la industrialización. Surgió el diagnóstico de un cierto agotamiento de la etapa de sustitución fácil y dificultad de pasaje a una etapa más compleja. Nutriéndose de una vertiente «neomarxista» el enfoque de la dependencia planteó las dificultades o la imposibilidad del desarrollo bajo situaciones de capitalismo dependiente. Un antecedente analítico inaugurador fue el de P. Baran que señaló que el excedente económico potencial de los países capitalistas pobres - es decir la parte del ingreso posible de ser usado para expandir las fuerzas productivas sin amenazar el consumo necesario para la reproducción de la sociedad - no se usaba para esa expansión por varias razones: las clases agrarias lo usaban en consumo suntuario, otra parte se escapaba directamente a los países centrales como utilidades de compañías extranjeras, otra lo consumía una burocracia estatal y también había corrupción (Baran, I969).

Los análisis dependentistas posteriores plantearán que en la base de todo lo anterior estaba el hecho que las estructuras y agentes económicos internos de los países dependientes son fuertemente moldeados por los intereses y las orientaciones de los países del capitalismo central. En definitiva, América Latina, como otras regiones dependientes, habían sido insertadas «desde fuera» en una economía mundial, para servir a los procesos capitalistas de acumulación de los países centrales, variables según cada momento del proceso de acumulación mundializado: provisión de metales preciosos, de alimentos, de materias primas, mercado para manufacturas y para bienes de capital. Ello no constituía falta de modernización sino una de tipo dependiente, ligada al proceso de expansión capitalista mundial, en que la dinámica interna no obedecía a impulsos endógenos. El análisis del subdesarrollo llevaba entonces a comprender y «denunciar» el sistema capitalista mundial y su imperialismo, visto desde el punto de vista de su significado para los países dependientes (Dos Santos, I972).

En cuanto a ese significado, el enfoque dependentista recogerá parte del análisis estructuralista cepaliano en curso acerca de los problemas de la industrialización, pero enfatizará la crítica al grado de dependencia y desnacionalización que empezó a tener aquélla. En ese marco interpretativo los empresarios nacionales no existieron como tales, sino como eslabón y sometidos de 
los agentes internacionales -en lo financiero, en lo tecnológico, en lo comercial- lo que los inhabilitaba para encabezar un proceso nacional de desarrollo, configurando una «lumpen burguesía» como los denominó A. G. Frank. Esa falta de autonomía se expresaba en un déficit esencial que presentaba la industrialización latinoamericana que era la no existencia de un sector nacional de medios de producción. Todo esto llevaba a la necesidad de un proyecto de desarrollo socialista con un rol central del Estado, la planificación y centrado sobre otras fuerzas sociales, lo que suponía un proceso de cambio radical y en que quedaban conectada ruptura del subdesarrollo con revolución (Marini, I974). Ello ocurría, además, en un contexto de fuerte movilización social y política continental y de un aumento del peso de los países no alineados en el concierto internacional. Este enfoque dependentista, si bien se ve abruptamente abortado por las nuevas circunstancias políticas de América Latina que vio surgir los regímenes de seguridad nacional, ha sido recogido parcialmente en las más actuales perspectivas del sistema y la economía mundo a través de las nociones de países centrales, periféricos, semiperiféricos y arenas exteriores (Wallerstein, I984).

\section{Debates normativos sobre desarrollo: pobreza, equidad, naturaleza y cultura}

En los años setenta surgen también cuestionamientos sobre la definición de desarrollo económico, abriéndose un campo más visible de tipo normativo, en que lo común, dentro de una diversidad de aspectos, es poner en cuestión su reducción al crecimiento o desarrollo de las fuerzas productivas y al PIB como indicador central (Bustelo, I998). Una primera vertiente son las consideraciones ecológicas. El llamado «Informe de Roma» establece un hito al mostrar que el crecimiento económico y demográfico ejercía efectos destructivos de escala global sobre el medio natural y que debían, por lo tanto, ser controlados (Meadows y otros, I972). Una serie de problemas que van a entenderse como de escala planetaria adquieren relevancia: aumento de la desertificación, deterioro de la capa de ozono, contaminación del aire, agotamiento de recursos naturales, pérdida de diversidad animal y vegetal. Las ideas de finitud o límites de los recursos y la atención a la reproducción del mundo físico hacen entrada en el análisis económico. La clásica referencia sobre la subutilización de recursos en los países pobres da paso a la visión de sobreexplotación mundial de ellos. En su expresión más crítica se da lugar a un cuestionamiento de la modernidad 
caracterizada como antropocéntrica, que no asume lo humano como parte de un cosmos envolvente dentro del cual existe, se reproduce y debe establecer relaciones de armonía.

Frente a esto, algunas vertientes plantearon la necesidad del «crecimiento cero» que comprendía a la producción, especialmente en el norte, y a la demografía, especialmente en el sur. Esto enfrentó dificultades de aceptación tanto de cara a la modernidad todavía incumplida de los países más pobres y en cuanto ponía en cuestión la lógica del sistema capitalista basado en la permanente acumulación de capitales y de aumento del consumo, en los países industrializados. Las economías socialistas, preocupadas también del «desarrollo de las fuerzas productivas» no tuvieron cercanía con esas propuestas. Así, las nuevas consideraciones ecológicas fueron aplacadas y terminaron entendiéndose, en los planteamientos más oficiales, armonizables con las estrategias de crecimiento, dando nacimiento a las nociones de desarrollo sustentable, sostenible o durable.

Esto condujo a su vez a un debate sobre el rol del Estado y a los acuerdos internacionales para asegurar dicha armonización. Pero también, con el tiempo, dieron origen a aproximaciones liberales que van a enfatizar el rol del mercado a través de incorporar en los precios ciertos costos ambientales, creando incluso mercados de derechos (bonos) de contaminación, junto a una afirmación optimista de que aquel generará un amplio campo de incentivos y oportunidades de inversión para «bienes y servicios ecológicos o verdes». Ello establece una importante fosa de separación con planteamientos ecológicos sobre la necesidad de cambios profundos en las pautas de consumo, tecnologías productivas y en los estilos de vida, y un rol activo de los sistemas políticos y el control social sobre la economía (Verhaegen, I998).

Una segunda corriente normativa dio origen a un «enfoque social» sosteniendo que sólo puede hablarse de desarrollo si junto al aumento del producto hay mejoras en el empleo, en la distribución del ingreso y en la satisfacción de las necesidades básicas. La ocupación por el empleo recogió la influencia de la Organización Internacional del Trabajo (OIT) motivada, a su vez, por estudios de principios de la década de los setenta, en África, que demostraban que en las ciudades de los países pobres, en medio de un intenso proceso de migración campo-ciudad ocurrido, el fenómeno más característico era no tanto el desempleo abierto sino la existencia de las actividades económicas «informales» (Portes y Haller, 2004). Éstas constituían un trabajo precario e ingresos bajos, aunque eran demostrativas del dinamismo de los pobres urbanos para generar iniciativas de sobrevivencia y no se les podía entender como sujetos anómicos 
o desintegrados como en las anteriores teorías de la marginalidad. Asegurar la creación de más y mejor empleo («formal») fue visto como la tarea central del desarrollo, abriéndose hacia la necesidad de influir en las trayectorias sectoriales y tecnológicas del aparato productivo.

La dimensión de la distribución del ingreso es expresada a raíz de la evidencia de la gran desigualdad existente, la que aparece aun mayor en los países más pobres, en los que las tendencias del estilo de crecimiento son hacia su reproducción. Dicho objetivo redistributivo aparecía en sinergia con la creación de más empleo en tanto se consideraba que una mejor distribución aumentaría la demanda agregada de bienes más intensivos en trabajo. La manera en que este enfoque plantea el mejoramiento distributivo es a través de lograr que cada punto adicional de crecimiento sea mejor distribuido que el producto anterior y fue popularizado a través de la idea de crecimiento con redistribución (Chenery y otros, 1974). Ello eludía lo conflictual de distribuir la riqueza antes concentrada, como la propiedad de la tierra u otros activos. Sin embargo, esta estrategia presentaba serias limitaciones para producir cambios más o menos perceptibles en plazos razonables y, a la vez, medidas concebidas menos conflictivas, como cambios en los niveles y estructuras de impuesto, se mostraron igualmente difíciles, dadas las relaciones de poder y la resistencia de las clases pudientes. En ese marco, una línea crítica planteará la imposibilidad de mejoramiento en la distribución de ingreso sin redistribución de activos económicos.

Finalmente, estas consideraciones sociales terminaron concentrándose en la dimensión de las necesidades básicas: el desarrollo debía significar la disminución de personas que estaba bajo la línea de su satisfacción. Ello significaba un acuerdo sobre qué constituye lo básico y sobre los umbrales críticos en que un componente — como la salud, la vivienda o la alimentación— puede ser considerado que está siendo satisfecho, lo que determina un campo discutible que no es estrictamente técnico ni puramente biológico. Así, por ejemplo, la recreación o de la participación como necesidades básicas pueden ser o no consideradas o serlo con distinta jerarquía; asimismo, como en el caso de la educación, es necesario precisar cuál es un mínimo aceptable. Este enfoque se asentaba sobre el trasfondo histórico del avance y consolidación de la idea de Estado de Bienestar, considerado como una contraparte institucional de la consagración de derechos económicos y sociales.

Desde un punto de vista crítico, esta focalización en las necesidades básicas puede verse como una minimización de lo social al expresarse en la fijación de objetivos muy básicos que permiten avances estadísticos pero que tienen 
significados limitados. Asimismo, porque el logro de lo básico queda separado de la distribución de los ingresos y de la riqueza y puede coexistir con un aumento de la desigualdad (Bustelo, I998). Sin embargo, esta aproximación tuvo la importancia de aportar a una discusión sobre el tema de las necesidades básicas que, también permitió expresiones más amplias e integrales como las de M. Max Neef (I985) y que también se ha prolongado y renovado en la noción de desarrollo humano de los años noventa. Asimismo, combinada con consideraciones ecológicas y psicosociales contribuyó a la emergencia de la noción de calidad de vida.

Por último, es interesante considerar dentro de estos debates normativos de los años setenta una vertiente menos influyente que las dos anteriores, de origen nórdico, que busca articular de nueva forma el desarrollo con la participación y la cultura (Dag Hammarskjöld, I975). Esto se realiza a partir de la valorización de las «comunidades locales» como sujetos de su desarrollo - y no objetos- acercándose a una perspectiva de «desarrollo de base». Aquéllas son comprendidas como poseedoras de una cultura, capacidades y recursos, propios. De la identidad cultural se infiere que deben ser esas poblaciones locales las que determinen sus metas de desarrollo y de la posesión de capacidades y recursos se deriva la necesidad de estrategias bajo una modalidad endógena, colectiva y participativa.

Dentro del panorama largo del debate sobre desarrollo, algo significativo de esta corriente es que, por un lado, cuestiona que aquel sea entendido con un contenido único y universal, sino que debe ser correspondiente con la cultura de cada comunidad territorial, aproximación que será profundizada por corrientes posteriores como las del etnodesarrollo. Por otro, establece una ruptura con la idea que el desarrollo puede ser aportado por capas técnicas modernas hacia poblaciones entendidas como objetos y beneficiarias de las políticas de desarrollo -disociando sujeto y objeto del desarrollo. Esta perspectiva que valorizó las escalas locales de desarrollo estableció posteriormente sinergias con ideas paradigmáticas como las de tecnologías apropiadas o intermedias (Dickson, I980) y de «lo pequeño es hermoso» (Schumacher, I987).

\section{Enfoques globalizadores: exportaciones, neoliberalismo, neoestructuralismo y capital humano}

Al calor de la globalización, asumiéndola como proceso irreversible y positivo, se generan en los años ochenta y noventa enfoques que hacen de la en- 
trada exitosa en aquélla en el eje del desarrollo, el que, a su vez, vuelve a ser fundamentalmente recentrado en el crecimiento. Un grupo de países asiáticos — particularmente Corea y Taiwán — sirven de antecedente paradigmático para fundamentar los buenos resultados a los que conducirían estrategias abiertas a los mercados externos bajo una estrategia de crecimiento y cualificación de las exportaciones (estrategia de «sustitución de exportaciones»). Se les contrapondrá a lo que habrían sido las estrategias fracasadas de América Latina, India y algunos países africanos utilizando modelos proteccionistas y de industrialización hacia el mercado interno (Lanzaroti, I990).

En realidad lo anterior constituyó un eje del enfoque neoliberal emergente que repuso en grados radicalizados la idea que la clave para el desarrollo era dejar que la economía fuese regulada por el mercado y desde procesos de acumulación de los agentes privados en escenarios competitivos (L'Heriteau, I986). ${ }^{8}$ El primero aseguraba una asignación óptima de los recursos productivos en función de las demandas de los consumidores y era presentado con una superioridad «ética» sobre la acción reguladora desde la política en tanto espacio de relaciones voluntarias, no coactivas, entre los individuos. Para que ello ocurriese era necesario que los precios de los bienes y servicios fuesen dejados «libres» expresando las escaseces y valoraciones sociales reales y permitiendo guiar correctamente las decisiones de cada agente. Ello permitiría, en el marco de una economía globalizada, sin fronteras «artificiales», que cada país y territorio se especializara en aquellos productos en los que ofreciera ventajas comparativas y adquiriera los otros a través de importaciones (incluyendo al capital y al trabajo). El espacio económico nacional fortalecido, propio de los proyectos de modernización nacional de los decenios anteriores, deja de ser la referencia central y el mercado interno cede la jerarquía a la inserción exitosa en el mercado mundial (Amin, I993).

Ese proceso es concebido como liderado por empresariados internacionalizados releídos como agentes casi únicos de la acumulación y en que los países deberán crear las condiciones para atraer el máximo de capital y de capitalistas hacia sí. Dejan de tener una importancia específica la formación de un empresariado nacional y la propiedad nacional de los recursos, evaluando la llegada

8. Esas visiones venían ya de los años cincuenta y combatieron de entrada los proyectos nacionales de industrialización nacional por intentar romper la natural división internacional del trabajo proveniente de la realidad de las ventajas comparativas dictadas por el mercado y asignarle un rol motor al Estado. 
de capital extranjero y la transnacionalización de la economía como signo de éxito del proceso de desarrollo, de la confianza en él y de una vía de mayor inserción en la economía global.

Bajo esas premisas, el «programa de acción» del enfoque neoliberal apuntó al «desmontaje del Estado» en sus dimensiones desarrollistas, bienestar y keynesiana que habían acompañado el siglo XX — constituyendo de acuerdo a V. Hayek el «camino a la servidumbre»- y que fueron sindicados como la base de los problemas de las economías del Sur, del Norte y del Este: la inflación, el ahogo de la iniciativa privada, la mala asignación de recursos, el estancamiento, la ineficiencia. Para dicho enfoque, esto expresaba el peso de ciertos grupos - particularmente atacados serán los sindicatos aunque también algunos sectores empresariales- que a través de ello obtenían beneficios («rentas distributivas») y el de una burocracia estatal que se reproducía en su interior. El Estado debía limitarse a asegurar condiciones de estabilidad política (orden interno); estabilidad macroeconómica a través de una política monetaria y fiscal que impida fenómenos inflacionarios; disminuir la extracción de excedentes desde la economía (impuestos), considerados como desincentivos para los inversores privados; flexibilizar los mercados del trabajo disminuyendo los costos de contratación y despido; crear condiciones institucionales para incentivar la inversión privada en áreas de interés público y con fines sociales, privatizando y mercantilizando áreas enjuiciadas como perjudicialmente monopolizadas por el Estado (salud, educación, transporte, seguridad social) (Emmerij, I998).

Algunos fenómenos empíricos y de orden teórico van a generar un liberalismo algo más moderado: la precarización económica y social en lugares en que se aplicaron políticas de esa naturaleza ( «los ajustes estructurales»); el surgimiento de una literatura sobre las «fallas de mercado» que mostraba sus imperfecciones para asignar los recursos, incluyendo las externalidades negativas y positivas que no procesaba; o las relecturas mucho más objetivas del «éxito asiático» que terminaron por mostrar el rol clave que había jugado el Estado en el impulso de ciertos sectores productivos, en la imbricación compleja entre apertura y proteccionismo, en su influencia en las altas tasas de ahorro y las pautas moderadas de consumo, y en la realización de reformas agrarias radicales. Esto hace que la discusión respecto del importante rol del Estado en los países asiáticos abandonara la lectura liberal y se centrara en si el Estado había sido un complemento clave del mercado o había sido un «distorsionador del mercado» (Wade, I999). Es por ello que, paradojalmente, tendió a sustentar 
posiciones neoestructuralistas. Es importante destacar, además, que el «éxito asiático» se había desarrollado dentro de condiciones políticas fuertemente autoritarias. Esto llevara a una inflexión en que el Estado hasta ahí entendido básicamente como un problema empieza a ser considerado como parte de la solución a ciertos desequilibrios y el discurso bruto deja un lugar central al de su modernización (Rodrik, I999).

Un agregado importante que ha tenido el enfoque liberal es la noción de desarrollo endógeno que destaca, a partir de estudios de Solow en la economía norteamericana, la centralidad del progreso técnico y capital humano, en el crecimiento (Jones, I998). Un grupo de autores, a diferencia del planteamiento original, sostiene que aquéllos son endógenos al proceso económico mismo, dado que las decisiones de los individuos y empresas por hacer aumentar aquellos factores - tomado como inversiones en capital humano o innovaciones - radican en las condiciones institucionales que permitan compensar adecuadamente esas conductas. Ello le concede un lugar central a la defensa de la propiedad privada intelectual y a los beneficios a obtener de ella. A la vez, dado que en las decisiones individuales no es posible incorporar todo el beneficio que tiene para cada uno que otro también aumente su capital de conocimientos, la inversión dejada al puro mercado es subóptima y abre la necesidad de una acción del Estado, dada la existencia de externalidades positivas (Jones, I988).

Asumiendo la perspectiva liberal de la centralidad de insertarse de manera exitosa en la globalización como el centro de una estrategia de modernización, surge en América Latina el neoestructuralismo, el que adquiere visibilidad en los años noventa. Ubicado dentro de la tradición estructuralista latinoamericana afirmará, sin embargo, que dicha corriente en el pasado, en sus expresiones cepalianas y dependentistas, habría exagerado su confianza en el Estado y su desconfianza en el mercado; no habría dado toda la importancia necesaria a los equilibrios económicos de corto plazo (nivel de precios, balanza de pagos), privilegiando sólo las estrategias de largo plazo; y no le habría dado la importancia debida al desarrollo exportador como eje del crecimiento.

La diferencia con el neoliberalismo quedaba establecida en que para el neoestructuralismo la inserción internacional de las economías como condición del desarrollo no podía ser sólo orientada por el mercado. De ser así, ello limitaría a los países latinoamericanos a retornar estructuras productivas especializadas en ventajas de productos primarios (recursos naturales), retomando un clásico postulado crítico del estructuralismo latinoamericano. Una situa- 
ción tal fue denominada una "competitividad espúmea» y de tipo rentista, pues dependía más de los recursos naturales que se poseían que del progreso técnico nacional. Para los neoestructuralistas ello conducía a un modelo económico sobreexplotador de recursos naturales, con baja generación nacional de ciencia y tecnología, limitado número de trabajos calificados y bien remunerados y, a raíz de ello, una mala distribución del ingreso (Fanjzilber, I990).

La forma de evitar esa situación suponía una política activa del Estado con tareas en la infraestructura, en el apoyo a las empresas más pequeñas, en castigar la sobreexplotación y exportación de recursos naturales en bruto, en el fomento de la educación, ciencia y tecnología, tomando, justamente, a los países asiáticos como ejemplo de Estado activo. Solo así se podría generar una inserción internacional basada en el progreso técnico, con alto valor agregado interno, menor cantidad de recurso natural por unidad de valor exportado, mayor cantidad de puestos de trabajo calificados y, finalmente, una mejor distribución de ingreso. Una particular importancia se le concederá al rol estatal en educación, ciencia y tecnología y formación de capital humano —en parte también inspirado en algunos países asiáticos- estableciendo un punto de encuentro aunque con diferencias, con las antes señalada aproximación neoliberal (Sunkel, I99I).

Todo ello fue simbolizado con la noción de «desarrollo desde dentro» y de «competitividad sistémica», la que depende no de empresas aisladas sino de la calidad institucional de los sistemas nacionales. Esto incluía los grados de integración social de un país, definido por una cierta equidad en la distribución de los beneficios del crecimiento, lo que, por tanto, era considerado positivo para una mayor competitividad internacional. En este sentido, para los neoestructuralistas los «equilibrios macrosociales» se agregan a la necesidad de los «equilibrios económicos» como condición de una inserción exitosa en la economía mundial.

\section{Otras perspectivas y contestaciones recientes}

En paralelo, o en cuestionamiento al predominio del enfoque liberal de los últimos decenios, surgen otros que ejemplifican bien las diferencias y antagonismos que constituyen al campo del desarrollo económico y que prolongan aproximaciones ya emergidas en decenios anteriores. El de mayor reconocimiento ha sido el enfoque de «desarrollo humano», posible de situar en la corriente más larga del «enfoque social», que se separa de hacer del crecimiento 
del producto un fin en sí mismo. A. Sen, el principal teórico de este enfoque, entenderá al desarrollo como un proceso en que se expanden las capacidades de las personas con los consecuentes aumentos del arco de opciones a su disposición; en definitiva, de su libertad (Sen, 2004). Para ello es necesario que la sociedad asegure una serie de condiciones básicas, sino las personas verían seriamente restringidas su arco de libertad. En su plano operacional ello ha llevado a establecer condiciones en el terreno de la educación, de la salud y de los ingresos que debiesen ser aseguradas para expandir las capacidades propias. La medición de estos factores conduce a la construcción de un índice de desarrollo humano que permite observar la situación de un país o territorio y que es considerado complementario o alternativo del PIB. Esto permite observar que países que figuran sobre otros de acuerdo al indicador del PIB per cápita caen por debajo cuando se consideran el conjunto de los aspectos señalados. Debe sí hacerse notar que, operacionalmente, el indicador resulta bastante precario o restringido respecto de la riqueza normativa de la noción que le da origen.

Fortaleciendo miradas desde la cultura, también ha madurado el enfoque del etnodesarrollo que plantea que es la referencia a la cultura de cada pueblo lo que debe hacer de referencia central para pensar su desarrollo, en específico desde la perspectiva del rescate de los pueblos originarios y sus luchas por el reconocimiento. Desde esa afirmación, el proceso de globalización es visto como amenazante en cuanto fundado en una idea única del desarrollo y homogeneizador de las culturas diversas. Ello lleva a simpatías por estrategias que combinan la resistencia con el despliegue de capacidades e identidades propias y el uso de instrumentos del progreso científico para enfrentar las necesidades de una comunidad local (Bonfil y otros, I982).

Esto suele establecer conexiones con otra corriente, promotora de una idea de desarrollo que privilegia a los actores locales como protagonistas y al mesonivel como escala de acción, en que se busca articular desarrollo con participación y democracia. El desarrollo local, en esta perspectiva, es visto como alternativa frente a proyectos centralistas y verticales de desarrollo y crítico a la globalización caracterizada como un proceso que «funcionaliza» y jerarquiza a los territorios según las necesidades de la acumulación económica y la competencia global. Frente a ello dicho enfoque valoriza los territorios como espacios concretos de vida de las personas, con su historia y cultura (González, I995). En algunas de sus variantes ello va fuertemente ligado al rescate de iniciativas económicas locales existentes y que suelen comprenderse como una 
economía popular territorializada aunque conectada en redes más amplias. Para algunos autores, en esas prácticas se expresa una racionalidad solidaria que constituye la base de otra economía o de una economía plural (Laville y García, 2009). Sin embargo, debe mencionarse que también hay una valorización económica de los territorios locales desde la perspectiva de estrategias de competitividad, en la lógica de territorios ganadores y perdedores, y en que se van a destacar sobre todo las economías internas al territorio y sus instituciones y su identidad como «capital competitivo» en la globalización.

También el panorama crítico muestra evoluciones de críticas más antiguas en los terrenos del daño y la destrucción del mundo vegetal y animal y del desequilibrio en los sistemas naturales. Desde aquí se plantea la necesidad de una transformación radical que permita revertir el proceso de destrucción planetaria. Se denuncia a la idea del desarrollo sustentable como una orientación que permite mantener la ideología de un crecimiento permanente (Apostel, 200I). Ello en tanto no altere con profundidad las pautas de consumo y producción vigentes.

Pero también en un ala más radical han surgido críticas al objetivo mismo del desarrollo entendido como una noción surgida en Occidente y que se ha buscado imponer sobre el resto. Ésta constituye una radicalización de las corrientes del «otro desarrollo» o «desarrollo alternativo» nacidas en los años setenta y se postula como un rechazo de raíz al desarrollo en cualquiera de sus versiones o posiciones. Esto porque es aquél la fuente del problema y no su naturaleza particular expresada en tal o cual corriente u orientación en tanto en todas ellas sigue presente la racionalidad del crecimiento, aun cuando sea con adjetivos (Latouche, I988). En términos generales ello da origen a una propuesta de "posdesarrollo» a favor del decrecimiento y de una simplicidad voluntaria del consumo (Latouche, 200I).

Esta descripción rápida de enfoques críticos en evolución permite constatar que la discusión del desarrollo es una discusión viva o latente que está lejos de fundamentar la idea de un «fin de la historia». También tiene la importancia de mostrar una brecha entre un conjunto amplio de ángulos críticos al estado de cosas en curso y la fuerza material del proceso fáctico de globalización liberal de los últimos decenios. Esa brecha genera un panorama incierto y sólo aparentemente consolidado y me parece que será el sustrato de crecientes debates en el futuro inmediato, aunque no sean claros los cambios a ocurrir. La manera de enfrentar eso es también fuente de debates. Si tomamos la corriente "alter mundialista» como referencia podemos, por ejemplo, observar tendencias que 
privilegian actuar en el nivel global, otras fortalecer la acción de bloques regionales supranacionales, otras fortalecer nuevamente los Estados nacionales y, por último, tendencias partidarias de fortalecer la acción y los agentes locales (Polet, 2008).

\section{Reflexiones finales}

De lo expresado se puede concluir que el área de los enfoques y estrategias de desarrollo ha estado compuesto de variadas interpretaciones y propuestas y no puede sino comprenderse como una en permanente despliegue y disputa. Han existido referencias paradigmáticas como modernización, industrialización, dependencia, necesidades básicas sustentabilidad, capital humano, globalización y otras, que van reflejando movimientos teóricos, nuevas circunstancias históricas y relaciones de fuerza en la sociedad. Un amplio entramado de aproximaciones se extiende desde la enunciación de círculos viciosos del subdesarrollo hasta los cuestionamientos de la racionalidad del crecimiento, desde las afirmaciones de subexplotación de recursos naturales hasta las denuncias sobreexplotación, desde la idea de falta de capital hasta la supremacía de capital financiero, etcétera.

En ese camino, además, aparecen recurrentemente consideraciones, pero que pueden serlo de manera opuesta respecto de sus virtudes o vicios, como el comercio internacional, el rol del Estado, la planificación y el mercado o la consideración de las culturas locales. Ello incluye, en especial en los decenios recientes, el debate y las inflexiones respecto de la misma noción de desarrollo. En la medida que el surgimiento de éste como referencia para la política debe entenderse como «refracción» (prolongación y desviación) de la idea de progreso que acompaña a la modernidad, los propios cuestionamientos a esta última, como época de la humanidad, revierten como dudas sobre la racionalidad del desarrollo «realmente existente». En contraste con una marcha económica que, aunque con crisis, sigue produciendo acumulación, progreso técnico y consumo, se debe reconocer que la duda sobre las bondades de desarrollarse se ha instalado en la propia historia de dicha noción. La emergencia última de la idea de crisis civilizatoria y de la necesidad consecuente de "políticas civilizatorias» da cuenta de ello (Hinkelammert, 200I).

Una parte voluminosa de esta historia ha estado marcada por la idea de existencia de una cierta trayectoria más o menos universal y racional que comprendía la industrialización. Era el pasaje de una civilización agrícola y rural a 
otra industrial y urbana, más ampliamente, el pasaje de sociedad tradicional a sociedad moderna. En general, como dijimos, ello se impuso a visiones, como las del populismo ruso o Gandhi, que buscaron rescatar modos comunitarios de existencia campesina y construir una bisagra que equilibrara aquéllos con el mundo nuevo de la tecnología, la productividad, la fábrica, la proletarización, el aumento de capitales. A la vez, implicó disputas, en particular por parte del estructuralismo latinoamericano contra sostenedores ortodoxos de las ventajas comparativas que justificaban especializaciones primarias de ciertos países dentro de una división internacional del trabajo que se diagnosticaba como favorable a todos y cada uno de ellos.

En el encuadre de aquel gran objetivo industrializador, quedan aprehendidos diversos y amplios debates sobre estrategias precisas, sobre las formas de desencadenar, acelerar o culminar ese proceso y, en particular, sobre derribar los factores que la impedían o bloqueaban: los planteamientos de una industrialización que va de lo simple a lo complejo o que pone acento inicial en los bienes de producción, que utiliza la tecnología más avanzada o la que asegura el máximo de empleo, que extrae más o menos excedentes y población de la agricultura, etcétera, constituyen corazones de ese debate y constituyeron la cuestión del desarrollo económico (Baldwin, I967). En ello queda también aprehendido el debate sobre el tipo de relaciones económicas internacionales que sería beneficioso para un país y que se moverá entre la reafirmación radical de las ventajas comparativas, un proteccionismo selectivo, o la denuncia del imperialismo y su extracción de excedentes desde los países periféricos. Desde posiciones opuestas, a su vez, con el tiempo, el ecologismo, y parcialmente el neoliberalismo, levantarán fuertes impugnaciones al proyecto industrializador.

$\mathrm{El}$ anacronismo o actualidad de esas discusiones pareciera que debe ligarse a la cuestión del «nivel de vida» o «condiciones materiales de la existencia» que se consideren deseables. Al respecto, debemos tomar nota que el sustento en legitimidad de la necesidad del crecimiento económico - y con ello las preocupaciones y valoraciones sobre la productividad, el ahorro, la inversión, el progreso técnico, la ciencia aplicada y la industrialización- estuvo en que ello permitiría superar un estado de miseria material y de línea de sobrevivencia en que había existido y existía la humanidad. Aún más, permitiría arribar a una situación de abundancia que actuaría como base de un nuevo estadio de libertad y bienestar. Es lo que dibuja Rostow en su idea de sociedad moderna, pero también es la cara progresista, aunque perecedera, que Marx ve en el rol histórico del capitalismo y que abrirá camino al comunismo. Constituyó, 
asimismo, una razón central en la justificación de roles nuevos del Estado que iban más allá del keynesianismo; y está en la base de la crítica dependentista al capitalismo periférico en tanto sistema limitado o inhabilitado para cumplir aquella tarea. En definitiva, el mejoramiento de las condiciones materiales de la existencia y el dejar atrás la línea de la sobrevivencia constituyó una «ética del desarrollismo», en sus diversas variantes. Dentro de ese encuadre se hacen inteligibles múltiples enfrentamientos sobre estrategias y políticas.

Ese piso de fondo se ha visto simultáneamente fortalecido y contestado. La aproximación neoliberal y aun del actual socialismo realmente existente -China, Vietnam, especialmente - se enmarcan y argumentan sus acciones en nombre del crecimiento bajo ideas como del desarrollo de capital humano, la modernización de la gestión empresarial, determinadas políticas económicas internacionales - más abiertas o reguladas - y otras materias.

Sin embargo, por otro lado, desde la segunda mitad de los años setenta se han levantado contestaciones a ese basamento. Primero, fueron argumentos ecológicos referidos a los efectos intensamente destructivos del estilo de crecimiento sobre la naturaleza. Este punto de mira puede redefinir el juicio sobre diversos aspectos del funcionamiento de la economía como, por ejemplo, la intensa globalización que hace aumentar enormemente el comercio a distancia y con ello el uso de transporte, lo que es una causa clave de la producción mundial de contaminación. Luego se generaron visiones que pusieron en duda la relación estrecha entre crecimiento y bienestar, mostrando que esas «curvas» tendían a separarse en el tiempo y cada adición al producto aportaba menos al bienestar. Finalmente, enfoques culturalistas que cuestionaron que la necesidad de crecer fuera propia de todo pueblo. Estas perspectivas críticas, cuando se relacionan con las específicas formas en que ocurre el crecimiento, fortalecidas en los últimos decenios, conducen a la denuncia de la acumulación capitalista globalizada, comandada por grandes empresas trasnacionales.

Frente a este punto de fondo no puede eludirse la discusión normativa, como lo explicitaron enfoques sociales de los años setenta, acerca de cuáles deben ser consideradas condiciones materiales dignas y al servicio de una "buena vida» pero que sean real alternativa a una visión miserabilista - a veces expresadas en líneas de la pobreza utilizadas para medir avances de los gobiernos- o a otra de un proyecto de consumo insaciable al que se transfieren otros vacíos sociales (González, 200I). Es decir, en que el crecimiento no es considerado un fin, sino un medio, si necesario, para ciertos objetivos socioeconómicos ubicados en el orden de los fines. Aparece justificado sostener, con la historia recien- 
te detrás, que un crecimiento concebido sin pensar si ello fortalece o debilita los lazos humanos, la «convivialidad» como diría Iván Ilich, puede generar sacrificios humanos que terminan justificando más crecimiento del producto como compensaciones o «remedios» a los «males» que genera, pero que no añaden nada al bienestar (Baudrillard, I974). En esa perspectiva, el enfoque del «desarrollo humano» puede ser destacado en tanto propone la finalidad de ampliación del arco de libertad del sujeto para usar sus capacidades. Sin embargo, si el desarrollo de la ciencia, tecnología, producción y productividad no parecen ser una respuesta autosuficiente como en las primeras etapas del desarrollismo tampoco nos podemos situar en su negación total sin reconocer en ello un campo de y para la inventiva humana y la superación de situaciones que son social y humanamente penosas.

La discusión sobre niveles aceptables de consumo tiene una relación con otra materia que ha estado, de manera explícita o implícita, transversalmente presente en los enfoques de desarrollo: la distribución de ingresos, consumo y riqueza. La industrialización supuso que tenía altas capacidades inclusivas; el evolucionismo etapista o el dualismo supusieron períodos de acumulación dura, un "período sacrificial» que daría paso a un acceso generalizado al consumo; las visiones keynesianas presentes en algunos enfoques, como en el estructuralismo latinoamericano, supusieron una correlación positiva y necesaria entre crecimiento y mejoramiento de la distribución, al generar ésta aumento de la demanda y posibilitar economías de escala en la producción. A la vez, siempre han existido enfoques del liberalismo ortodoxo o neoliberalismo actual que han enfatizado la oposición a las políticas de distribución, bajo la acusación de populismo, y entendidas como directo desincentivo a la inversión privada y, con ello, al crecimiento y al empleo.

En otro momento, S. Kuznets planteó que el crecimiento tenía una primera fase de acentuación de la desigualdad de los ingresos y luego otra con tendencia a la una mayor igualación. Sin embargo, esto último parece ocurrir no como una tendencia natural o espontánea, sino producto de cambios institucionales que resultan de determinadas fuerzas sociales que logran influir en la construcción de aquéllas. Es decir, ciclos de expansión económica pueden implicar aumento o disminución de desigualdades según sea la institucionalidad en que esté enmarcada esa expansión. Fue esa constatación la que llevó, aunque sin ponerlo en cuestión, a relativizar al solo crecimiento como índice de desarrollo, en algunos enfoques. La idea de primero producir para luego distribuir olvida que ese proceso genera las condiciones para reproducir la desigualdad y expre- 
sa los intereses de quienes son favorecidos, generando sociedades articuladas en la asimetría y conectadas en la desigualdad socioeconómica; aumentando los miedos, las inseguridades y los recursos familiares y sociales asignados para la represión de una serie de consecuencias de aquello. Pero distribuir teniendo sólo como finalidad sustentar el crecimiento y el empleo al aumentar la demanda agregada — perspectiva keynesiana retomada por críticos al liberalismo actual frente a la recurrencia de las crisis - tampoco parece suficiente frente a las señaladas externalidades negativas de dicho crecimiento y a los límites actuales de un «crecimiento verde». Tampoco la distribución más justa puede sustentarse exclusivamente en el miedo a las inestabilidades políticas a las que la desigualdad puede conducir. Es necesario afirmar un marco normativo, que debe estar respaldado política y culturalmente, que haga de la justicia distributiva un valor social dominante (González, 2000).

Otro eje que puede ser detectado en una mirada retrospectiva y transversal es sobre los sujetos constructores del desarrollo. Los empresarios han sido destacados por el liberalismo como los sujetos del desarrollo en la medida que les sea brindado el espacio del mercado libre y sin fronteras nacionales, de acuerdo a su variante más radical actual. Ese comportamiento de homus economicus empresarial se planteó, además, como universal, aún presente en campesinos pobres de África que reaccionaban de esa misma forma ante el estímulo de los precios (Bustelo, I997). Los enfoques de sustitución de exportaciones, en sus lecturas más objetivas, realzaron la fuerte coalición entre Estado y grupos empresariales en la dirección de la economía, mixtura también presente en las propuestas del estructuralismo cepaliano. En general, el desarrollismo considerará siempre al Estado en un rol propulsor y acompañante más o menos imprescindible de la modernización económica. A veces para cubrir la falta de un empresariado, complementarlo, a veces buscando asegurar determinadas orientaciones del crecimiento económico para que fuese desarrollo, o sencillamente para encabezar el desarrollo productivo, como en el socialismo. Sumados esos Estados a las entidades internacionales de cooperación se constituiría una institucionalidad como agente o sujeto impulsor de estrategias y proyectos de desarrollo para «sacar» a las poblaciones del subdesarrollo.

Es esa perspectiva la que es puesta en cuestión por enfoques - como el desarrollo local o etnodesarrollo- que hacen ver que con aquello se transforma a la población en la beneficiaria de las acciones de otros agentes que serían los sujetos protagonistas del desarrollo, es decir, la primera resulta concebida como objeto del desarrollo, cuando sólo ella podría ser el sujeto de su propio 
desarrollo. Ello estuvo también ideológicamente presente en el enfoque socialista de una primera época, con relación a la participación de los trabajadores y estructuras de base en la gestión de la economía o en ciertas variantes más autogestionarias que lo acompañaron. Dicha perspectiva conduce a reforzar la idea de no separar «sujetos» y «objetos» del desarrollo y de recoger tradiciones «antitecnocráticas», discusión también presente en aquellos procesos socialistas en los debates acerca de la burocratización y centralización del poder. El desarrollo debe articularse con procesos democráticos que permitan su gestación por la sociedad. Sin embargo, ello no puede ser planteado como algo idílico desconociendo, por un lado, la complejidad social y la necesidad del saber y, por otro, las relaciones de poder que están presentes también en aquella. La realidad socioeconómica e institucional es generada por agentes que incluyen relaciones de poder y jerarquías cuya democratización enfrenta múltiples barreras.

Dentro de esa consideración anterior debe discutirse la cuestión del grado de «constructivismo» de la economía desde el sistema sociopolítico, con sus dimensiones tecnoprofesionales y político-administrativas y el rol del mercado y las iniciativas privadas. Las experiencias socialistas y asiáticas muestran el carácter verticalista y autoritario que puede tomar la relación del Estado con la sociedad, pero el neoliberalismo reciente muestra a su vez cómo el peso de los grandes agentes privados en el mercado puede hacer bastante formal los sistemas políticos democráticos. Ciertas vertientes del desarrollismo inicial concedieron una racionalidad suprema a la política tecnificada y al Estado versus las fuerzas espontáneas del mercado y la sociedad. El liberalismo radical concede la virtud de la racionalidad al mecanismo mercantil y atribuye la irracionalidad a la política y el Estado a través de calificativos como populismo, «precios políticos» o apropiación y redistribuidor de rentas, fundamentando altos grados de mercantilización de la sociedad y un desmontaje del Estado de Bienestar y de la economía no mercantil.

Todo esto refiere a cuál es la capacidad de la sociedad y sus sistemas de gobernanza de orientar la dinámica económica y, en el contexto actual, al control de una que está intensamente organizada desde la lógica de la acumulación del capital. En la medida que no hacemos asimilable al desarrollo con esa lógica, y guardamos para éste una definición centrada en el mejoramiento de la situación individual y colectiva, la regulación de dicha lógica aparece una condición del desarrollo. En esa perspectiva cobra valor la afirmación de la importancia de asegurar la construcción de «territorios de vida» organiza- 
dos en función de su calidad y no, exclusivamente, de la capacidad competitiva global de cada uno de ellos. Esto, como se planteó anteriormente, plantea la cuestión de las escalas de gobierno de la economía que abren a la discusión sobre la jerarquía de lo local y de lo global como niveles y escalas de gestión de la sociedad.

Estas consideraciones son suficientes para justificar que el desarrollo reclama miradas holísticas y una perspectiva histórica que aprehenda la complejidad de un proceso tal. Tanto en la dimensión «positiva» como en la «normativa» del desarrollo, los análisis de los procesos históricos y de las estructuras que se van formando como la imaginación de órdenes mejores que expresen deseos de mejor vivir, supone la confluencia de saber mirar las dimensiones amplias que marcan la vida social. En todo caso, a diferencia de otras «ramas» de la economía, la economía del desarrollo ha establecido conexiones permanentes con otras disciplinas de las ciencias sociales. Al respecto, cuando A. Lewis señalaba que la clave para entender la modernidad económica era explicar por qué una sociedad pasaba a ahorrar e invertir un porcentaje significativo de su producción e ingresos como condición permanente, concluía que ello era algo que debían responderse desde el conjunto de las ciencias sociales. Es decir, los teóricos del desarrollo en general han tenido claro la multiplicidad de factores y dimensiones comprendidas en él. La limitación estaba en cierta precariedad para entenderlos más profundamente, en verlos desde la pura funcionalidad al crecimiento, o en establecer dicotomías simples entre cultura moderna y cultura tradicional, etcétera.

La necesidad de considerar esas dimensiones amplias supone una aproximación desde una «socioeconomía política» que ponga en intersección plena a la economía con las otras ciencias sociales para aproximarse a los mundos concretos. Estos, además, son complejos, pues parecieran componerse de deseos de modernidad incumplida, de nuevos problemas emergidos con su avance y de búsquedas de condiciones posmodernas.

\section{Referencias}

Almond, Gabriel (1960). The politics of the developing areas. Princeton: Princeton University Press.

Amin, Samir (I993). «Nacionalismo». En J. Eatwell, M. Milgane y P. Newman (compiladores), Desarrollo económico. Barcelona: Icaria. 
Apostel, Leo (2001). Population, développement, environnement: pour des regards interdisciplinaires. Lovaina: Academia Bruylant, L'Harmattan.

Baldwin, Robert (1967). Desarrollo económico: un análisis introductorio. Buenos Aires: Amorrortu.

Baran, Paul (I97I). La economía política del crecimiento. La Habana: Editorial Ciencias SocialesBaudrillard, Jean (I974). La sociedad del consumo: sus mitos, sus estructuras. México: Siglo XXI.

Blaug, Mark (200I). Teoría económica en retrospección. Buenos Aires: Fondo de Cultura Económica.

Bonfil, Guillermo (1982). América Latina: etnodesarrollo y etnocidio. México: Facultad Latinoamericana de Ciencias Sociales (Flacso).

Bustelo, Pablo (1997). Teorías contemporáneas del desarrollo económico. Madrid: Síntesis.

Centre Tricontinental (200I). Socialisme et marché: Chine, Vietnam, Cuba. Lovaina: L'Harmattan.

Chenery, Hollis y otros (I974). Redistribution with Growth. Cambridge: Oxford University Press.

Dag Hammarskjöld (I975). «What now. Another Development. Dag Hammarskjöld Report». Development Dialogue.

De MatTos, Carlos (1984). Paradigmas, modelos y estrategias en la práctica latinoamericana de planificación regional. Bogota: ILPES, Bogotá.

Dickson, David (I980). Tecnología alternativa. Madrid: H. Blune.

Dos Santos, Theotonio (I972). Dependencia y cambio social. Santiago: Centro de Estudios Sociales (CESO).

EMMERIJ, Louis (I998). «Teoría y práctica del desarrollo: ensayo introductorio y conclusiones de política». En L. Emeerij (editor), Teorías del desarrollo a principios del siglo XXI. Banco Interamericano de Desarrollo.

FAnjzilber, Fernando (I990). «Industrialización en América Latina: de la caja negra al casillero vacío». Cuadernos de la Cepal núm. 60. Santiago.

Furtado, Celso (1970). Theoríe du developpement économique. París: PUF.

García de Fanelli, Ana (1986). «Talcott Parsons y la teoría del cambio social». Buenos Aires: Instituto de Desarrollo Económico y Social.

GonzÁlez, Raúl (I995). Espacio local, sociedad y desarrollo: razones de su valorización. Santiago: Universidad Academia de Humanismo Cristiano y Programa de Economía del Trabajo.

-. (2000): «La desigualdad: ¿vía para superar la pobreza?». Debates Económico Sociales núm. I. Programa de Economía del Trabajo. Santiago. 
-. (200I): «El consumo: más allá de lo privado, más acá de la condena». Revista de Economía y Trabajo, I I. Programa de Economía del Trabajo. Harrod, Roy. (I948): Towards a Dynamic Economics. Londres: Macmillan. Hinkelammert, Franz y H. Mora (200I). Coordinación social del trabajo, mercado y reproducción de la vida humana. Costa Rica: Departamento Ecuménico de Investigaciones.

Hirschman, Albert (I96I): «La estrategia del desarrollo económico». Fondo de Cultura Económica. México.

Jones, Hywell (1988). Introducción a las teorías modernas del crecimiento económico. Barcelona: Antoni Bosch.

Kanbur, Ravi y J. McIntosch (I993). «Economías duales». En J. Eatwell, M. Milgane y P. Newman (compiladores), Desarrollo económico Barcelona: Icaria.

KARDELJ, Edvard (I976). Les contradictions de la propriété sociale dans le systéme socialiste. París: Anthropos.

Kuklinski, Antoni (1985). «Desarrollo polarizado y políticas regionales. En Homenaje a Jaques Boudeville. México: Fondo de Cultura Económica.

LANGe, Oskar (1965a). «Problemas de la construcción socialista». En Problemas de economía política del socialismo. México: Fondo de Cultura Económica.

-. (1965b). Papel de la planeación en la economía socialista». En «Problemas de economía política del socialismo. México: Fondo de Cultura Económica.

-. (1965c). «Problemas de la construcción socialista». En Problemas de economía política del socialismo. México: Fondo de Cultura Económica

Lanzarotti, Mario (1990). La Corée du Sud, une sortie du sous-développement. París: IEDES.

Latouche, Serge (I988). "Contribution A l'histoire du concept de développement» . En C. Coquery-Vidrovitch, D. Hemery, J. Piel (eds), Pour une histoire u développement. (Etats, societés, développements). París: L'Harmattan.

-. (200I). La déraison de la raison économique. París: Albin Michel.

LAVILle, Jean Louis y Jordi García (2009). Crisis capitalista y economía solidaria. Barcelona: Icaria y Antrazyt.

Le Goff, Jaques (2005). Pensar la historia: modernidad, presente y progreso. Madrid: Paidós.

Leibenstein, Harvey (I957). «The theory of underemployment in backward economies». Journal of Political Economy, 65.

LEWIs, Arthur (1964). Teoría del desarrollo económico. México. 
L'Heriteau, M. F. (1986). Le Fond Monetaire International et les pays du Tiers Monde. París: Presses Universitaires du France.

Max Neef, Manfred (1985). El desarrollo a escala humana. Santiago: Cepaur y Fundación Dag Hammarskjöld.

Meadows, Donella y otros (1972). Los limites al crecimiento. Cambridge: Instituto Tecnológico de Massachusetts.

Myrdal, Gunnar (I959). Teoría económica y regiones subdesarrolladas. México: Fondo de Cultura Económica.

MARINI, Ruy Mauro (I974). Subdesarrollo y revolución. México: Siglo XXI.

Nurkse, Ragnar (1973). Problemas de formación de capital en países insuficientemente desarrollados. México: Fondo de Cultura Económica.

Peemans, J. Philippe (2002). «Le développement des peuples face à la modernization du monde». (Les theories du développement face aux histoires du développement «reel» dans la seconde moitié du XXème siècle). Lovaina: Academia Bruylant, L'Harmattan.

Perroux, Francois (1958). La coexistence pacifique. París: Presses Iniversitaires de France.

Polet, Francois (2008). L'Alter-Mondialisme. Bruselas: Centro Tricontinental.

Prebisch, Raúl (I95I). Problemas teóricos y prácticos del crecimiento económico. Santiago: Cepal.

-. (1963): Hacia una dinámica del desarrollo latinoamericano. México: Fondo de Cultura Económico.

Portes, Alejandro y William Haller (2004): La economía informal. Santiago: Cepal. División de Desarrollo Social.

Preston, Paul (I999). Una introduccion a la teoría del desarrollo. México: Siglo XXI.

Ranis, Gustav (I993). «Economías con excedente de mano de obra». En J. Eatwell, M. Milgane y P. Newman (compiladores), Desarrollo económico. Barcelona: Icaria

Rodríguez, Óscar (I980). La teoría del subdesarrollo de la Cepal. México: Siglo XXI.

RoDrik, Dany (I999). The new global economy and the developing countries: making openness work. Washington: Overseas Development Council.

Rosentein-Rodan, Paul (I962). "Notes on the theory of the big push». En H. S. Ellis (comp.), Economic development for Latin America. Londres: Macmillan. 
Rostow, Walt (1963). Las etapas del crecimiento económico. México: Fondo de Cultura Económica.

RutKowski, Jerzy (I965). "Algunos problemas de la industrialización socialista». En Problemas de economía política del socialismo. México: Fondo de Cultura Económica.

SEN, Amartya (2004). "Capital humano y capacidad humana». Cuadernos de economía. Foro de Economía Política-Teoría económica. Disponible en $<$ www.red-vertice.com/fep $>$.

Schumacher, Fritz (1987). Lo pequeño es hermoso. Madrid: Blume.

Sunkel, Osvaldo (comp.) (I99I). El desarrollo desde dentro: un enfoque neoestructuralista para América Latina. México: Cepal y Fondo de Cultura Económica.

VerHAEgen, Etienne (I998). «Le développement durable; entre science et politique». En M. Loriaux (editor), Populations et développement: une aproche globale et systémique. Lovaina: Academia Bruylant, L'Harmattan.

Wade, Robert (1999). El mercado dirigido. México: Fondo de Cultura Económica.

Wallerstein, Inmanuel (I984). El moderno sistema mundial. Madrid: Siglo XXI.

\section{Sobre al autor}

Raúl González Meyer es académico de la Universidad Academia de $\mathrm{Hu}$ manismo Cristiano. Economista Universidad de Chile. Magíster en Desarrollo Urbano Universidad Católica. Magíster en Desarrollo y Doctor en Ciencias Sociales (Desarrollo, Población y Medio Ambiente) por la Universidad Católica de Lovaina. Su correo electrónico es <rgonzalezm@docentes.academia.cl>. 



\title{
Desarrollo andino: sustentable y con identidad
}

\author{
Andean Development: Sustainable and with Identity
}

BERNARDO GUERRERO JIMÉNEZ

Universidad Arturo Prat, Iquique, Chile

RECEPCIÓN: 25/09/20I2 · ACEPTACIÓN: I3/05/20I3

RESUMEN El concepto de desarrollo ocupa buena parte de la agenda de los Estados y los gobiernos en América Latina. Sin embargo, esta idea esconde algunos supuestos que en este artículo discutimos. El desarrollo y su vinculación a la identidad cultural, al territorio, contraviene la idea hegemónica que anima a este concepto nacido en Occidente. Analizamos el itinerario en América Latina y lo ubicamos en el Norte Grande de Chile, enfatizando las ideas centrales desde los años sesenta en adelante del siglo XX. Finalizamos argumentando a favor del llamado posdesarrollo.

PALABRAS CLAVE Desarrollo, desarrollo andino, posdesarrollo.

ABSTRACT The concept of development occupies an important part of the states and latin american government agenda. However, this idea hides some items that are discuused in this article. The develpment and its link to the cultural identity, the territory, counterparts the hegemonic idea that brings up this concept born in the western world. We analyse its itinerary in Latin America and we locate it in the Chilean North, emphasizing the central ideas from the 60 years onwards. We end up supporting the so called post development.

KEYWORDS Development, andean development, post development. 
En las páginas que siguen establecemos una discusión en relación a las ideas que subyacen en torno a la concepción occidental y andina del desarrollo. Nos interesa, sobre todo, especificar los elementos de fondo que animan a ambas posiciones. Argumentamos en base a consulta de fuentes directas como indirectas, planes y estrategias de desarrollo aplicados desde el Estado y la empresa privada, orientados a «desarrollar» esta parte del territorio. Este artículo termina con algunas sugerencias para potenciar el desarrollo andino desde dentro.

\section{El concepto de desarrollo}

El día I7 de febrero de I992, el entonces intendente de la región de Tarapacá, Nelson Garrido Álvarez, recibía una carta de la Junta de Vecinos de ChucuyoParinacota (zona andina de la provincia de Arica) en la que se solicitaba dejar sin efecto un programa para estimular lluvias en forma artificial. En sus partes principales la carta decía:

I. Cuando el avión hace sus vuelos sobre las incipientes nubes, inmediatamente produce una dispersión de ellas, con lo cual no deja que se arme la lluvia, es decir, cuando las nubes están tomando una posición adecuada que nosotros llamamos maduración, el avión produce un fenómeno abortivo de la lluvia.

2. Desde que se ha iniciado este programa, jamás se ha producido lluvia alguna, por lo menos así lo hemos notado durante todo el tiempo en que se viene desarrollando este programa.

3. Nuestro conocimiento campesino nos señala que las lluvias tienen un proceso natural de apareamiento entre las nubes hembras de la costa y nubes machos del altiplano y para su fecundación es necesario no interrumpirlas, ya que paulatinamente se va generando un ciclo climático propicio para las precipitaciones normales.

4. Durante varios años hemos cobijado la esperanza en este programa experimental, pero nos damos cuenta que no hay resultados positivos para nuestra zona. Más bien consideramos que está provocando perjuicios.

Lo anterior debió de haber producido más que extrañeza en el destinatario por los términos de la carta: «nubes hembras» y «nubes machos». Tales conceptos desafían el lenguaje moderno y nos conectan, más que nada, con la existencia de una visión del mundo diferente (Berman, I987). Los hijos de la modernidad 
y entusiastas promotores del desarrollo habrán escuchado con risa irónica tales argumentos. Sirva esta carta para adentrarnos en el tema que nos convoca.

Si hay algún concepto que animó la vida social, económica, cultural y política de la segunda mitad del siglo XX es, sin duda, el de desarrollo. La promesa y consecución del mismo ha dinamizado guerras, conferencias de paz, desarme y un largo etcétera. Sin embargo el desarrollo como concepto tiene su genealogía. Y su partida de nacimiento es posible encontrarla en la palabra progreso.

El mundo moderno se sostiene en la fe en el progreso. La adhesión con la que el hombre moderno se vincula a la ciencia y la tecnología proviene de esa fe (Bury, I97I). Aunque hoy en día la palabra progreso no maravilla como antes, aún es posible, sobre todo en el sentido común, observar el tremendo prestigio que ésta tiene. Como paradoja, en los sectores más pobres del Tercer Mundo, muchas poblaciones sin agua, luz ni sistemas de eliminación de excretas se llaman «Progreso».

La Unión Soviética trabajó casi en forma mesiánica el concepto, y los norteamericanos, al concluir la Segunda Guerra Mundial, se convirtieron en los paladines de la civilización occidental, defensores y exportadores de su estilo de vida. La Alianza para el Progreso fue un signo emblemático de esa tradición.

El mundo dividido en dos bloques ofrecía al resto de la humanidad bajo diferentes estéticas lo mismo: progreso. En ambos casos el enemigo era uno solo: la ignorancia y la superstición. El progreso se nos aparecía en forma de electrodomésticos, conquistas espaciales, automóviles, etcétera.

En los años cincuenta, el Presidente Truman lanza la era del desarrollo. Las regiones que antes eran conocidas como incivilizadas o atrasadas empezaron a llamarse subdesarrolladas. Detrás del nuevo concepto, el de desarrollo, quedó implícita la marca del progreso. Como una especie de catecismo, Ayres en el prólogo del libro La teoría del progreso económico escribió:

Ya que la revolución tecnológica es irresistible por sí misma, la autoridad arbitraria y los valores irracionales de las culturas precientíficas y preindustriales están condenados [...] La resistencia [...] no puede salvar a los valores tribales [...] No les queda más alternativa que aceptar inteligentemente y voluntariamente el modo de vida industrial y todos los valores que le acompañan.

No necesitamos disculparnos por recomendar ese camino. La sociedad industrial es el modo de vida más exitoso que la humanidad ha conocido. Nuestra gente no sólo come mejor, duerme mejor, tiene alojamientos más 
confortables, se traslada mejor y más cómodamente y vive más tiempo de lo que los hombres jamás lo han hecho. Además de oír la radio y mirar la televisión, lee más libros, escucha más música y ve más películas que ninguna otra generación previa o ningún otro pueblo lo ha hecho. En el clímax de la revolución tecnológica vivimos en una época de oro de la lucidez científica y los logros artísticos. Para todos aquellos que logran el desarrollo económico el cambio cultural profundo es inevitable. Pero las recompensas son considerables (en Sbert, I996: 303).

Los supuestos de esta concepción del desarrollo descansan a su vez en una nueva forma de mirar el tiempo, la historia y al hombre. El tiempo ya no es cíclico. Ya no retorna eternamente sobre sus ejes fundacionales en los que encuentra su razón de ser: el tiempo primordial, del que cual nos habla Eliade (I968), en el que los hombres participan solidariamente en la renovación del Cosmos junto a los dioses. Dussel (20I I) habla de la sustantividad del cosmos. El tiempo es ahora lineal. No hay espacio ni para el destino y tampoco cabe la Divina Providencia. El hombre se define como un ser racional y autónomo (Bauman, I997). Racional por cuanto es capaz de controlar su subjetividad y actúa de acuerdo a las disposiciones entre medio y fines. La razón se convierte en su guía y motor. La exigencia de la modernidad es por la racionalidad. Es autónomo ya que se percibe como el dueño del mundo. La ideología que lo legítima lo ubica en el centro del universo. Ya no depende de los dioses. El futuro lo construye con su razón. El tema de la fe y de la salvación son aspectos que sólo se reflexionan en el ambiente de lo íntimo, en la esfera de lo privado. Se define la modernidad como un movimiento histórico de la racionalización de la experiencia social, de dominio sobre la naturaleza, como un triunfo progresivo y total de la epistemología racional-cristiana (Dussel, I994).

La siguiente cita así lo dice:

El progreso consagra la sustitución de la esperanza, que confía en la bondad de la naturaleza o la divinidad, por la expectativa de un futuro promisorio proyectado y construido por los instrumentos del hombre. Excluye la visión tradicional de las limitaciones del hombre, junto con la creencia en poderes superiores al suyo. La humildad, de santa virtud se convierte en excéntrica herejía. Las condenas de la codicia, primordiales en todas las sabidurías tradicionales y la filosofía, se transforman en exhortaciones a entregarse a ella, abiertamente o bajo el disfraz del trabajo. 
Tal pecado se percibirá en lo sucesivo como el motor psicológico del progreso (Sbert 1996: 305).

Las ideas del desarrollo habrían de propagarse rápidamente a este sector del mundo. Como ya no somos atrasados o incivilizados, sino que subdesarrollados, la tarea es ofrecer el desarrollo como una meta a alcanzar. Meta que cada vez que nos parece cercana, se nos aleja más.

El desarrollo como tema ha sido planteado por casi todos los pensadores sociales. Ya sea enfatizando algunos aspectos como negando otros, hombres de izquierdas y de derechas coinciden con ese ideario. Gente como Lenin, Castro, Reagan, Voltaire, Darwin, Sastre, Debray y Vargas Llosa esgrimen argumentos para el logro de tal meta.

En nuestro continente, la Revolución Cubana se alza como respuesta al subdesarrollo y a la explotación. La Alianza para el Progreso reacciona a la amenaza castrista. Bajo el rótulo de la «ayuda para el desarrollo» se legitiman invasiones, se destruyen los recursos naturales, se sacrifica la democracia, se violan los derechos humanos. Las últimas dictaduras conjugaron la doctrina de la seguridad nacional con el neoliberalismo, acaso la faceta más nueva del desarrollo. El neopopulismo que aparece en América Latina ofrece la democratización en el consumo. El neoliberalismo en el resto del continente trata de ecualizar lo imposible: el modelo con la igualdad de oportunidades.

\section{Desarrollismo y desarrollo en América Latina}

América Latina ha sido objeto de diversas políticas de desarrollo. Todas ellas caben bajo la denominación de "políticas desarrollistas». Por éstas se ha de entender el conjunto de acciones (técnicas y de planificación, de control y de asignación de recursos) destinadas a sobrepasar la situación de subdesarrollo. Sin embargo, el relevar el aspecto material no significa necesariamente que la pobreza material desaparezca. No hay una mejoría real de las condiciones de vida de los grupos más pobres.

El «desarrollismo» como tendencia, y como bien señalan Morandé (I984) y Van Kessel y Droogers (I988), está presente en todas las escuelas: desde la Cepal hasta la Escuela de Chicago, pasando por la teoría de la dependencia.

El «desarrollismo» ha tenido como motivo el soslayar aspectos importantes de la configuración de América Latina. Asuntos como la identidad cultural y la religión son francamente ignorados. Para estas tres escuelas, uno de los ob- 
jetivos principales debía ser el provocar la pérdida de significación pública de la religión. Ésta era vista como «un obstáculo al desarrollo» o, como dijo Karl Marx, en su tiempo y contexto, «un opio del pueblo». ${ }^{1}$

Lo anterior tiene dos raíces que es necesario discutir. Una de ella dice relación con el origen europeo de los modelos aplicados en América Latina; y la otra parte de una imagen-meta trazada en Europa donde la religión y la cultura, por obra del proceso de secularización, se han convertido en un asunto privado.

De acuerdo a la lectura del texto de Morandé (I984), se pueden usar como sinónimos conceptos tales como modernización, desarrollismo y secularismo; sinónimos en el sentido de que estos tres conceptos parten del supuesto de que el desarrollo en América Latina sólo se logra en la medida en que los valores culturales, como la religión popular, desaparezcan o bien pierdan importancia como fenómenos de masas.

El desarrollismo en nuestro continente, según Morandé, ha recorrido tres etapas. Una de ellas, la primera, es la aplicada por mediación de la sociología de Parsons. La idea es transformar a América Latina en una sociedad moderna. Tal concepto es un paradigma y al hablar de sus referentes siempre se pensó en Europa o en Estados Unidos. Esta tendencia, según Morandé, sólo pretendía aplicar, cual si fuese una mágica receta, el método científico y, de este modo, cosechar los frutos de una calidad de vida mejor. Su más lúcido e ilustrado representante fue el argentino Gino Germani que, en su libro Política y sociedad en una época de transición (I973), plantea los caminos que ha de recorrer América Latina para convertirse en una sociedad moderna.

La segunda etapa se caracteriza por la llamada sociología comprometida, como respuesta a la crisis del desarrollismo made in USA. Ésta pretende ahora combinar los principios científicos que portan «el marxismo científico», entre otros, con una propuesta política e ideológica de desarrollo. Pero esta sociología, autodenominada crítica al decir de Morandé, se vuelve más acrítica reificando sus argumentos en el discurso ideológico-político.

Igual que sus colegas norteamericanos, «los dependentistas» cometieron el

I. La frase dice: «La miseria religiosa es a la vez la expresión de la miseria real y la protesta contra la miseria real. La religión es el suspiro de la criatura oprimida, el sentimiento de un mundo sin corazón, así como el espíritu de una situación sin alma. Es el opio del pueblo» y aparece en el libro Contribución a la crítica de la filosofía de derecho de Hegel ( 1843$)$. 
error de concebir la religión como un tema que tendría que desaparecer de escena. La construcción del socialismo puede perfectamente soslayar el tema de Dios. Las tesis weberianas o neoweberianas, según Parker (I992: I9), fueron desechadas por idealistas o por ser simples consecuencias de la base económica de la sociedad.

A la crítica de la excesiva ideologización en la sociología comprometida le corresponde el surgimiento "de una mentalidad tecnocrática para todas las ciencias sociales». El desarrollo es ahora visto como un problema técnico. El mercado se convierte en el mejor asignador de recursos. El tecnicismo reemplaza a la política. Los "Chicago Boys», apodo con que el se conoce a los economistas chilenos que estudiaron en la universidad de esa ciudad, discípulos del neoliberalismo puesto en boga por Milton Friedmann, irrumpen en el escenario con el aval del neoliberalismo y con el argumento de la fuerza militar.

Hay una curiosa coincidencia entre los desarrollistas y los dependentistas en términos de que ambos están inspirados en sus discursos-metas: el desarrollo estilo norteamericano y el desarrollo estilo soviético, con algunas variantes locales como Cuba o Corea, hacen caso omiso del tema de la cultura. Para ellos, orientados por la idea del progreso, la religión, igual que la tradición, es un resabio irracional, un obstáculo al progreso.

\section{El desarrollo andino}

Es casi ya lugar común sostener que el Norte Grande de Chile es una zona esencialmente minera. Algo de cierto hay en esa afirmación. Sin embargo, una mirada a la historia larga de este territorio señala la preponderancia de una economía agroganadera y de una visión del mundo que se sostiene sobre la noción de "criar la vida» (Van Kessel y Condori, I992). El trabajo en esta sociedad es más que una actividad económica, es la resultante de la conjunción de elementos materiales y simbólicos. De allí la idea de que hayan meses secos (masculinos) y húmedos (femeninos), cerros hembras y cerros machos. La tecnología andina es la base de la economía de esta parte del territorio (Van Kessel y Condori, I992: I8). La consecución del bienestar en el más amplio sentido de la palabra («estar y sentirse bien en el mundo») es la que encauza todas las actividades en un lugar administrado por el ayllu.

De acuerdo a las ideas anteriores, ¿’es posible hablar de desarrollo andino? ¿Es legítimo adjetivar con andino una palabra europea que tiene tantas implicancias como las ya anotadas? ¿Hubo antes de la conquista un desarrollo andino? 
Al parecer, antes de la conquista española las civilizaciones de este continente habían logrado un estado de bienestar relativamente aceptable. No había hambruna y las enfermedades parecían controladas. En esta parte del mundo, los incas lograron diseñar una economía planificada que les permitía controlar los vastos territorios que conquistaban (Murra, I975).

Su política de control de pisos ecológicos y la percepción del mundo en términos de concebir a la naturaleza, la sociedad y el espacio en términos de una totalidad equilibrada gracias a una ideología heterónoma, les autorregulaba su capacidad de producción. Esto se tradujo, por cierto, en una explotación de los recursos naturales mediatizada por elementos culturales y religiosos (Van den Berg, I989).

Si hemos de hablar de un desarrollo andino, tenemos que enfatizar la idea de un territorio. Por territorio es menester referirse primero que nada a la divinidad que le da sentido. Esto es la Pachamama. Esto contrasta notablemente con la idea occidental que afirma que el territorio no tiene vida y es enajenable. El desarrollo andino, siguiendo a Javier Medina (I994), hay que entenderlo bajo las claves del territorio, de la autosustentabilidad y del etno y ecodesarrollo. El territorio es un espacio de vida no mercantil. En él se desarrolla la vida no sólo económica y política, sino que también cultural y simbólica. Van Kessel discute las características de un desarrollo alógeno y de otros endógeno. Se inclina por el segundo (I99I: I6). Escobar (2010) plantea la idea de que un desarrollo del llamado Tercer Mundo debe considerar la existencia de un lugar, de una cultura y de la naturaleza. Estos tres conceptos deben ser vistos en su relación y en movimiento. Construidos desde el paradigma de Occidente, aparecen como realidades estancas, pero desde la visión del mundo andino no se pueden separar. En otras palabras, la idea es superar la visión dicotómica entre cultura y naturaleza. Desde el ayllu, el lugar por excelencia del mundo andino, la naturaleza se construye y se establece con ella una relación de respeto. La Pachamama, el símbolo mayor de esta forma de ver el mundo, referente de la fertilidad, resume la economía, la cultura y la religión, además del medio ambiente.

Acorde con el territorio es necesario recordar la idea de ayllu (Espinosa Soriano, I990: I I 5). La familia extendida con sus múltiples relaciones de todo tipo, con una autoridad basada en la tradición, es la que mejor conoce el lugar o el territorio. La administración del territorio y de sus recursos pasa por el fortalecimiento del ayllu. En éste se reproduce la ética comunitaria y el respeto a la vida en sus amplias dimensiones. El ayllu es la instancia que permite la 
recreación y la socialización de la práctica histórica y mitológica que funda la singular apropiación sobre el territorio.

De lo anterior es posible deducir una ética para el desarrollo andino. El modelo occidental no la necesita por lo mismo que se proclama dueño del mundo. La ética fija límites, establece modelos de comportamientos. La ética andina del desarrollo es antes que nada ética religiosa. Al plantearse el territorio en forma animada, le otorga a la Pachamama la administración de los recursos. De allí la necesidad del ritual, sobre todo el de producción. La venia de la Pachamama es esencial para el éxito de las labores tanto de la ganadería como de la agricultura. El floreo de las llamas, la limpieza de las acequias, entre otras ritualidades, constituye el centro de la productividad ligada a una ética que concibe al mundo no como un recurso a su libre disposición, sino como un don que hay que actualizar (van Kessel, 1992).

El Estado chileno, una vez que conquistó los territorios de Perú y Bolivia, organizó una campaña sostenida de civilización/chilenización y evangelización sobre estos lugares. Inventó el Norte Grande y lo dotó de significados. Uno de ellos fue concebir a sus habitantes como paganos e incultos. De allí la misión civilizadora, agenciada por los militares, sacerdotes y profesores. Además lo catalogó como tierras heroicas, raíz de la Guerra del Pacífico. A partir de los años sesenta del siglo pasado, el Estado chileno inició sistemáticas campañas en pos del desarrollo de este territorio. Las primeras décadas del siglo pasado, el altiplano, la zona más alejada, se mantuvo en relativo aislamiento. Tanto es así que un escritor llamaba la atención que los niños de Isluga estudiaran en escuelas de Bolivia. ${ }^{2}$ No ocurría lo mismo en los valles y quebradas, en los que por influencia del ciclo salitrero (I830-I980) ${ }^{3}$ sus habitantes fueron «integrados» a la economía del salitre.

El Estado nacional hacía la ecuación entre desarrollo y chilenización. ${ }^{4}$ Castro (2005) analiza los primeros intentos por dotar de una política de desarrollo regional a esta zona anexada a Chile. Estudia las décadas del I880 al I930, señalando el interés que tienen las nuevas autoridades para dinamizar la ex-

2. Se trata de Héctor Pumarino Soto, en una nota aparecida en el diario El Tarapacá: «Los niños chilenos de Isluga se educan en Bolivia», 26 de noviembre de I944, pág. 7 .

3. Para el caso de Tarapacá el fin del ciclo salitrero se produce con el cierre de la Oficina Victoria el año I979.

4. Para una discusión sobre el tema de la chilenización en el norte andino, aparte de Van Kessel, véase el texto de Díaz (2003). 
tracción del salitre. El ciclo salitrero produjo la conversión del indio, si bien es cierto no en proletario, pero sí en mano de obra barata en tanto surtidor de leña y de productos agroganaderos. Una buena descripción de la miserable vida de los indios en el salitre la encontramos en Ciar (I 897). En el año I930, Carlos Harms (1930) ya identificaba los problemas del desarrollo que tenía el Norte Grande. Su énfasis, por cierto, estaba en la minería como motor del desarrollo. Los andinos como grupo étnico no eran considerados. Sus territorios eran definidos en función de dos elementos claves para esta zona, la búsqueda de metales y la existencia de agua (Billinghurst, I 886).

Los indios, resabios del pasado, se convertían en objeto clientelares de las políticas de desarrollo. Uno de sus principales símbolos fue la escuela nacional. Los maestros fueron los encargados de promover el nuevo sentimiento. Construcción de caminos de accesos, instalación de postas médicas, de grupos generadores de electricidad, fueron obras realizadas por el Estado. Prospecciones mineras, a cargo del Estado o bien de privados, buscaron continuar con la bonanza del salitre. Planes ganaderos y de reforestación en la pampa del Tamarugal, ejecutados por la Corfo, fueron, entre otras, las principales actividades. En el gobierno de Allende (I970-I973) se diseña en Plan Andino (Taberna, I97I), destinado a incorporar a los aymaras a los beneficios del desarrollo (Pérez Rodríguez, I984).

Sin embargo, fue durante la dictadura militar de Pinochet (I973-I989) que la política de chilenización alcanza sus puntos más altos. Consideraciones geopolíticas y de doctrina de la seguridad nacional, hacen que este proceso iniciado a fines del siglo XIX alcanzara su mayor paroxismo. La instalación de las llamadas Escuelas de Concentración Fronteriza, un régimen de concentración para estudiantes aymaras, permitía una concientización mucho más efectiva, y con ello alteraba el uso del lugar por parte de los aymaras, ya que se «inventaba» un nuevo centro distinto y hasta contradictorio del centro ceremonial tradicional. Es el caso de la creación de la comuna de Colchane, que rompe la unidad andina centrada en el pueblo de Isluga (Podestá Arzubiaga, I985). A este proceso le acompaña, por cierto no en una relación de causalidad, la acción proselitista de grupos evangélicos agrupados en la Iglesia Evangélica Pentecostal, que portan un discurso civilizador más radical que el de la Iglesia Católica (Guerrero, I994). En forma paralela, las acción de las organizaciones no gubernamentales, como el Crear, TEA y TER, ${ }^{5}$ intentaban, con

5. Se trata del Centro de Investigación de la Realidad del Norte, Crear, del Taller de 
énfasis distintos, apoyar propuestas de desarrollo bajo la idea enunciada por Van Kessel ( I980) de que el desarrollo debe tener un motor, y ése debe ser la cultura y la religión. Muchas de estas ideas están enunciadas en el documento de trabajo «Organización, desarrollo e identidad en Tarapacá» (I986). ${ }^{6} \mathrm{Se}$ habló de etnodesarrollo, desarrollo con identidad, desarrollo ecosustentable, entre otros. La organización de campesinos para la venta de su artesanía a los mercados nacionales y extranjeros no dio los resultados esperados. Lo mismo sucedió con la venta de quinoa. Los intermediarios, gente no aymara, terminó apropiándose del negocio. ${ }^{7}$

Todas estas acciones del Estado y de privados son vistas como un genuino interés por desarrollar esta zona. La acción de la Zona Franca (I975) y la expansión del nuevo ciclo minero (I990) acentuará la mirada desarrollista sobre este territorio. El territorio andino es visto como un recurso natural que posee enorme riquezas, sin ninguna consideración sobre sus componentes culturales y menos medioambientales. La búsqueda y extracción de agua se convierte en el punto de conflicto entre las comunidades y las empresas mineras (Lemereis, I987). ${ }^{8}$ Sin embargo, el panorama no es nada de esperanzador. Un análisis de esas luchas señala que muchas comunidades terminaron negociando, una a una, con las mineras. Muchas comunidades se dividieron. Una buena cantidad de jóvenes trabaja en la minería y viven en Iquique, Alto Hospicio y Pozo Almonte, entre otras comunas.

La dinámica del comercio que impulsó la Zona Franca convirtió al territorio andino en un corredor por donde se movilizan vehículos transportando cargas de Iquique a Paraguay, vía Bolivia.

Estudios Andinos y del Taller de Estudios Regionales. Estas dos últimas organizaciones ya no existen.

6. Véanse las publicaciones en el apartado Documentos de Trabajo en <www.crear.cl>.

7. Van Kessel (I987) estudia un caso que él llama «repunte económico» de una comunidad campesina en la provincia de Iquique. Demuestra que sólo fue un éxito relativo ya que terminó con la erosión de las tierras. Se trata de la comunidad de Sibaya. Éste puede ser leído como un estudio de caso de una situación excepcional.

8. Hay que destacar el documental realizado por la Fundación Andina de Holanda Y es nuestra, realizado en la década de los ochenta, que trata de la organización de los aymaras para la defensa del agua. 


\section{A modo de conclusiones}

El mundo andino de hoy dista mucho de aquel que los españoles encontraron. Los gobiernos republicanos, la ayuda internacional y los regímenes autoritarios, y cada a uno a su modo, alteraron profundamente el funcionamiento de esta sociedad. Como si lo anterior fuera poco, aparecen nuevos fenómenos como los grupos evangélicos y pentecostales, que portan una nueva oferta religiosa atrayente para los campesinos. Pero también han ocurrido fenómenos de indianización y/o reetnificación que auguran una nueva consciencia étnica. Quizás producto de los fenómenos de globalización, las sociedades locales vuelven la mirada hacia sus historias y sus mitos, tratando de hallar allí un cable a tierra que los proyecte al futuro. Frente a ello, nos planteamos algunas preguntas.

Habiendo una situación de descrédito respecto a la modernidad y a sus promesas, es pertinente hablar de una revalorización de la cultura tradicional. Siendo ésta un producto mestizo, mezcla de la herencia andina con la modernidad acontecida en estas últimas décadas, corresponde revalorar por lo menos los siguientes elementos que a mi juicio son fundantes como base para un desarrollo andino sustentable.

I. Revalorización del ayllu. El ayllu es el lugar por excelencia del hábitat andino. No es sólo una unidad productiva, sino que también es cultural y política. Éste debiera ser la base sobre la cual diseñar y aplicar estrategias de desarrollo, pero no al modo occidental, sino que andino, y que tome en consideración elementos ecológicos, económicos y culturales.

2. Redefinición del concepto de trabajo al modo andino. La noción de trabajo en el mundo andino se sostiene en una visión del mundo que privilegia las relaciones de armonía y de integración con el mundo.

3. Introducción de una ética del desarrollo acorde con la ecología y las personas. Un nuevo desarrollo, un posdesarrollo, al decir de Escobar, precisa abandonar las visiones iluministas que animaron las diversas políticas de desarrollo aplicadas en el Norte Grande andino de nuestro país.

4. Un desarrollo, o mejor dicho, un «mejor vivir», edificado sobre las bases de una economía agropecuaria, que se proponga como meta el bienestar y el bien común.

5. Lo anterior adquiere sentido en la medida en que se conecta la noción de lugar/ayllu a una espacialidad mayor. Esto es, la idea de la pan-andinidad. La idea de pertenecer a algo mayor, a un territorio común que las guerras nacionalistas, como la del Pacífico que enfrentó a Chile con Perú y Bolivia, segmentaron. 


\section{Referencias}

Bauman, Zygmunt (I997). Legisladores e intérpretes. Sobre la modernidad, la posmodernidad y los intelectuales. Quilmes: Universidad Nacional de Quilmes.

Berman, Morris (1987). El reencantamiento del mundo. Santiago: Cuatro Vientos.

Billinghurst, Guillermo (i886). Estudio sobre la geografía de Tarapacá. Santiago.

Bury, John (I97I). La idea del progreso. Madrid: Alianza.

CASTRO, Luis (2005). Regionalismo y desarrollo regional: Debate público, proyectos económicos y actores locales (Tarapacá I880-I930). Valparaíso: Universidad de Valparaíso.

Ciar, H. ( ( 897). El defensor de los pampinos. Iquique.

DíAz, Alberto (2003). «Problemas y perspectivas socio-históricas en el Norte chileno: Análisis sobre la 'chilenización' de Tacna y Arica». En Si somos americanos (Universidad Arturo Prat), 5 (4): 49-8 I.

Dussel, Enrique (1994). I492. El encubrimiento del Otro. Hacia el origen del «mito de la modernidad». La Paz: Plural.

-. (20I I). Filosofía de la liberación. México: Fondo de Cultura Económica.

Eliade, Mircea (1968). El mito del eterno retorno. Buenos Aires: Emecé.

Escobar, Arturo (2010). Una minga para el post-desarrollo. Lugar, medio ambiente y movimientos sociales en las transformaciones globales. Lima: Universidad Nacional Mayor de San Marcos.

EsPinosa Soriano, Waldemar (I990). Los incas. Economía, sociedad y Estado en la era del Tahuantinsuyo. Lima: Amaru.

Germani, Gino (I973). Política y sociedad en una época de transición. Buenos Aires: Paidós.

Guerrero, Bernardo (I994). A Dios rogando... Los pentecostales en la sociedad aymara del norte grande de Chile. Ámsterdam: Free University Press.

Harms, Carlos (I930). Los grandes problemas de la Zona Norte. Santiago: Imprenta y Lit. La Ilustración.

Kusch, R. (1970). El pensamiento indígena americano. México: Ediciones Puebla.

Lemereis, J. (I987). «La lucha por el agua de los aymaras del Norte de Chile». En Cuaderno de Investigación Social (Centro de Investigación de la Realidad del Norte), 20. 
Marx, Karl (1843). Contribución a la Crítica de la Filosofía de Derecho de Hegel. Salamanca: Sígueme.

Medina, Javiera (1994). Del alivio a la pobreza al desarrollo humano. Buscando la Bolivia del próximo milenio. La Paz: Hisbol.

Morandé, Pedro (1984). Cultura y modernización en América Latina. Santiago: Pontificia Universidad Católica de Chile.

Murra, John (1975). Formaciones económicas y políticas del mundo andino. Lima: Instituto de Estudios Peruanos.

Parker, Cristian (1992). Otra lógica en América Latina. Religión popular y modernización capitalista. México: Fondo de Cultura Económica.

Pérez Rodríguez, Eduardo (1984). «Políticas de desarrollo en la zona del interior y altiplano: Tarapacá, Chile». En Cuaderno de Investigación Social (Centro de Investigación de la Realidad del Norte), 9.

Podestá Arzubiaga, Juan (1985). Estado, espacio, educación. El etnocidio de los aymaras en Chile entre I974-I985. Tesis para obtener el grado de Magíster en Antropología Cultural. Universidad Libre de Ámsterdam. Amsterdam, Holanda.

Sbert, José María (i996). «Progreso». En Wolfang Sachs (editor), Diccionario del desarrollo. Una guía del conocimiento como poder (pp. 299-3 I 8). Lima: Proyecto Andino de Tecnologías Campesinas, PRATEC.

TABerna, Freddy (I97I). Los Andes y el Altiplano tarapaqueño. Iquique: Departamento de Ciencias Sociales Universidad de Chile, núm. I, CEDOC. VAN DEN BERG, Hans (1989). La tierra no da asi no más. Ámsterdam: Cedla. van Kessel, Juan (1980). Holocausto al progreso. Los aymarás de Tarapacá. La Paz: Hisbol.

-. (I987). «El llamado 'repunte económico' en la precordillera de Tarapacá: el caso de Sibaya». En Cuaderno de Investigación Social (Centro de Investigación de la Realidad del Norte), 25.

-. (I99I). El concepto de desarrollo.Puno: CIDSA.

-. (I992). Cuando arde el tiempo sagrado. La Paz: Hisbol.

van Kessel, Juan y Dionisio Condori (I992). Criar la vida: trabajo y tecnología en el mundo andino. Santiago: Vivarium.

van Kessel, Juan y André Droogers (I988). «Secular views and sacred vision: sociology of development and the significance of religion in Latin America». En Quarles van Ufford y Matthew Schoffeleers (eds.), Religion and Development. Towards an Integrated Approach (pp. 53-72). Ámsterdam: Free University Press. 
Wachtel, Nathan (1978). La visión de los vencidos. Lima: Instituto de Estudios Peruanos.

\section{Sobre el autor}

Bernardo Guerrero Jiménez es sociólogo y director del Instituto de Estudios Andinos Isluga de la Universidad Arturo Prat de Iquique, Chile. Su correo electrónico es < bernardo.guerrero@gmail.com>. 



\title{
Género y trabajo social: algunos desafíos
}

\author{
Gender and Social Work. Some Challenges
}

MÓNICA DE MARTINO

Universidad de la República del Uruguay

RECEPCIÓN: 8/I I/2OI2 · ACEPTACIÓN: I3/O5/20I3

RESUMEN El presente artículo es un subproducto de la investigación titulada "Ser hombres, ser padres en contextos de pobreza", desarrollada en el marco del posdoctorado en el Programa de Doctorado en Ciencias Sociales Interdisciplinarias de la Facultad de Ciencias Sociales de la Universidad Federal de Santa Catarina. Si bien la investigación apunta al campo de los estudios sobre masculinidades, es necesario detenerse en la amplia bibliografía sobre género producida en las últimas décadas para comprender los dilatados debates en torno a tal categoría. Sin intención de agotarla y sin centrarse específicamente en los estudios sobre masculinidades, el presente artículo intenta establecer una interpretación posible —entre otras- sobre la evolución teórica del concepto. Pensamos que la evolución en las formas de interpretación del mismo y las formas de debatirlo podrían apuntar a una posible fetichización o cosificación del propio concepto. Para fundamentar tal proposición colocaremos en debate a las filósofas Simone de Beauvoir y Judith Butler, como exponentes de dos corrientes epistemológicas que marcan posturas sobre la temática. A saber: una postura materialista-existencial y otra que puede enmarcarse en lo que ha sido denominado como constructivismo radical. A parte de ellas, desde el campo de los estudios sobre masculinidades retomaremos la propuesta de Connell, quien aporta una mirada diferente, trayendo a la luz las categorías de interés y capacidad heurística. A partir de estos autores intentaremos señalar algunos desafíos para 
el trabajo social, aunque los mismos pueden involucrar al conjunto de las profesiones asistenciales. Tal vez los más notorios sean: i) la ausencia de una reflexión epistemológica a la hora de afiliarse a ciertas posturas hoy en boga; y ii) la ausencia también de una perspectiva de género a la hora de intervenir en diferentes campos de actuación. Esta última es aún más paradójica en la medida que contamos con un cuerpo profesional altamente feminizado.

PALABRAS CLAVE Género, materialismo, constructivismo radical, trabajo social.

ABSTRACT This article is a product of the research entitled Be Men, Be Fathers in the context of poverty, developed under the postdoc in the PhD Program of the Federal University of Santa Catarina. While the research points to the field of men's studies is necessary to stop the extensive literature on sex and gender in recent decades product to understand the lengthy discussions over this category. Without intending to exhaust, without focusing specifically on masculinity studies, this article attempts to establish a possible interpretation, among others - on the theoretical evolution of the concept. We think that the evolution in the interpretation of the ways and forms of debate may point to a possible fetishization or reification of the concept. In support of this proposition will place in the debate to philosophers Simone de Beavoire and Judith Butler, as exponents of two currents which mark epistemological positions on the issue. Namely, a materialist - existential position and one that can be framed in what has been called radical constructivism. From the field of men's studies took up the proposal for Connell, who brings a different perspective, bringing to light categories of interest and heuristic. From these authors try to point out some challenges for social work, although they may involve the whole of the caring professions. Perhaps the most notable are: (i) the absence of an epistemological reflection when joining certain viewscurrently in vogue, and (ii) the absence also of a gender perspective when intervening in different fields of action. The latteris even more paradoxical to the extent that we have a highly feminised professional body.

KEYWORDS Gender, materialism, radical constructivism, social work. 


\section{Introducción}

Como se adelanta en el resumen, intentamos aportar algunos elementos sobre cómo el concepto género se encuentra involucrado con el trabajo social en términos de determinados desafíos teórico-metodológicos. Para ello, sin la intención de agotar la bibliografía existente sobre sexo y género, en un primer momento colocaremos en debate algunos de las/los autoras/es que consideramos han realizados esfuerzos superlativos para comprender el género, claro está, desde posturas epistemológicas muy diversas. En la medida que realizamos este diálogo triangulado, deslizaremos ciertas líneas de interpretación sobre la propia categoría género y sobre su incidencia en el trabajo social.

Vale la pena recordar que en décadas pasadas, especialmente a partir de los años setenta, el género asumió el carácter de concepto analítico central tanto para el estudio sobre la condición de la mujer como para el accionar de grupos y proyectos interdisciplinarios y también políticos. Si bien siempre tuvo la condición de ser una categoría estrictamente gramatical que habilitaba subdivisiones dentro de una clase, comenzaron a imputársele otros contenidos asociados a características culturalmente específicas de la masculinidad y la feminidad, es decir, comenzó a implicar caracteres culturales imputados a cuerpos sexuados.

En primer lugar, el uso del concepto género permitió rechazar el determinismo biológico haciendo visible la amplia gama de construcciones culturales de lo femenino y lo masculino. Las discusiones sobre género en distintas esferas se ha convertido en una característica del saber contemporáneo. Las décadas de los setenta y los ochenta han sido generosas en términos de pensar el género. Pero creemos que no todos los debates sobre género han impactado en nuestro colectivo profesional. En líneas generales, algunos de ellos han llegado a estos lares a través de difusoras básicamente latinoamericanas. Son escasas/os las/os autores cuyas obras han sido recepcionadas de manera directa por los/las trabajadores/as sociales. Por lo tanto, pensamos que nuestra profesión se alimenta, siempre a modo de tendencia, de teorías de segunda generación, por decirlo de alguna manera. Esto deviene en una apropiación acrítica y disolvente de las diferentes formas de abordar este concepto.

$\mathrm{Al}$ adoptar una perspectiva de género, si este es el caso, el trabajo social deberá también interrogarse respecto a dos cuestiones que consideramos fundamentales: i) ¿puede el género ser considerado una herramienta analítica que disipa cualquier postura natural y naturalizante al respecto?; y ii) ¿puede ser 
abordado como explicación totalizadora? Para explorar estas preguntas, este artículo investiga y coloca en debate esfuerzos por teorizar el género.

\section{Judith Butler versus Simone de Beauvoir}

\section{En nombre de la madre}

Ya es sumamente conocida la posición de Beauvoir respecto al género, plasmada en la reiterada frase: «nadie nace mujer, se hace mujer». Pero se hace mujer en una situación particular que por definición es el lugar fáctico donde la libertad, en tanto plenitud, puede ejercerse sólo de manera limitada. Todo sujeto ni es absoluto ni tiene libertad absoluta: se trata de un sujeto en interacción con otros, intrínsecamente libre pero también socialmente construido y limitado. Para el caso de la mujer, los límites impuestos por su situación en tanto mujer son paradigmáticamente ilustrativos. Subordinada y expuesta a la opresión, la mujer es objetivada, en tal situación, como lo otro (Femenías, 2000).

Lo otro no es una categoría ontológica sino cultural, por tanto modificable. $\mathrm{Al}$ respecto, el análisis que realiza sobre el cuerpo de las mujeres y de la maternidad nos habla de ese otro culturalmente modificable. Beauvoir desmitifica la maternidad al señalar que las mujeres se reconocen socialmente más como madres que como mujeres por el vínculo singular que entablan madres e hijos y por el olvido de sí que la maternidad implica (Femenías, 2000). Abrirá nuevas puertas al legitimar el no deseo de ser madre o la opción por la interrupción del embarazo, indicando la necesidad de que las mujeres se apropien de su cuerpo y de las decisiones en torno a él. Al respecto, si bien acepta una base biológica del dimorfismo sexual, reconoce que puede elegirse legítimamente otro del propio sexo como objeto de deseo. No adopta, por tanto, respecto a la biología una postura determinista. Si para la autora el sexo es ante todo sexo vivido, es decir, vivido culturalmente, nadie puede entonces situarse más allá de su sexo. En este sentido, el cuerpo es el locus de las experiencias vividas concretamente, es el cuerpo-sujeto en situación (Femenías, 2000).

Podríamos resumir burdamente su postura indicando que es la sumatoria de un universal (su concepto de sujeto trascendente), particularizado en un cuerpo sexuado y oprimido (mujer). Teórica y metodológicamente, el género, el devenir mujer u hombre con cierta orientación sexual, es una mediación más del proyecto que define a ese sujeto, tal como posteriormente lo definirá Sartre en el apéndice a su Crítica a la razón dialéctica, denominado "Cuestiones de método». 
Los feminismos estructuralistas y/o constructivistas radicalizados de los sesenta y setenta parten de esta concepción de cuerpo situado y - mal que les pese- Beauvoir se convirtió en una suerte de condición de posibilidad de su existencia. Al decir de Staton ( I980), las feministas posestructuralistas radicales norteamericanas que recepcionaron la obra de la autora francesa, lo hicieron a partir de una desconexión transatlántica, es decir, sin una apropiación del corpus de la filosofía existencialista ni de la obra de la autora in totum. Para confrontar ideas, seleccionamos las elaboraciones de Judith Butler, representante de ese constructivismo radical, poskantiano y poshegeliano, del cual se han apropiado de manera acrítica nuestra profesión y otras también vinculadas al trabajo socio-asistencial (Femenías, 2000).

Para Butler, las elaboraciones de Beauvoir indicarían que ser mujer es un acto de voluntad cultural, una construcción que designa los variados modos del proceso de autoconstrucción del género mujer, a lo que se suma que sólo existiría ese género. Si el cuerpo era un cuerpo situado, el ser mujer es, entonces, en ese proceso de autoconstrucción, una interpretación cultural del cuerpo hembra. Llegar a ser mujer es un proceso propositivo de autoconstrucción y de apropiación de un conjunto de actos y de habilidades que encuadra arbitrariamente en el concepto de proyecto sartreano, a la manera de la asunción de un cierto estilo y de ciertos significados corporales, como un trabajo consciente de incardinamiento (embodyment). Por tanto, a su juicio, Beauvoir ignora en sus análisis el objetivo performativo del género sobre el sexo, que se construye excluyendo ciertas posibilidades e invisibilizando otras. Entonces, este llegar a ser el propio género debe ser entendido como un proceso de elección que nos lleva a donde siempre estuvimos, en una circularidad asfixiante: nacimos hembras-nos hacemos mujeres, siempre en el eterno femenino (Femenías, 2000).

El libro Gender Trouble de Butler nos informa acerca de cómo la «naturalidad» de sexo, sexualidad y género está «constituida a través de actos performativos discursivamente constreñidos que producen el cuerpo a través y dentro de las categorías de sexo" (I990: x). Butler advierte al principio que «ser un sexo o un género es fundamentalmente imposible» (I990: I9). Las oposiciones binarias hombre/mujer y masculino/femenino son incompatibles con la variabilidad y complejidad de las características humanas, y construyen no sólo una falsa oposición entre los sexos, sino también una homogeneización artificial dentro de cada término de ese par binario. Los géneros estereotípicos deben entenderse como "señales ontológicas que son fundamentalmente inhabitables» (I990: I46). Rechazando el «viejo sueño de la simetría», Butler 
argumenta que el género se debe entender no como un conjunto de atributos, sino como un hacer, una reiteración de conductas, una performance, que constituye la identidad que da a entender qué se es (I990: 24).

Para la autora, el género es el proceso que construye esa supuesta coherencia interna del sexo, deseo (hetero)sexual y práctica (hetero)sexual dentro del sujeto moderno. Es el mecanismo que permite pensar un «cuerpo presocial» moldeado por la cultura y que proporciona un criterio de inteligibilidad para las personas que inspira tanto el paradigma naturalista como el paradigma del yo, tan caro este último a Beauvoir.

Género es el medio discursivo/cultural mediante el cual se produce la naturaleza sexuada o un «sexo natural» y se establece como un «prediscursivo", anterior a la naturaleza, una superficie políticamente neutral sobre la cual actúa la cultura (Butler, I990: 7).

El género realiza este trabajo de naturalización de la «repetición estilizada de acciones a través del tiempo (Butler, I990: I4I). O sea, la actitud «natural» se produce a través de la repetición de palabras, actos y gestos. Tales reiteradas repeticiones llevan a concebir la «naturalidad» del cuerpo y de la heterosexualidad y a actuar de acuerdo con los «dictados de la naturaleza». El género funciona, pues, como un padrón regulatorio, «una fabricación, una fantasía instituida e inscrita en la superficie de los cuerpos» (Butler, I990: I36).

Pero Butler fuerza a Beauvoir. Para la autora francesa, la libertad incardinada, el sujeto como proyecto, sugiere la indistinción del sexo/género, subsumidos en la noción de cuerpo vivido. Es decir, experimentado como el cuerpo que yo soy.

Butler interpreta a su manera la noción de hacerse, en el sentido que en el marco filosófico sartreano el género sería también parte del proyecto, una elección impregnada de los resabios cartesianos del sujeto intencional, tributario del modelo humanista, de un pensamiento materialista, que Butler rechaza (Femenías, 2000: 36).

Pero para Beauvoir el género es a su vez construcción cultural y elección. Las mujeres son existencia, el eterno femenino es una mera construcción de la cultura dominante, producto de un mundo masculino que las heterodesigna. El otro no es ni recíproco ni simétrico con los varones. Esa es su peculiaridad, que siendo libertad, en tanto humanas, quedan definidas como inesenciales, 
inmanentes y polo de alteridad, solamente. Al respecto, para Butler las mujeres de Simone han antepuesto su condición de mujeres a su condición de humanas, lo que sería inconcebible para Beauvoir, para quien cada mujer debe identificarse a sí misma como un ser humano, que además es mujer y se inserta en una situación totalmente diferente a la de los varones (Femenías, 2000).

\section{Aportes desde los estudios sobre masculinidades}

El libro Gender and Power de R. W. Connell (I987) se identifica con tendencias neomarxistas, existencialistas y posestructuralistas, lo que lo hace un autor referente. ${ }^{1}$ Connell expone una «teoría social sistemática del género» que lucha por representar su historicidad; el papel dinámico del género en el plano del trabajo, el poder y la catexis. Intenta, además, vincular agencia y estructura social en la formación y reproducción del género, así como la turbulencia y las contradicciones que pertenecen al género como experiencia vivida. Como él mismo expresa, desarrolla una teoría del género «basada en la práctica», atenta tanto al poder limitante del género como a los intentos de liberarse de tales limitaciones.

Existen, obviamente, líneas que lo separan de Butler: el género como una práctica social es algo más que una simple marca del cuerpo humano, «es el tejido de una estructura de símbolos que exageran y distorsionan el potencial humano» (1987: 79). Se opone al dualismo mente/cuerpo, insistiendo en que «la transformación práctica del cuerpo en la estructura social del género no se realiza sólo a nivel del simbolismo: tiene efectos físicos en el cuerpo, la incorporación es material» (I987: 87).

Para construir una mirada histórica sobre el género o, en otras palabras, analizar la historicidad del mismo, Connell apela a Marx y Sartre para delinear una concepción de las prácticas humanas en relación con las estructuras sociales. Según esta perspectiva, las prácticas son las acciones diarias de los seres humanos que se apropian de y transforman la naturaleza para satisfacer sus necesidades y, en el proceso, transformarse a sí mismos, produciendo nuevas necesidades y nuevas prácticas. Las prácticas también pueden ser definidas como transformaciones sobre el mundo natural que abren nuevas posibilida-

I. Si bien Connell es actualmente una mujer transgénero, utilizamos el masculino en la medida que las obras citadas corresponden a su trayectoria académica como hombre. 
des, así como nuevos riesgos y presiones. También pueden instituirse e institucionalizarse, creando un grado de disciplina en el mundo social que limita la libertad de futuras prácticas. Connell define la estructura social en términos de esos límites:

Una estructura social es un padrón de constreñimiento sobre la práctica inherente a las relaciones sociales. Aunque las estructuras marcan la fijeza del mundo social, la sedimentación de prácticas pasadas que limitan la acción presente, la dimensión de la vida colectiva que existe más allá de la intención individual, no son impermeables al cambio.

La práctica se puede volver contra lo que la constriñe; así la estructura puede ser deliberadamente el objeto de la práctica. Pero la práctica no puede eludir la estructura, no puede flotar libre de sus circunstancias (Connell, I987: 95).

Como mejor puede entenderse el género es como un conjunto interrelacionado de estructuras sociales que organizan la vida social en torno al sexo y la sexualidad. Es más, el autor argumenta que el género puede concebirse en términos de estructuras muy específicas vinculadas a prácticas sociales particulares de trabajo, poder y catexis, es una estructura autónoma constitutiva de esos campos. Así, por ejemplo, en el ámbito del trabajo, opera como una limitante al definir la división sexual del trabajo, la organización de la vida doméstica, la división entre trabajo pagado y no pagado, etcétera. Dentro del ámbito del poder, el género estructura la autoridad, el control y la coerción, bajo el monopolio masculino del ejercicio de la violencia. En el plano de la catexis, nos habla de prácticas que construyen relaciones emocionalmente, en las que el género estructura sujetos deseantes y objetos deseables, padrones de deseo y prácticas sexuales, así como los términos y condiciones del intercambio sexual. Estas estructuras de género existen en una interrelación compleja que denomina composición histórica. El género así entendido es «un concepto vinculante. Se trata de vincular otros campos de la práctica social con prácticas modales de generización» (Connell, I987: I40).

Forzando la comparación, tal vez para la creación y transformación del género, sea un punto común entre las posturas aquí analizadas la importancia de la agencia, en términos de Connell, la performance según Butler o el proceso de devenir mujer de acuerdo a Beauvoir, algo que aquella postura natural no incorpora. No obstante, si Beauvoir y Connell expresan diferentes posturas 
materialistas, Butler se extravía en un constructivismo radical que hace sinónimos al sexo y al género. Su apuesta es a la intelección de los problemas de las minorías sexuales. Intelección radical, en tanto pérdida de la materialidad corpórea y del reconocimiento de las diferencias.

Y si Beauvoir hace gala de la comprensión de un sujeto trascendental singularizado en un cuerpo de hembra que se transforma en un particular -esa hembra que devino mujer- Connell coloca énfasis en los constreñimientos de la estructura sobre la agencia y en la necesidad de explorar nuevas formas de pensar el género de manera tal que diferentes esferas de lo social puedan ser analizadas a partir de esta perspectiva teórica no totalizadora.

\section{Prácticas profesionales y producción social de vocaciones}

No debemos olvidar que muchas de las profesiones asistenciales, entre ellas el trabajo social, son, casi por definición, altamente feminizadas. Si analizamos históricamente a la profesión, la continuidad de la presencia femenina de las protoformas del servicio social hasta su formato profesional, hace que se desdibujen las propias determinaciones de la institucionalización profesional. Desde las damas de la caridad a los agentes profesionales parece haber habido una «evolución» por acumulación de conocimientos y técnicas en la población femenina de ciertos segmentos sociales (Piriz, I994).

Cabe entonces preguntar junto a Grassi (2005: Io) cuando interroga al trabajo social argentino:

¿Significa esto que es el género de sus agentes [...] lo que determina las características de este campo profesional y su lugar relativamente subordinado entre las disciplinas de lo social? ¿O es más conducente distinguir las preguntas referidas a la profesión y la construcción de su objeto de intervención, de aquellas que se refieren a la producción social de las vocaciones y la «natural» elección de carreras, que atrae a las mujeres al trabajo social y aleja a los varones?

Tal vez ambos componentes de estas interrogantes nos permitan comprender la feminización de ciertas profesiones y/o de algunas de sus especializaciones. Debemos remontarnos al siglo XIX, cuando el higienismo pautó la constitución del surgimiento del campo de muchas de las profesiones, digamos, modernas. Paralelamente la mujer quedaba relegada a su papel de enfermera, monja o visitadora social. Si estas coacciones caracterizaron la primera etapa 
de algunas profesiones, luego las mujeres las «eligieron», pero a partir de vocaciones producidas socialmente con base en atributos imputados arbitrariamente a las mujeres: ayuda, colaboración, cuidados, profesiones que permiten conciliar una doble o triple jornada, etcétera (Barros Cassal y Abrahão da Silva, 20ıо; Guiliani, 2006; Rebollo, González y García, s/f).

Existen dos fuentes de debilidad para el trabajo social respecto a su sensibilidad ante una perspectiva de género. En primer lugar, una inherente al propio concepto: nos permite conocer en parte al cuerpo profesional y, en menor medida, nos permite conocer sus prácticas y sus objetos de intervención. Prácticas y objetos en general asistenciales, difusos y compulsivos, que colocan en juego a «la madre interior» que toda mujer que se precie lleva dentro (Chodorow, I978; Piriz, I994). En segundo lugar, otra inherente al habitus ${ }^{2}$ profesional: el remitirse a textos de «segunda generación», ignorando la génesis de teorías, las posturas de autores con relación a determinadas escuelas, etcétera.

Para superar estas fuentes de debilidad, el trabajo social deberá construir un conjunto de categorías que permitan definir y explicar sus procesos y procedimientos y sus mutuas y específicas relaciones. No así con las categorías estrictamente teóricas con las que trabaja, pues ellas provienen del amplio campo de las denominadas ciencias sociales. A partir de ello, podrán colocarse en un lugar de autoridad e interdisciplinariedad y no en un lugar subordinado que implica la necesidad de defender espacios, hacerse visible, así como las mujeres en sus luchas políticas (Grassi, 2005).

Lo interesante, en líneas hipotéticas, es que tal vez ese lugar de subordinación del trabajo social se encuentre relacionado con su propia feminización. Pero lo que queda claro es que aquel desafío no puede entenderse solamente bajo estas condiciones. La defensa de un cuerpo profesional feminizado, asociado a las luchas feministas, no es la única condición de posibilidad del surgimiento de prácticas profesionales entendidas «como unidad reflexiva de acciones con fundamento, referida a problemas de cuya definición [...] deberá(n) ser partícipe(s) y no 'consumidor(es)' pasivos» (Grassi, 2005: I2).

Deriva de ello que, en términos de género, un segundo desafío lo constituye superar la ausencia clara de cualquier perspectiva de género. O la incorporación ingenua, empirista y no relacional del concepto: se trabaja la cuestión femenina o la cuestión masculina, se trabaja con mujeres o con hombres. El tra-

2. Entendemos la categoría habitus como la ha trabajado Pierre Bourdieu a lo largo de su obra. 
bajo social, y tal vez otros colectivos profesionales, se encuentran impregnados, por defecto, por lo que Garfinkel (1967) ha denominado una actitud natural hacia el género, es decir, por una postura basada en un empirismo naturalista que necesita ser superado. Tal actitud natural, más allá de los discursos y a la hora de analizar las prácticas profesionales, incorpora una serie de axiomas dicotómicos no cuestionables sobre la categoría género: existen dos géneros, sólo dos que son invariables, la genitalidad es el signo esencial del género, etcétera. Superar este empirismo naturalista es un emprendimiento fundamental. Desnaturalizar lo naturalizado y asumido profesionalmente (Piriz, I994).

En segundo lugar, derivaría de lo anterior que, para muchos profesionales, la naturaleza del género sigue siendo mera evidencia, reforzando esa postura natural hacia el mismo. Y lo hacen abrevando teóricamente en las ricas concepciones producidas, especialmente, a partir de la mitad del siglo XX, que indican que el concepto se ha tornado en algo sumamente controvertido tanto en el ámbito de las teorías feministas como en el de los estudios sobre masculinidades. El problema radica en los niveles de apropiación de los debates teóricos relativos a género. A este tipo de profesión no le correspondería producir teoría al respecto, sino buscar las formas más apropiadas para instrumentalizarlo a nivel de prácticas profesionales.

Si observamos esta proliferación de autores/as y las diferentes formas de entender el género, podríamos indicar, a modo de hipótesis, que existe una tendencia disolvente del concepto. $\mathrm{O}$, en otras palabras, identificamos una tendencia hacia la cosificación o fetichización del mismo. Parecería ser que puede explicar todo y que puede ser explicado también desde todas las perspectivas y esto no es problematizado a la hora de la intervención o a la hora de pensar el objeto de conocimiento e intervención.

En aras de no hipostasiar una de las tantas dimensiones que explican lo que sucede entre hombres y mujeres y entre agencia sexuada y estructura social, es que hablamos de una fetichización del concepto que, además, ha sido asociado básicamente a la condición femenina, condición de las mujeres o estudios sobre la mujer. Esta feminización e incardinación del concepto es lo que también lo transforma, teóricamente pero también desde una perspectiva de la práctica, en un fetiche: género es igual a mujer y su condición, aún en plural, cuando teóricamente ningún concepto es, por definición, sexuado.

Creemos que este es un problema fundamental en y para las prácticas profesionales. Con una postura natural, y alimentados de teorías de segunda generación, es muy difícil apropiarse de la génesis del concepto y de las escuelas 
teóricas que se conjugan en él. Este fetiche es el que, en líneas generales, es utilizado a la hora de la intervención.

Para definir esta tendencia a la cosificación del concepto nos hemos basado en otras elaboraciones. Ya algunas feministas han planteado algunas dudas sobre la utilidad del género como categoría analítica. Bordo ha identificado dos corrientes que alimentan lo que ha llamado un nuevo «escepticismo sobre el género» (I993: 216). Una corriente proviene de las experiencias de feministas de raza negra y de feministas lesbianas que han sugerido que el «riesgo múltiple», característico de sus vidas, plantea serias preguntas sobre la validez de las generalizaciones del género. Si siempre está mediado por la raza, la clase, la etnia, la orientación sexual, entonces un marco referencial que aísla el género, que lo construye en términos de "modelo aditivo" tiene graves fallas (King, I988; Spelman, I988). La otra corriente emana de ciertas críticas posmodernas que describen las narrativas de género totalizadoras y que crean una falsa homogeneidad a partir de colectivos - mujeres u hombres- que son básicamente heterogéneos. Además han puesto en duda la oposición binaria que fija a hombres y mujeres en sus cuerpos, desafiando así la base de la distinción sexo/género.

Si el género si inventó para iluminar la construcción social de la masculinidad y la feminidad y de manera ingenua dio por supuesto el cuerpo sexuado, entonces tiene poco que ofrecer en un mundo posmoderno que entiende el cuerpo, el sexo y la sexualidad como socialmente construidos (Hawkesworth, I999: 6).

Para aportar a esa construcción de procesos, procedimientos y relaciones, necesaria para la construcción de campos profesionales autónomos, atravesados por el género y por la lucha de las mujeres — cosas diferentes, por cierto-, mencionamos a continuación algunos puntos que consideramos desafiantes para las prácticas profesionales rutinarias.

\section{Género y prácticas profesionales rutinarias}

\section{La producción de los sexos}

Si hay algo en común, más allá de las diferencias epistemológicas, entre los autores brevemente reseñados es la importancia otorgada a las relaciones de poder, a las instituciones, prácticas y discursos que establecen y regulan la for- 
ma y significado del género. En otras palabras, los dispositivos que permiten que los sexos sean establecidos. Cabe preguntarse, entonces, cuáles prácticas producen género. Podríamos enumerar algunas: el falocentrismo, la norma que establece como padrón normativo la heterosexualidad, el tabú del incesto. Todas estas concepciones internalizadas naturalizan la agencia sexual masculina, la colocan como padrón que: i) marca la diferencia (Butler, I990); ii) la diferencia y la opresión (Beauvoir); iii) el constreñimiento de las prácticas del agente en un orden social dado (Connell, I987).

Tales prácticas funcionan en un complejo circuito de prohibición, producción y naturalización del sexo/género/deseo y es en ese circuito donde se insertan las prácticas profesionales, ya sea para reproducirlo o para -raramente- sublevarlo. Como ya se ha dicho, en líneas generales estas prácticas son funcionales a esa producción tanto cultural como material, trasladando acríticamente significados e imposiciones atribuidas a cada sexo.

Estas limitaciones de nuestra profesión, compartida con otras también modernas, se hace más evidente cuando, como las/los autoras/os analizadas/os, nos deslizamos de una concepción del género como categoría analítica a una concepción del mismo como proceso activo que estructura múltiples aspectos de la vida social. Ninguna profesión es ingenua, entonces, al respecto. El trabajo social históricamente produce y reproduce prácticas de género y con género, no sólo respecto a aquellos con quien trabaja sino a la interna del propio colectivo profesional, donde aún pesa la invisibilidad de todo lo realizado, en general asociado a tareas de reproducción (Piriz, I994).

\section{La atribución de género. El ansia de clasificar}

En una línea cercana a Butler, Kessler y McKenna (I978) tratan de poner entre paréntesis las pretensiones ontológicas sobre género. Su objeto de estudio es el proceso de atribución de género, esa urgencia que rige la vida cotidiana por «clasificar» a las personas en uno u otro sexo y la inquietud ante lo ambiguo. Señalan, en la obra de referencia, que cada vez que la naturalización del género es problematizada, surgen nuevas formas que la revitalizan. Así, por ejemplo, la clasificación dicotómica entre hombres y mujeres según sus cuerpos sexuados ha sido a veces sustituida por un nuevo interés científico: la identidad de género, o sea, el sentido psicológico individual que se atribuye al ser hombre o mujer, como un fundamento más firme de una dicotomía fija.

Transexual es una categoría construida para poner de relieve la ambigüe- 
dad, para evitar los tipos de combinaciones (genitales masculinos e identidad de género femenina) que hacen que las personas se sientan incómodas porque violan reglas básicas sobre el género. Como actualmente se pueden cambiar los genitales, la identidad de género se ve ahora como un criterio menos flexible, marcando así el triunfo de los cirujanos sobre los psicoterapeutas en la urgencia por restaurar al género una realidad sin ambigüedad (Kessler y McKenna, I978: I 20).

En una postura también constructivista radical, Kessler y McKenna (I978) sostienen que el dimorfismo sexual no está dado por la naturaleza, sino que es impuesto a la naturaleza por quien lo percibe.

El género es una construcción social, un mundo de dos sexos es el resultado de los métodos compartidos socialmente y dados por hecho que las personas de un grupo social emplean para construir un mundo (Kessler y McKenna, I978: $\mathrm{x})$.

La concepción de géneros lleva a la percepción de dos sexos forzando a colocar todos los fenómenos percibidos dentro de las categorías dicotómicas postuladas. Anomalías y ambigüedades se ocultan, permitiendo que el fenómeno percibido se conforme y confirme la validez de la expectativa clasificatoria binaria.

Estos procesos que las autoras analizan en la vida cotidiana también modelan las percepciones socialmente legitimadas de los científicos, cuyos trabajos se toman como prueba incontrovertible de la validez de categorías y conceptos.

Los científicos construyen el dimorfismo allí donde hay continuidad. Hormonas, comportamientos, características físicas, procesos de desarrollo, cromosomas y cualidades psicológicas se han hecho encajar dentro de categorías dicotómicas. El conocimiento científico no informa la respuesta a la pregunta: ¿qué hace que una persona sea un hombre o una mujer? Más bien justifica (y parece que da bases a) la convicción ya existente de que una persona es o un hombre o una mujer y que no hay problemas para diferenciar entre ambos. Las diferencias biológicas, psicológicas y sociales no conducen a que veamos dos sexos. El hecho de que veamos dos sexos conduce al «descubrimiento» de diferencias biológicas, psicológicas y sociales (Kessler y McKenna, I978: I63).

De acuerdo con el supuesto ilustrado de que la biología proporciona el fundamento de lo masculino y lo femenino, es natural creer que la genitalidad brinda el criterio definitivo para la atribución de género. Pero las autoras indican que en la vida cotidiana, la atribución casi siempre se hace sin que haya ninguna confirmación sobre los genitales. A la que hace el médico a la hora 
del parto, sigue la asignación de sexo al nacimiento, pero en las interacciones sociales, la categorización del otro como hombre o mujer rara vez se basa en esa inspección directa. El énfasis en la identidad de género para continuar con tal clasificación dicotómica disloca la base de tal clasificación de la biología a los saberes «psi».

Cabe resaltar que, en líneas generales, el trabajo social realiza asignaciones dicotómicas de género, ya no sólo por esa actitud natural hacia el mismo sino también a partir de otras prácticas: encuentros visuales, análisis del contenido del habla y de la narrativa del self de los/las usuarios/as de los servicios, etcétera. Pero lo hace especialmente a partir de la constatación de los caracteres sexuales secundarios y terciarios de usarios/as, a las que estas autoras denominan «genitales culturales», lo que genera el reforzamiento de la actitud natural hacia el género.

Cuando los caracteres primarios y secundarios pueden ser modificados, la medicina solicita a los saberes $"$ psi» ${ }^{3}$ nueva bases para la reproducción dicotomizada del género: la identidad, como problemática entra en escena. Las profesiones asistenciales, y el trabajo social obviamente, juegan un papel secundario a la hora de definir categorías y criterios clasificatorios, pero aunque subordinado, es un papel fundamental a la hora de la circulación de sentidos sexuados.

\section{A modo de cierre}

Las propuestas teóricas sobre género que hemos analizado nos dicen que el género como explicación universal plantea graves problemas a los beneficios potenciales del género como concepto. Si las profesiones asistenciales van a confundir teóricamente el género con aquella actitud natural en lugar de ser confundidas por el género, sería útil que enriquecieran sus marcos analíticos, aprovechando distinciones cruciales como corporización sexuada o incardinamiento, sexualidad, identidad sexual, relaciones de trabajo y/o sociales marcadas por el género, simbolismos de género, experiencia situada (Beauvoir), órdenes e inventarios de género (Connell, 1987) en lugar de subsumir todo ello en un solo término: género.

Deberían tales profesiones - y no sólo ellas, como hemos visto en el caso

3. Para una comprensión de los saberes «psi» y sus funciones sociales, véase Donzelot (I986). 
de la medicina y los saberes «psi»— resistir firmemente la tendencia a tratar el género como explicación universal, a construirlo como una fuerza causal en terrenos tan dispares como la psiquis, el self, las relaciones sociales, en otras palabras, el cuerpo, el alma y la psiquis (Lamas, I994).

Las pretensiones universales sobre la invariabilidad del género o el papel desmesurado dado a la cultura en su producción, es decir, todo aquello que tiende a privatizarlo y no a verlo como agencia situada, significan la persistencia de la actitud natural, un fracaso sostenido que hay que superar.

Para ello no debemos justificar la ausencia de audacia teórica y práctica por la composición genérica - feminización - de los colectivos profesionales a los que hacemos referencia. Sería, como señala Grassi (2005), justificar la primera por tal condición. Esto constituiría no sólo un juicio injusto y sexista, sino teóricamente insostenible. Hablaría de una tendencia hacia la privatización de los dilemas y ausencias teórico-prácticas colectivas.

\section{Referencias}

Barros Cassal, Luan y Ana Lúcia Abrahão da Silva (20I0). Atravessamentos de Gênero e Produção de Subjetividade no Trabalho de Gestão de Nível Médio em Saúde. Revista Psicologia e Saúde, Vol. 2, Nro. I, Programa de Mestrado em Psicologia, UCDB, Campo Grande, MS, pp. I 8-23

Bordo, Susan (1993). Unbearable Weight. Feminism, Werstern Culture and the Body. Berkeley y Los Ángeles: University of California Press.

Butler, Judith (1990). Gender Trouble: Feminism and the Subversion of Identitiy. Nueva York y Londres: Routledge.

Connell, Robert W. (1987). Gender and Power. Stanford, California: Stanford University Press.

Chodonow, Nancy (1978). The Reproduction of Mothering. Berkeley: University of California Press.

Donzelot, Jaques (1986). A polícia das famílias. Río de Janeiro: Graal.

Femenías, María Luisa (2000). Sobre sujeto y género. Lecturas feministas desde Beauvoir a Butler. Buenos Aires: Catálogos.

Garfinkel, Harold (1967). Studies in Ethnomethodology. Englewood Cliffs, NJ: Prentice Hall.

Grassi, Estela (2005). «Prólogo». En La profesión de trabajo social, ¿̇cosa de mujeres? Estudios sobre el campo profesional desde la perspectiva de los 
trabajadores sociales. Genolet, Alicia y otros. UNER, Espacio Editorial. Buenos Aires, pp. 9-I4.

GiUliani, Delia (2006). "La práctica profesional del Trabajo Social y la inherente condición de lo femenino». UBA FCS. Disponible en <http://www. catedras.fsoc.uba.ar/ferraros/BD/DG\% 2opptsycdlf\% 20.pdf>.

Hawkesworth, Mary (г999). "Confundir el género». Debate Feminista, ıo (20).

Kessler, Suzanne y Wendy McKenna (1978). Gender: An Ethonomethodological Approach. Nueva York: Wiley.

KIng, Deborah (1988). «Multiple Jeopardy, Multiple Consciousness: The Context of a Black Feminist Ideology». Signs, I 4 (I): 42-72.

Lamas, Marta. (1994). «Cuerpo: diferencia social y género». Debate Feminista, 5 (Io): 3-3I.

PIriz, Clara (1994). «Profesión Clase B de ciudadanas de segunda». En Varios autores, Demandas y oportunidades para el trabajo social (pp. 2I3-237). Montevideo: Eppal.

Rebollo, M. de los Ángeles, Eva González y M. del Rosario García (s/f). «Identidades profesionales en educación desde una perspectiva de género». Disponible en <http://www.revistafuentes.es/gestor/apartados_revista/pdf/ numeros_anteriores/nnwfjcdd.pdf $>$.

SARTre, Jean Paul (2004). «Cuestiones de método». Apéndice. En Crítica de la razón dialéctica. Vol. I (pp. I 5-I 55 ). Buenos Aires: Losada.

Spelman, Elizabeth (1988). Inessential Woman. Boston: Beacon.

Staton, Donna (1980). «Lenguage and Revolution: The Franco-American Disconnection». En H. Eisten y A. Jardin (eds.), The Future Difference. Boston: G.K. Hall.

\section{Sobre la autora}

Mónica de Martino es académica de la Universidad de la República del Uruguay. Trabajadora Social, doctora en Ciencias Sociales por la Universidad Estadual de Campinas, Brasil. Su correo electrónico es < monica.demartino@ cienciassociales.edu.uy>. 



\title{
El gillatún de Traitraico de 1891
}

\author{
ALFREDO CAÑAS PINOCHET
}

\section{Nota introductoria}

Esta descripción de la celebración de un gillatún en Traitraico el 2 I de diciembre de I89I, en el territorio del cacique Huenul, hecha por Alfredo Cañas Pinochet, forma parte del Estudio de la lengua veliche presentado por este autor en el Cuarto Congreso Científico celebrado en Santiago de Chile del 25 de diciembre de 1908 al 5 de enero de I 909 y cuya publicación se incluyó en el undécimo volumen de los trabajos de dicho congreso que reunió contribuciones de la sección tercera bajo la dirección del profesor Carlos E. Porter. ${ }^{1}$

En el «Vocabulario de la lengua veliche» que el estudioso adiciona a sus análisis etimológicos, lexicográficos y morfológicos del mapudungun de Chiloé o lengua veliche, como él lo llama, Alfredo Cañas tuvo la iniciativa de incluir, al llegar al vocablo gnillatún, estos «apuntes» de la ceremonia de Traitraico, de cuyo relato se desprende que el autor fue testigo presencial.

Traitraico es un territorio colindante con la ciudad de Nueva Imperial y según los descendientes del lonko Juan Luis Huenul (que debe ser a quien se refiere Cañas como cacique Huenul o Huemul), éste habría sido quien cedió las tierras para que el general Urrutia fundara la ciudad de Nueva Imperial en

I. Volumen XI de los Trabajos del Cuarto Congreso Científico (ı. Panamericano) celebrado en Santiago de Chile del 25 de diciembre de I908 al 5 de enero de I909. Trabajos de la III sección: Ciencias Naturales, Antropológicas y Etnológicas publicados bajo la dirección del prof. Carlos E. Porter, Tomo I. Santiago: Imprenta, Litografía y Encuadernación Barcelona, I9I I. 
I 882. De hecho, en septiembre de 2012 fue inaugurada en la plaza Pedro de Valdivia de esta ciudad una escultura en homenaje a Huenul, con lo cual la administración municipal actual reivindica la figura de este personaje en desmedro de Lorenzo Lemunao, quien era considerado anteriormente como aquel que pactó con los chilenos la fundación de Nueva Imperial.

Nos parece relevante poner a disposición del público esta relación oculta al interior de un vocabulario por el valor cultural e histórico de esta temprana descripción del principal ritual mapuche y como una manera de contribuir a la desclasificación de documentos que pueden aportar a una mejor comprensión de la realidad intercultural de nuestros territorios.

Aunque hemos ajustado la acentuación en algunos casos, ésta es una transcripción literal y la ortografía, la puntuación y el uso de las cursivas son las del original. Agradecemos a María Inés Flores su colaboración en la transcripción (José Manuel Zavala Cepeda).

\section{El gnillatún de Traitraico de 1891}

Apuntes sobre el gnillatun, celebrado por los indios de Nueva Imperial, en el lugar de Trraitrraico (entre ríos), reducciones del cacique Huemul, el 2 I de diciembre de I89I, destinado a obtener de Genmapun (señor del mundo), los librase de la invasión de la langosta argentina que había aparecido en los campos del sur del Cautín. La langosta apareció en Guipe, al sur del Cautín el día I6, y el gnillatun fue presenciado por el autor.

La mañana estaba tranquila y el sol oculto por los nublados, regalaba a todos con una temperatura suave y agradable: los ardores del sol, que entraba en los dominios del verano, estaban amortiguados.

Acompañado del gobernador del departamento, don Alberto Barros Ovalle y del Tesorero Fiscal don Ramón Bórquez, nos dirigimos a eso de las ocho A.M. al sitio en que iba a tener lugar la ceremonia, que era la vega del Cautín, frente a la ciudad de Nueva Imperial. El sitio escogido era plano, cubierto de vegetación baja, aunque desparramados por aquí y por allá se veían algunos árboles corpulentos; al sur, a alguna distancia corrían atropelladas las impetuosas aguas del río, y más cercanas se deslizaban las de un arroyo que con aquél más hacia el poniente se confundían. El lugar se llama Trraitrraico y las tierras pertenecen al cacique Huenul. En medio del campo en que iba a tener lugar las ceremonias se habían plantado tres manzanos, amarrados a los cuales había I 7 corderos. 
Las machis, que eran tres, aparecían sentadas a la sombra de los manzanos, teniendo por único tatuaje una línea como de dos centímetros, hecha en tinta negra que les atravesaba la cara a la altura de la nariz.

Al comenzar las ceremonias el cacique Huenul se acercó a la machi principal a recibir sus prescripciones, que fueron la de dirigirse todos los indios que andaban montados al próximo arroyo a lavar la cola y las patas de sus caballos.

Así lo hicieron todos y nosotros con ellos. Regresamos pronto a todo galope, formados en columna de a seis, desplegadas las banderas negras y al grito de ya! ya! ya! repetido por todos, para ahuyentar a Pillan.

Sin interrumpir la carrera, la concurrencia siguió al mismo paso alrededor de los manzanos, ñuinprun, imitando a las machis que hacían lo mismo, cantando al toque de sus cultrrunes y estrechando cada vez más el círculo. Poco a poco el círculo fue tomando expansión, hasta que gran parte de los indios quedaron formados en un semicírculo.

Las machis continuaron sus cantos lastimeros, tocando sus cultrrunes con el trrapue o palillo con que se toca el cultrrun y bailando a veces.

A las nueve y cuarto de la mañana, después de largo rato de permanecer los indios en esta situación, acompañando a las machis en sus cánticos, una banda de indios, a cuya cabeza iba un hermano del cacique, pasaba por delante de los otros para saludarlos.

En el campo estaban colocados en forma también de semicírculo, gran número de platos (llicanes) de madera que contenían chicha de maíz o cebada (muday) que los indios en cuclillas asperjaban con ramas de maqui hacia el Oriente, dirigiéndose al Sol, a los gritos de may! may! may! mientras otros dirigían al Sol en alta voz, una plegaria.

De repente cesan estos asperges del muday, para arrojar el residuo de los llicanes al aire, siempre en igual dirección, en forma de rocío, con la boca.

Los corderos son asimismo rociados con el mismo muday. El Sol ha andado mucho en el cielo y ha llegado para los corderos la hora del sacrificio: I7 indios armados de sendos puñales les dan muerte, recogiendo la sangres en los llicanes en parte, así como la restante es vertida en un recipiente que conserva la machi principal.

Como cosa convenida por las exigencias del ritual, los indios cortan las orejas de los corderos, que de una en una son colocadas medio perdidas en la sangre de los llicanes.

Mientras aquellos indios extraen la piel a los corderos, los restantes en 
cuclillas asperjan el aire siempre para el oriente con ramas de trapelahuen o culen, la sangre de los llicanes, mientras las machis, sentadas bajo los manzanos, cantan con sus cultrrunes, como cantan en coro todos los indios e indias.

Mientras tanto y desde el principio varios indios se metían entre la concurrencia, andando por todas partes, daban la nota alegre en la fiesta. Uno de estos era el cullon (enmascarado), que llevaba sobre la faz un mamilcullon, (máscara de palo) y que corría incitando o provocando la risa: otro con una buada o calabazo que hacía sonar a modo de cascabel y que como el cullon iba en todas direcciones; y a estos acompañan el pifuilca que tocaba un pito y otro la trrutrruca, especie de corneta abisinia, compuesta de una larga caña de 3 a 4 metros, que llevaba en el extremo opuesto un cuerno.

Los corderos del holocausto están listos: las pieles entregadas o distribuidas por la machi a varios indios, son llevadas al próximo arroyo para lavarlas y verter sangre en sus aguas. El hígado aún caliente de los corderos, es devorado crudo por los circunstantes, mientras la machi sepulta en la tierra la sangre que había sido vertida en su cántaro.

Los indios que fueron al arroyo regresan (son las $9^{1 / 4}$ ) trayendo en alto las banderas negras, y corriendo a todo escape gritando ya!... ya!... ya!... con que ahuyentan a Pillan.

Entonces todos cabalgan y siguiendo a las machis que rodean, cantando los manzanos, describen una espiral que estrechan, acompañando con sus gritos el canto de las machis.

En los momentos en que la machi enterraba la sangre de los corderos, le entregamos nosotros una langosta argentina, que habíamos cogido en Lautaro, la cual, asida por la machi, la zabulló en la sangre, la revolvió en ella y sacándola fuera, mostrándola con sus manos ensangrentadas le decía, en su lengua: «Vete, vete: regresa a tu tierra y si no lo haces, así como a ti te ahogo en sangre, así ahogaré a tus compañeras: no vengas más a nuestros mapus, que esta sangre te sirva de cocavi. Vete, vete».

La ceremonia, después de lo anterior, tomó otro giro: se bailaba en común entre hombres y mujeres, al sonido de los cultrrunes y al compás del canto de las machis, agrupados unas veces, en hileras otras, con cierta cadencia, pausa y gravedad: se agitaban el cascabel y las ramas de maqui que muchos indios e indias llevaban en alto; al mismo tiempo que la pifuilca, lanzaba sus sonidos agudos la trrutrruca sus tonos o notas graves.

Así en estos bailes, tranquilos, que por lo mismo eran imponentes, pues nada de grotesco había en ellos, pasaron largo rato, aunque el Sol picaba de 
una manera incómoda para los que no estábamos acostumbrado a recibir sus rayos directamente.

De repente se avisa que dos machis de la vecindad, Vallentu e Inaipi, que son sus nombres, vienen a honrar la ceremonia y acompañar a sus amigas Huehuei y Juanita, las machis que presidían el gnillatun.

Toda la concurrencia se volvió para dirigirse al camino que traían las visitantes, bailando sus apacibles bailes, entonando sus cánticos, o tañendo sus instrumentos.

A poco las machis anunciadas se acercan y con presentarse, comienzan a bailar una danza, para la cual necesitaban de toda su habilidad, baile que secundaba la concurrencia, que había ido a encontrarlas.

Eran estas machis una mujer de hasta 30 años y una muchacha de I2, profusamente alhajadas con prendas de plata, en especial Vallentu, la mayor, que brillaba con los rayos del Sol en los instantes en que ejecutaba los diversos movimientos del arte coreográfico indígena.

El baile continuó por largo rato, con pasmosa agilidad y aguante por las machis recién llegadas, rodeadas como estaban de todos los concurrentes, hasta que Vallentu cayó casi exánime de fatiga, sudorosa, en los brazos de dos indios, que impidieron que cayese su cuerpo en tierra.

El baile tenía tanto de nuevo para nosotros como de armónico, todo se hacía al perfecto compás de las músicas y saliendo del rito común: se bailaba en todos sentidos, hacia adelante, hacia atrás, hacia los lados, asidos de las manos, desligados o sueltos, hasta llegar al sitio donde estaban las otras machis. Todo aquello fue, no sólo bello, sino imponente.

Mientras tanto las indias encargadas de la cocina habían preparado la comida.

Los indios tomando sus respectivas colocaciones, sentados en el suelo formando un gran círculo, comieron, servidos los alimentos por las indias.

Esto dio fin o puso término a la ceremonia, siendo las I0.35 de la mañana.

Nuestras impresiones de aquellos momentos fueron sumamente gratas y plácidas.

Encontramos el espectáculo digno de un pueblo culto, eliminados algunos incidentes, y hasta cierto sabor de los ritos de los pueblos clásicos.

Nada había de grotesco o ridículo en esas ceremonias: todo nos obligaba a pensar en que el pueblo que a tales prácticas se entregaba como manifestaciones de su culto, era capaz de idealizar y de tener altas sino ilustradas concepciones de la divinidad a quien iban dirigidas sus preces. 
La música producida por, sí bien, toscos instrumentos; el canto, si no variado y de combinaciones melódicas o artísticas, eran capaz de expresar sentimientos engendrados por sus sencillas creencias, por la necesidad de rendir culto a un Ser superior, son las formas más elevadas con que todas las sociedades cultas creen mejor expresar o elevar sus preces.

¿En qué en estos ritos, se extravía el sentimiento indígena del modo como todas las comuniones religiosas y en especial las cristianas, manifiestan el culto inspirado por sus creencias?

El indio no ha levantado templos al ser que adoran; adoran a Dios y le dirige sus súplicas bajo el cielo, que es el templo de la naturaleza. No tiene ministros ni esas jerarquías de otras religiones, pero en sus machis, tiene sus sacerdotisas, que se comunican con Dios (Gnemapun) y le elevan sus pensamientos.

En conclusión diremos, que el gnillatun, es una ceremonia digna de ser observada y estudiada desde el punto de vista comparativo con los ritos o prácticas religiosas de otros pueblos. 


\title{
Las ciencias sociales en la Universidad Católica de Temuco en 1971
}

\author{
VÍCTOR RAVIOLA MOLINA
}

Discurso pronunciado por el director de la Sede Regional Temuco de la Universidad Católica de Chile, don Víctor Raviola Molina, en el acto de inicio de actividades de I97I.

\section{Nota introductoria}

Hasta el golpe de Estado, nuestro país se perfilaba como una «cosmópolis intelectual», exhibiendo condiciones como estabilidad política, modernización del sistema educacional universitario y gestión de redes internacionales tejidas desde algunas universidades. Esto propicia el florecimiento de centros académicos de investigación y formación, constituyendo un polo para intelectuales latinoamericanos, europeos y americanos que se insertan en estas instituciones con el objetivo de fortalecer dichas iniciativas, y analizar los procesos sociopolíticos que estaban teniendo lugar. En este contexto, y aun cuando en una condición periférica que implica sobre todo precariedad de recursos, las instituciones regionales buscaron afianzar su posición, se pensaron no sólo como instancias formativas, sino también de investigación, contribuyendo a través de la ciencia al desarrollo en el plano local.

En la década de los setenta, la sede regional de la Pontificia Universidad Católica de Chile, hoy Universidad Católica de Temuco, abría un panorama auspicioso para el desarrollo de las ciencias sociales. Desde el Centro de Estudios 
de la Realidad Regional (CERER), y con el propósito de formar investigadores locales, se da apertura en I97 I a un programa de especialización denominado "Carrera de Investigadores en Ciencias Sociales», el que fue antesala de la fundación de la carrera de Licenciatura en Antropología en I973, la tercera en el país y la segunda regional.

Consideramos relevante este discurso pronunciado por el entonces director de Sede, don Víctor Raviola, en la inauguración anual de actividades académicas, en tanto deja testimonio de un estilo de universidad, a saber: regionalista, comprometida con la investigación científica aplicada, y vinculada con el medio local. Las palabras del profesor Raviola resultan señeras respecto del desarrollo de las ciencias sociales a nivel regional, proyecto que decae paulatinamente a partir de 1973 y que concluye con el cierre de la carrera de Antropología en I978. En I970 se da inicio a un proyecto que quedará inconcluso y que sólo volverá a cobrar fuerza en la década de los noventa con la apertura de las carreras de Antropología y Trabajo Social y la posterior creación de la Facultad de Ciencias Sociales en el primer decenio del siglo XXI.

Agradecemos a Gloria Vergara Segura la transcripción de este texto (HÉctor MORA NaWrath).

\section{Discurso}

Consolidado el proceso de admisión, matrículas e inscripciones en cursos, y casi a un mes de haberse iniciado las actividades propiamente lectivas y académicas correspondientes a I97I, nuestra Sede Regional Temuco de la Universidad Católica de Chile entra de lleno en el funcionamiento de su duodécimo año de vida. Con la presente ceremonia oficial queremos simbolizar la reapertura de esta actividad académica y el comienzo de una nueva trayectoria anual que, al procurar por naturaleza un mejoramiento en la preparación técnica, humanística y científica de una parte de la juventud de nuestro país, se presenta promisoria y fructífera.

Comprendemos que educar a la juventud en los tiempos actuales es tarea difícil, no tanto en cuanto a los principios y metas de dicha misión, cuanto a la movilidad e inestabilidad del mundo contemporáneo y a las nuevas actitudes de las generaciones jóvenes; esto último ha mostrado el carácter obsoleto de los moldes académicos tradicionales y ha hecho imprescindible una nueva orientación del aparato universitario de acuerdo con los avances tecnológicos, económicos y sociales de nuestro tiempo. Por esto, al iniciar este nuevo año, 
cumplo con señalar públicamente que la Sede ha venido poniendo en marcha, en la medida de sus posibilidades, muchos de los aspectos contemplados por la Reforma y por las nuevas exigencias, principalmente en aquellos como abrirse a todos los que tienen méritos suficientes, el de ofrecer a todos los postulantes iguales posibilidades de desarrollo, el de permitir a todos el acceso a la cultura y el de valorar constantemente el mérito y la calidad más que la procedencia socioeconómica.

También se proyectan a nuestras inquietudes actuales la necesidad de atender al clamor constante de la juventud responsable que aspira a alcanzar buenos y rápidos niveles de formación; la necesidad de lograr y mantener un nivel académico acorde con el ritmo de progreso de nuestro tiempo y con las grandes necesidades del país; la necesidad de adecuar racionalmente los procesos de reforma, sobre todo en cuanto a perfeccionamientos docentes y renovación del aparato curricular, a los más modernos sistemas educativos en vigencia; también, la atención a las perspectivas de cambios en nuestra sociedad y en nuestra economía, junto con pretender un permanente espíritu de servicio a las reales necesidades y mejores intereses del país. Esto último, entendido dentro de una concepción de una Universidad libre, democrática, pluralista y crítica, lo que implica apertura y no enclaustramiento; diálogo y convivencia, no tirantes sectaria ni instrumentalización política de la Universidad.

Comprendemos, por otra parte, que la contribución de la Universidad para el desarrollo regional y nacional está en función directa con la preparación y los niveles académicos que muestran sus egresados; por ello, su papel será tanto o más eficaz, a través del aporte concreto de sus profesionales idóneos, cuanto sus directivos realicen una adecuada planificación y un estricto control de sus sistemas educativos y cuanto sus diversos estamentos aúnen imaginación y esfuerzos solidarios para lograr concretar las proposiciones de crecimiento y reforma.

En la línea de los postulados generales precedentes, cabe recordarse ahora que durante 1970 esta Sede dio pasos muy importantes en materia de planificación universitaria a través de estudios de gran trascendencia que significarán un profundo impacto en el desarrollo regional de las actividades de Educación Superior, con acciones y planteamientos indiscutiblemente novedosos en nuestro medio.

Hasta hace algunos años, las universidades limitaban sus propósitos a la formación de profesionales, al cultivo de las ciencias, las artes y las letras, ya sea transmitiendo conocimiento o fomentando la investigación; era, induda- 
blemente, una misión circunscrita y delimitada, al margen de otras preocupaciones que la maduración de los pueblos ha hecho cada vez más notorias y urgentes. La Universidad vive en un tiempo histórico y, por lo tanto, evoluciona a su compás y debe tomar el pulso a la sociedad que sirve, considerando las necesidades e intereses de ésta. Con imaginación y talento, pues, los directivos y los diversos miembros que componen la comunidad universitaria de nuestra Sede se dieron a la tarea de vislumbrar el devenir de sus actividades en la zona; el resultado de este esfuerzo está contenido en el Proyecto de Desarrollo Académico cuya característica más notable, amén de su calidad como documento científico, es que plantea el desarrollo de la Sede como un desafío a la originalidad de sus diversos estamentos. No se trata de idear -como sucede a menudo- el crecimiento de la institución como una aproximación competitiva y cada vez más perfecta a lo que son las universidades santiaguinas; por el contrario, se ha pretendido crear una estructura universitaria tal que sea fácilmente permeable a los problemas regionales y, por ende, estructuralmente apta para esta tarea.

La Sede Regional Temuco de la Universidad Católica de Chile está perfectamente consciente de los problemas que semejantes metas implican, puesto que no hay mayores experiencias previas en el país que puedan servir de patrón o guía. Se tiene claridad en que lo que se pretende hacer es precisamente «proponer a la región un modelo de universidad» y que ello será posible en la medida del esfuerzo de todos y de cada uno de los miembros de los diversos estamentos institucionales, del aporte generoso de la comunidad regional y de la asesoría oportuna de la Casa Central.

Hasta ese momento, la vida de la Sede constituyó una etapa heroica en la cual se consolidó una estructura académica seria y positiva; llegado el momento de la Reforma, esto es, del autodiscernimiento de nuevos destinos, la Sede ha elegido el camino del regionalismo. Dentro de dichos planes, especial relevancia alcanzan la creación del Centro de Estudios de la Realidad Regional (CERER), la ampliación de las actividades de Comunicaciones, fundamentalmente al campo de la cultura popular, y la implantación del sistema de Educación Permanente.

Las actividades docentes e investigadoras del CERER, actualmente bajo la dirección del doctor Milan Stuchlik, quien hoy dicta la Clase Magistral I97I, han confluido hasta el planeamiento de la Carrera de Investigadores de Ciencias Sociales. A través de un currículum interdisciplinario que aúna ciencias como la antropología, la lingüística, la sociología y la enseñanza de lenguas 
extranjeras, con una gama de actividades vinculadas al área regional, específicamente «indígena», constituye el primer paso de un entronque con otras carreras santiaguinas, como sociología y antropología.

Las actividades de Cultura Popular, todavía embrionarias, descansan en algunos postulados que dicen relación con la concepción de la Universidad en permanente comunicación con el medio social en que se encuentra inserta; en su deber de aportar el esfuerzo sistemático de sus miembros en el análisis de los principales problemas del país y colaborar en la búsqueda de soluciones que permitan la construcción de una sociedad que, en permanente cambio, sirva los intereses de todo el pueblo; en constituir a la Universidad en un centro de vida cultural en que se encuentran todas las manifestaciones del pensamiento y del arte y en que se institucionalicen las vivencias culturales de las clases populares para ponerlas en estrecho contacto con la cultura universitaria en la creación de los cauces necesarios para lograr la vinculación de las actividades universitarias con los sectores populares, colocando el quehacer académico en una interrelación con los grupos mayoritarios, procurando descubrir e interpretar sus proyectos e intereses.

De todo lo presentado, quizás lo más interesante de destacar en este momento sea la puesta en marcha del sistema de Educación Permanente. Un convenio con la CUT que permitió realizar en los meses de enero y febrero recién pasados la Primera Universidad Popular de Verano (I97I) y un convenio con la Dirección Provincial de Educación Primaria Particular e Indígena que permitió realizar la primera etapa de un Curso de Regularización para Profesores Primarios permitieron echar las bases de estos nuevos programas de Educación de Adultos que, en los países desarrollados, ha dado en llamarse «Educación Permanente». El fundamental principio del nuevo sistema que, cronológicamente, impulsaron los británicos y los escandinavos justo antes de la Segunda Guerra Mundial y principalmente después de I945, insiste en que el adulto instruido ha de perfeccionarse continuamente o readaptarse su instrucción. Es una forma de educación popular «que pretende aportar a las masas obreras y campesinas, desfavorecidas por el sistema de educación en vigor, los bienes, a los cuales sólo habían tenido acceso entonces los privilegiados de la cultura, procedentes de los medios pudientes». Como programa adoptado por la Unesco a partir de I967, entiende a la educación en una concepción global que comprende todos los sectores y todas las edades de la vida y en que la educación escolar y la extraescolar forman un solo todo; estos principios permiten mejorar la educación de los jóvenes y ofrece a los adultos posibilidades de 
renovarse y de ascender socioeconómicamente. «Los problemas de calificación profesional y de reconversión -tal como ha escrito Louis François- que han de afrontar los trabajadores de todas las clases de oficios; las modificaciones profundas que intervienen en la organización de la vida, del trabajo, del reposo y de las diversiones, la diversidad y la amplitud crecientes de las tareas y de las responsabilidades de los hombres y de las mujeres en las sociedades modernas, la mutación de modelos tradicionales de pensamiento y de relaciones, al progreso del espíritu científico que tiene hacia una concepción relativa y evolutiva del saber y de la civilización, todo invita a organizar la educación permanente y por lo tanto revisar el sistema de enseñanza cuyas formas y contenido tradicionales no pueden ya responder a las necesidades del hombre en esta materia».

Quiero terminar esta intervención con un especial saludo para todos los miembros de la comunidad universitaria de nuestra Sede que con su trabajo van desarrollando las actividades de I97I; sobre todo un saludo especial para los jóvenes estudiantes que hoy ingresan en nuestra institución. Este saludo, lejos de ser una formal cortesía pretende estimularlos a ser elementos progresistas, verdaderamente vehículos al servicio del desarrollo de la Sede y de la Universidad Católica. 


\section{Normas para autores}

CUHSO utiliza como normas bibliográficas y de presentación de manuscritos las normas APA, sexta edición, que pueden ser consultada aquí: <apastyle.org>.

- Los artículos deben ser presentados en letra Verdana, tamaño número I 2, a espacio simple.

- CUHSO promueve la utilización de estándares abiertos. Los artículos serán recibidos preferentemente en formato ODT (procesadores como Libre Office u Open Office). También se aceptan el formato Doc (Microsoft Word).

- Se aceptan artículos en inglés, portugués y español.

\section{Tipos de manuscritos recibidos}

- Artículos en que se presenten resultados de investigación. Deben incluir una introducción, el cuerpo del texto y conclusión. Debe incluir problema de investigación, hipótesis o preguntas de investigación y presentación de resultados. Serán sometidos a revisión de pares e indexados. Extensión entre 8.000 a I 2.000 palabras.

- Artículos en que se presenten adelantos de trabajos de investigación en curso. Deben incluir una introducción, el cuerpo del texto y conclusión. Deben incluir propuesta de investigación y, cuando corresponda, presentación de resultados preliminares. Serán sometidos a revisión de pares e indexados. Extensión entre 4.000 a 8.000 palabras.

- Textos en que se presenten discusiones teóricas actuales sobre tópicos específicos de las ciencias sociales y humanidades o en que se haga una revisión de aspectos específicos de la obra completa de uno o más autores. Deben incluir introducción, cuerpo del texto y conclusión. Serán sometidos a revisión de pares e indexados. Extensión entre 8.000 y I 5.000 palabras.

- Reseñas de libros en que se comenten publicaciones recientes y relevantes de las ciencias sociales y humanidades, la estructura de presentación 
es libre. Estas publicaciones no son sometidas a revisión de pares, ni indexadas. Extensión entre I.000 y 2.000 palabras.

\section{Estructura del manuscrito}

- Las páginas no deben estar numeradas.

- Todos los tipos de artículo deben incluir una portadilla con el título del manuscrito. En el caso del texto para revisión, debe ser entregado en una versión anónima; en la versión aprobada para publicación se debe indicar nombre del autor y filiación institucional.

- No se publicarán trabajos del mismo autor en números consecutivos.

- El documento presentado a evaluación no debe contener ninguna referencia al autor, deben ser borrados los datos de firma digital del artículo, así como cualquier referencia que lo identifique como la autocita, por ejemplo, "como discutió el autor», "como expresé en otro momento", etcétera. Se puede citar a sí mismo en tercera persona.

- En la siguiente página debe escribirse un abstract de entre 300 a 400 palabras, e incluir hasta cuatro palabras claves. Resumen y palabras claves deben ser presentados en español e inglés (la versión en inglés sólo en caso de versión aprobada o aprobada con correcciones). El resumen debe incluir presentación del problema, propuesta teórica y/o metodológica, según corresponda, y principales resultados y/o conclusiones.

- Cuadros, tablas y citas de más de 40 palabras se deben presentar con un espaciado adicional antes y después.

- A continuación debe presentarse el manuscrito con hasta cuatro niveles de encabezados siguiendo lo estipulado por las normas APA. I) Título del manuscrito: centrado y mayúsculas; 2) título de sección: centrado, altas y bajas; 3) primer nivel de subtítulos: cursivas, altas y bajas, centrado; 4) segundo nivel de subtítulos: cursivas, altas y bajas, alineado a la izquierda; tal como se muestra a continuación:

TÍTULO DEL MANUSCRITO

Título de sección

Primer nivel de subtítulos

Segundo nivel de subtítulos 


\section{Citación y referencias}

Las referencias a autores se efectuarán en el texto siguiendo lo estipulado por las normas APA, sexta edición:

- Trabajo de un solo autor: Pérez (2000), como señala Pérez (2000), en el 2000 Pérez señaló.

- Si un trabajo tiene dos autores deben ser nombrados los dos siguiendo las mismas normas de cita del primer punto.

- Cuando son tres o más autores, cítelos a todos la primera vez y si es necesario citarlos nuevamente, cite al primer autor seguido de la expresión «y otros».

- Cuando cite a una organización, utilice el nombre completo y entre paréntesis la abreviación; en las siguientes citas, sólo utilice la abreviación.

- Si cita a dos autores con el mismo apellido, debe diferenciarlos a lo largo de todo el texto con sus iniciales: Pérez, José (2009) y Pérez, Homero (2010).

- Citas textuales de menos de 40 palabras se colocan en el mismo texto entre comillas, citas de más de 40 palabras se inician en párrafo aparte, con una tabulación adicional de ( $\mathrm{I}, 5 \mathrm{cms}$.).

- En las citas textuales indique siempre el año de publicación y número de página (Pérez, 2010: 68). 
